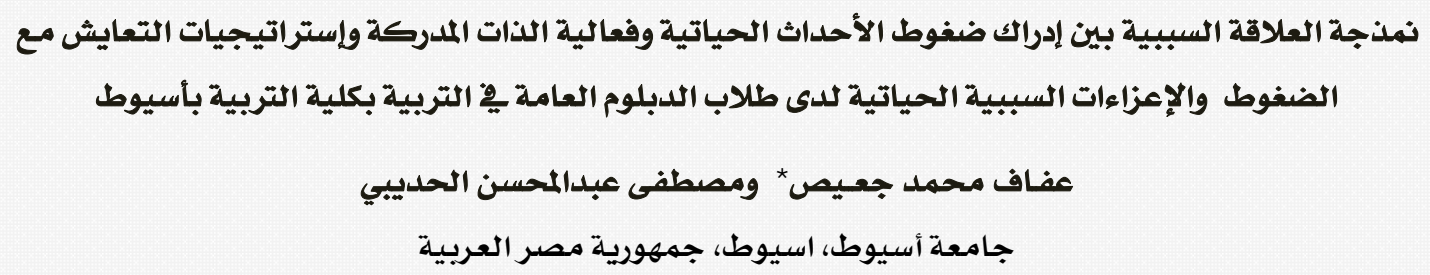

\title{
Causal relationshipsamongperception of Life Stressful Events, Self-efficacy, Coping Strategies, Stress and Life Attributions among H igher Diploma Students at A ssiut College of Education
}

\author{
Afaf M. Geis* \& Mostafa A. Elhudaybi \\ Assiut University, Assuit, Egypt
}

The study aimed to test a model of the relationship between perception of stresfful life events and perceived self-efficacy as well as coping strategies with life attributions of higher diploma students at Assiut faculty of education by testing direct and indirect effects between perceiving stressful life events and the study variables. In addition, the study aimed to find out whether there are differences in perceived self-efficacy and coping strategies as well as attributionsbetween those with positive and negative perception of stressful life events.Also, differences in perceiving stressful life events were tested across classes of the demographic variables: gender, specialization, place of living, and marital status. The sample included 410 students. Results showed that there was a causal relationship in which perception of stressful life events was affected by perceived self-efficacy (direct effect is .631, indirect effect is .356), by coping strategies (direct effect is .676, indirect effect is .313), and life attributions (direct effect is .781, indirect effect is .211). There were significant differences in perceived self-efficacy, and coping strategies as well as the problem centered coping strategies in favor of those with positive perception of stressful life events. There were significant differences in the perception of stressful life events due to demographic variables including place of living and specialization in favor of humanities majors and those who lived in cities.

Keywords: perception of stressful life events, coping strategies, perceived self-efficacy, life attributions.

*mam_1981_6@yahoo.com 


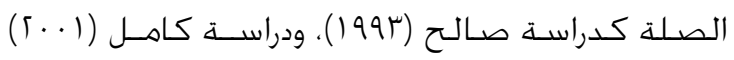

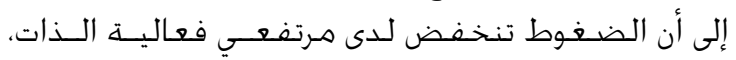

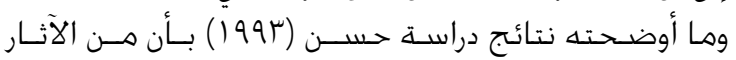

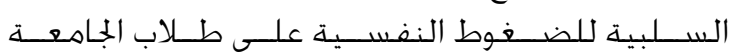

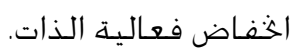

ويتسـق هذا مع ما أوضـحــ Bandura (1994, 13 أن فعالية

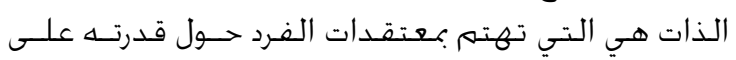

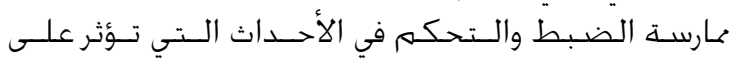

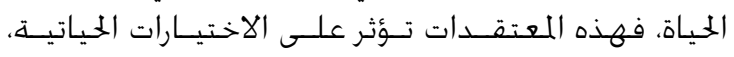

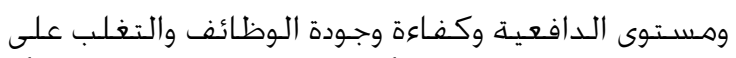

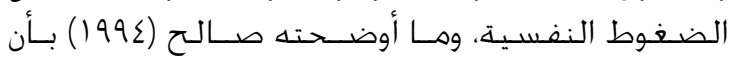

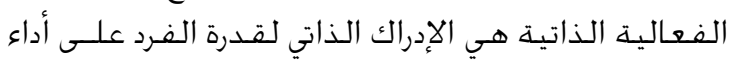

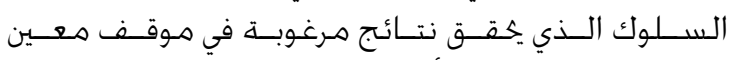

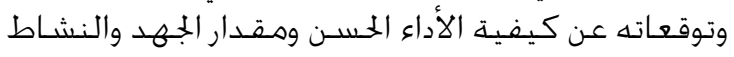

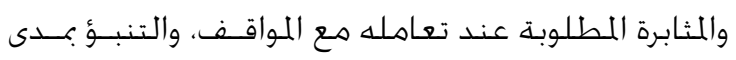
النجاح في خَقيق ذلك السـلوك.

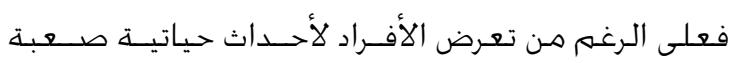

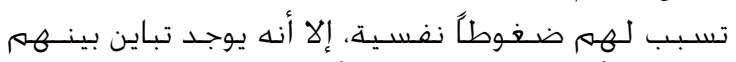

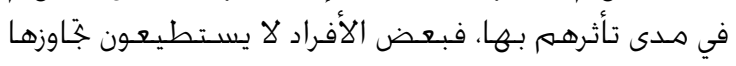

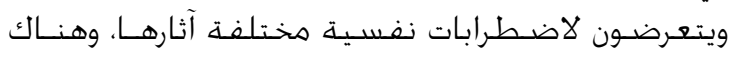

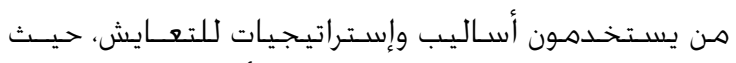

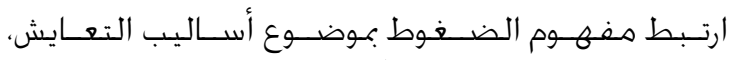

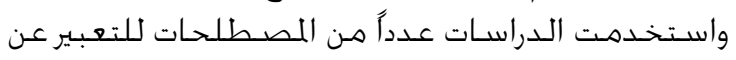

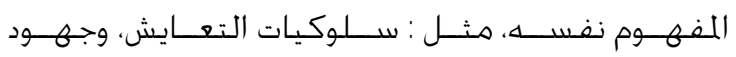

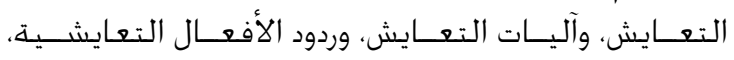

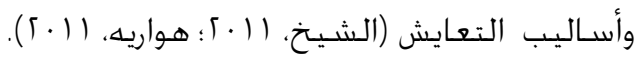

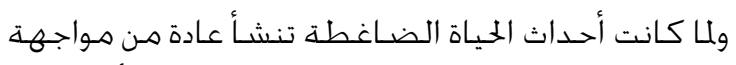

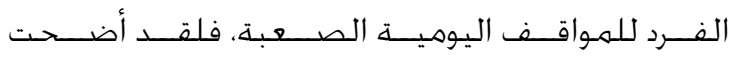

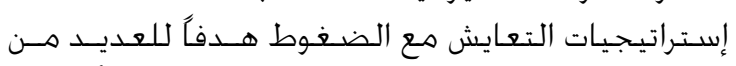

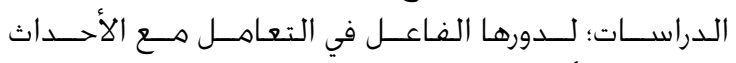

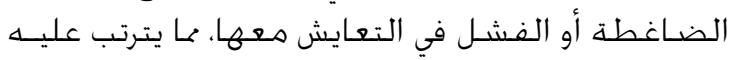

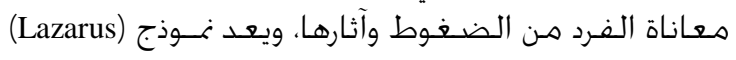

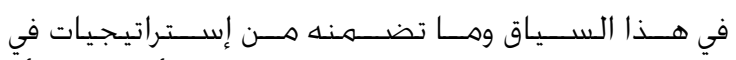

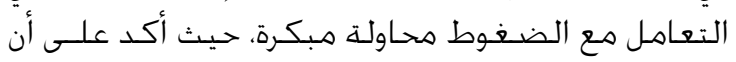

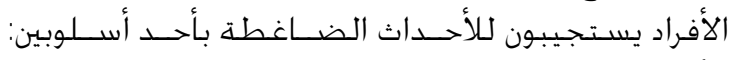

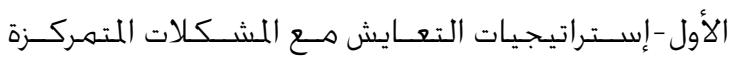

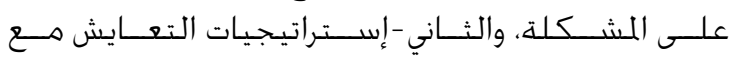

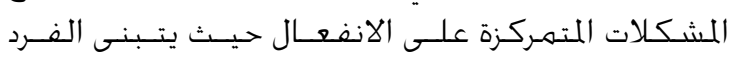

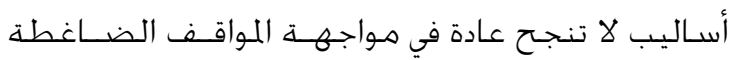

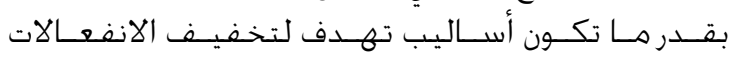

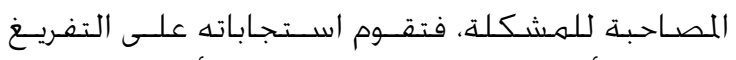

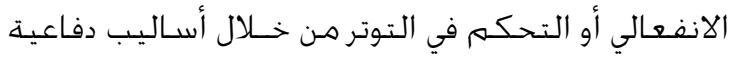

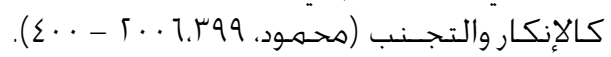

تعد الضغوط الحياتية إحدى الظواهر المرتبطة بطبيعة الإنسانه

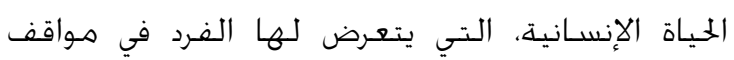

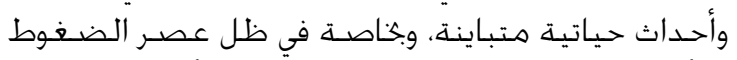

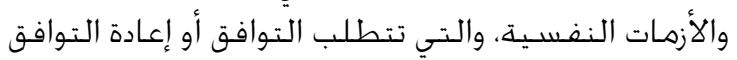

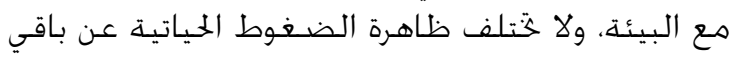

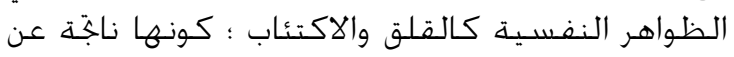

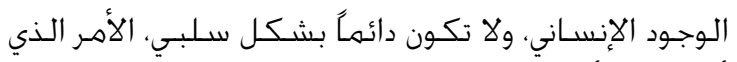

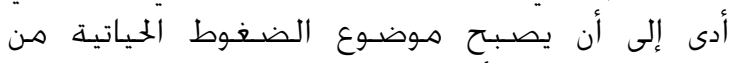

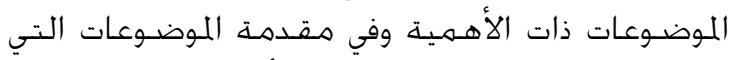

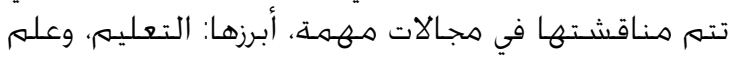

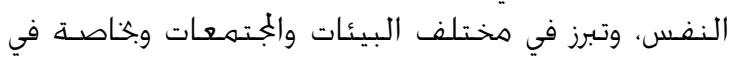

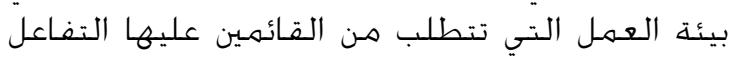

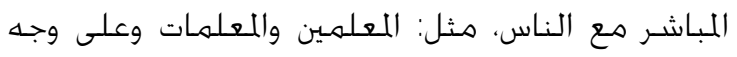
الخصوص الذين في بداية اختيار هذه المهنة.

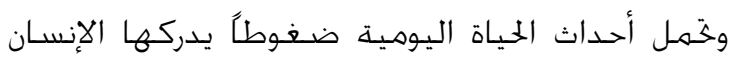

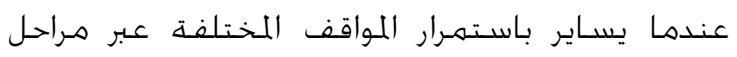

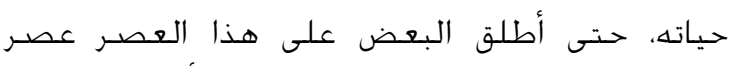

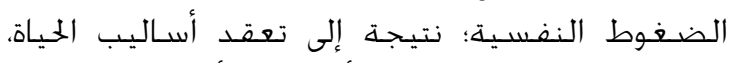

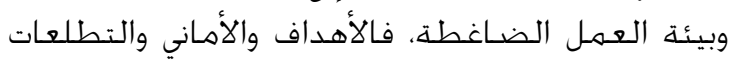

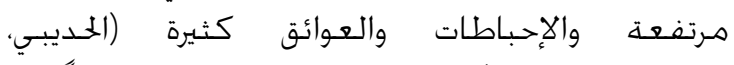

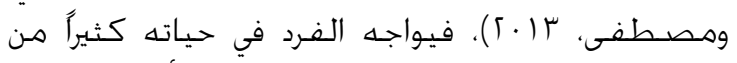

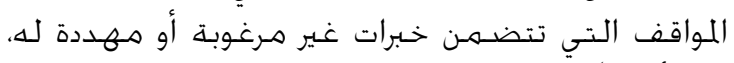

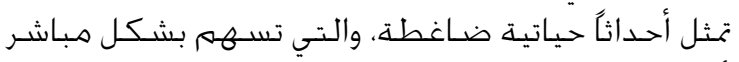

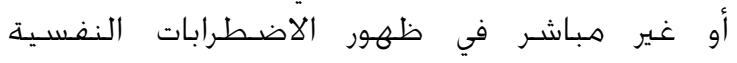

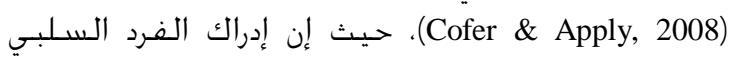

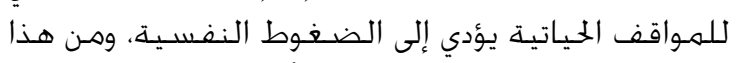

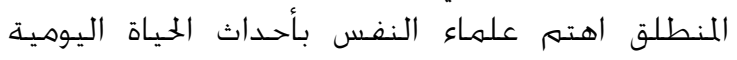

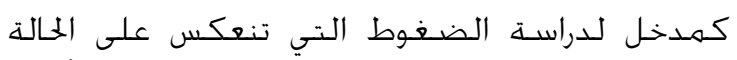

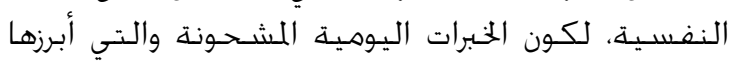

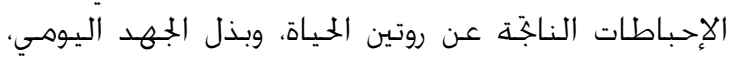

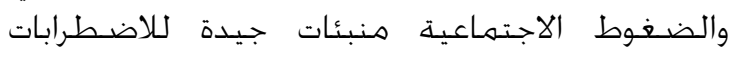
الجسـمية والنفسية (الشقماني والمفتي، 1 ؟).

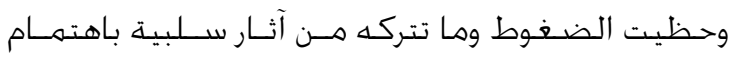

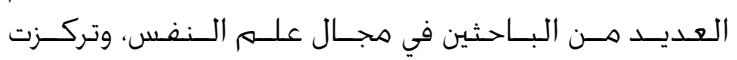

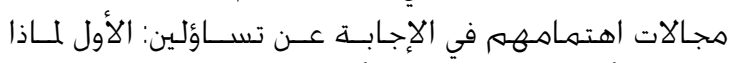

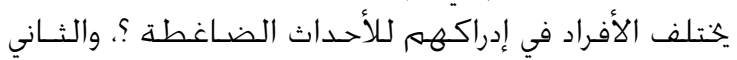

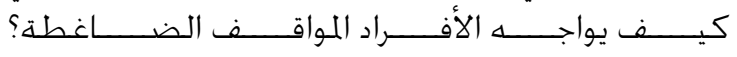

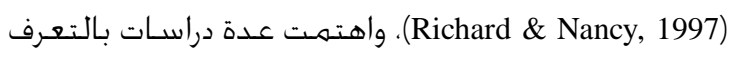

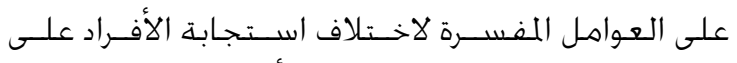

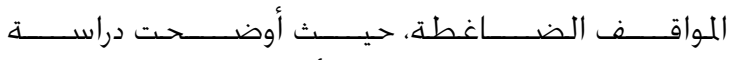

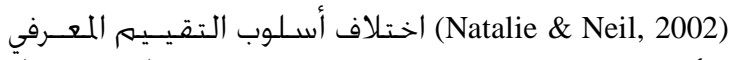

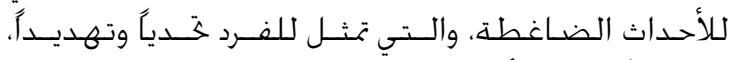

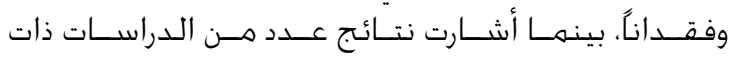


في الحدث الضـاغط، وكذلك قدم أيضاً عملية التعايش

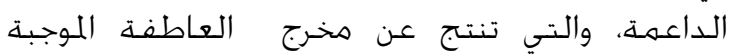

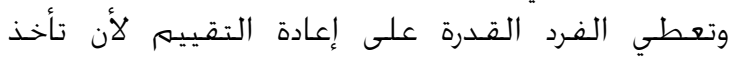

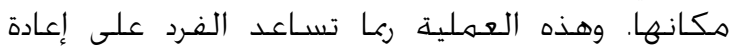

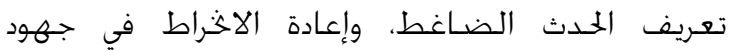

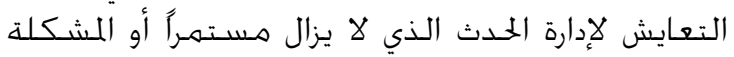

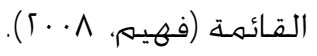

ورغم الاهتمام الواسعح، والاستحسـان المتناهي لآثار

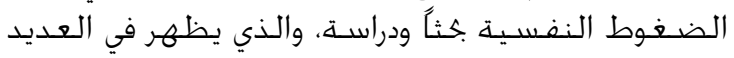

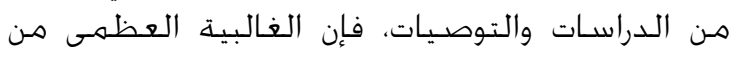

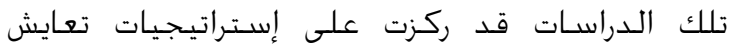
الضغوط في بيئات مختلفة وعلاقتها ببعض النهات المتغيرات النفسية، وعدد قليل منها مخائل ركز على طلاب الجامعة. والنادر منها ركز عليها لدى الباحثين بالدراسات العليات البهاب.

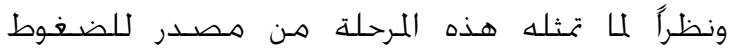

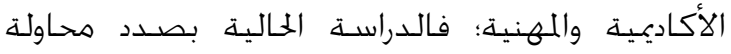

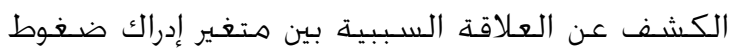
الأحداث الحياتية ومتغيرات فعالية الذات الذات المدركة

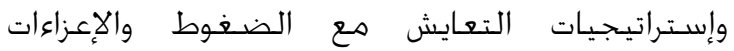
السببية الحياتية لدى طلاب الدبلوم العامة في التربية

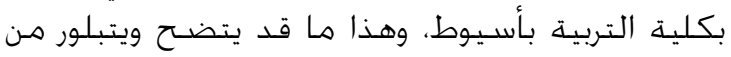
خـلال مشـكلة الدراسـة.

\section{مشكلة الدراسـة}

هناك بعض المشكلات التي يعاني منها طلاب الدراسـات

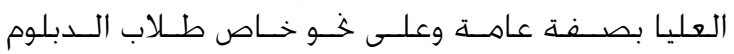

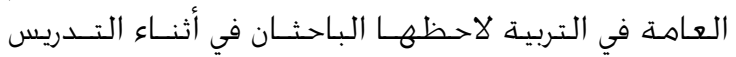

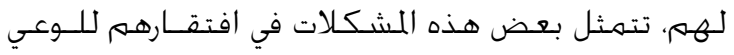

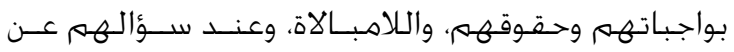

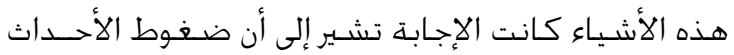

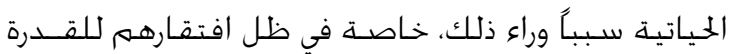

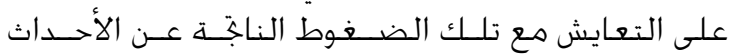

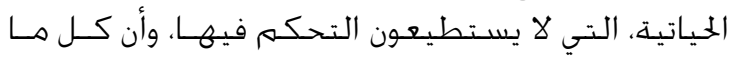

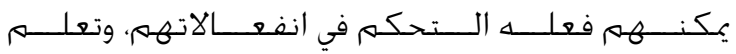

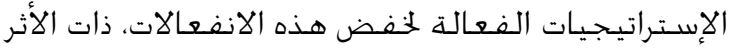

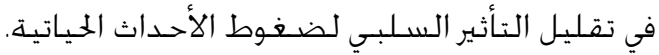

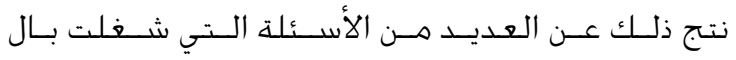

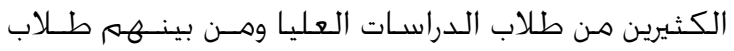

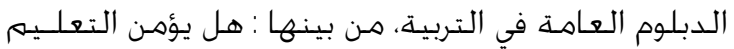

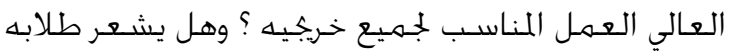

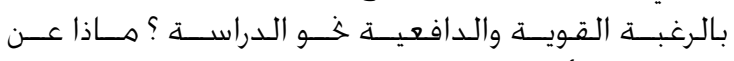

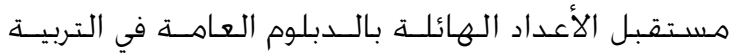

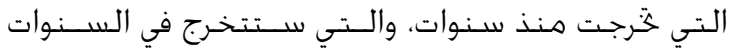

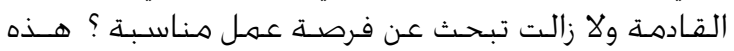

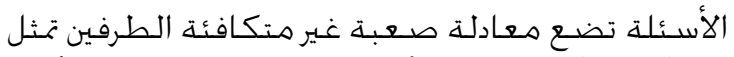

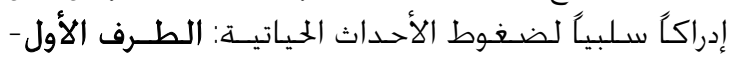

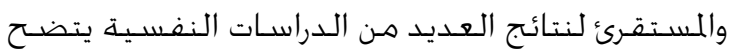

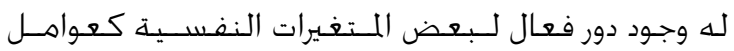

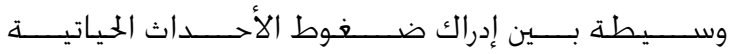

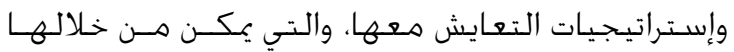

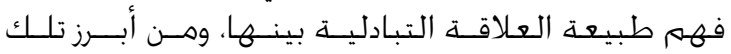

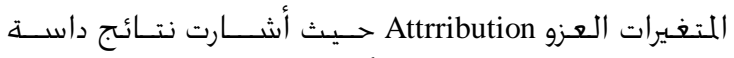
(Benjamin et al., 2005)

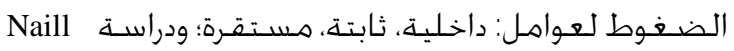
( \& Adam, 1995)

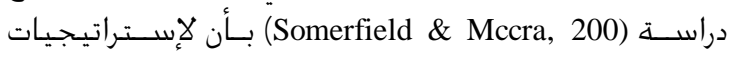

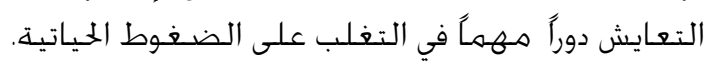

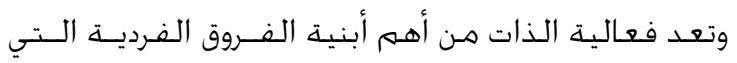

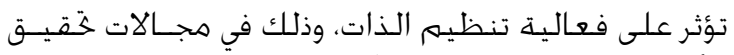

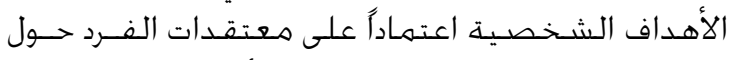

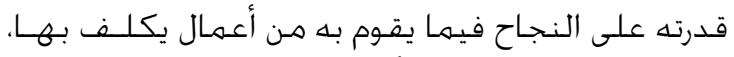

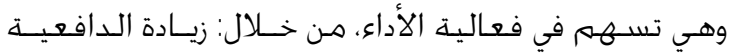

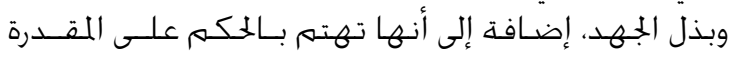

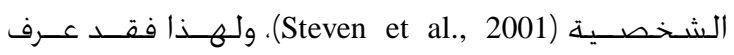

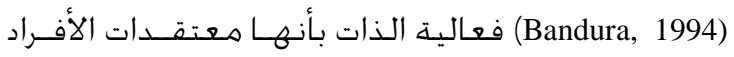

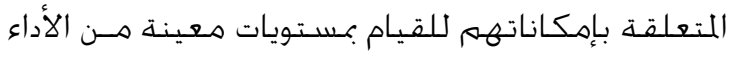

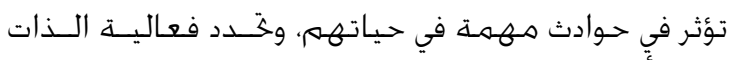

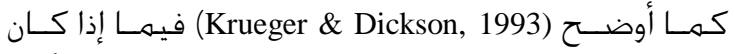

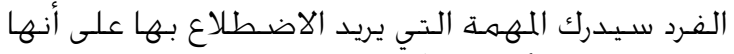

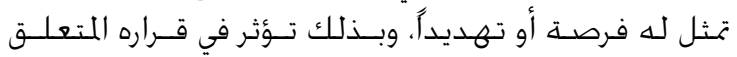

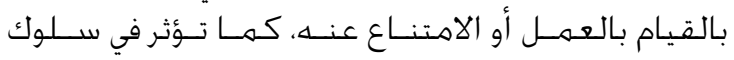
المبادرة والمثابرة لديه في مواقف الإجناز.

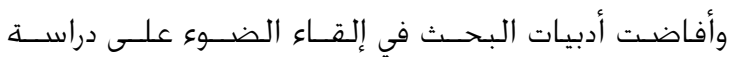

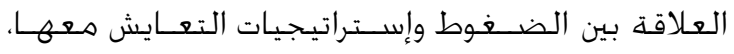

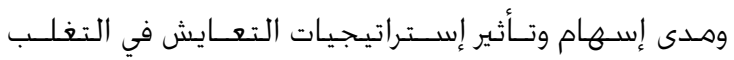

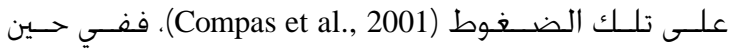

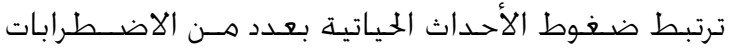

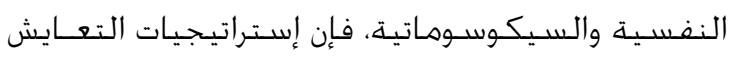

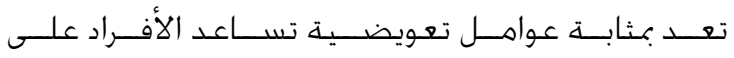

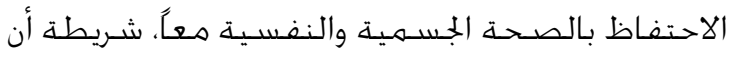

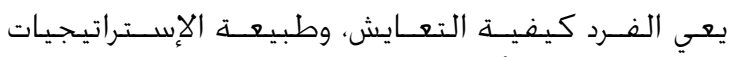
الملائمة العالجة الأحداث الحياتية (النيال وعبد اللهّ، 997 ().

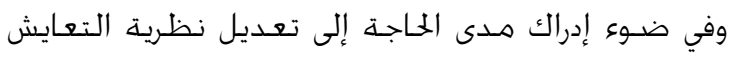

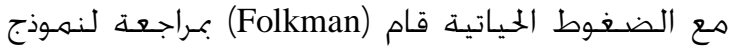

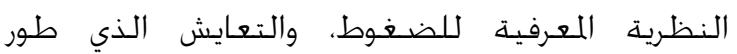

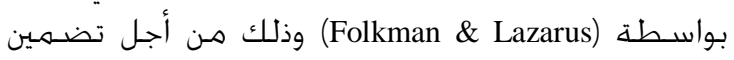

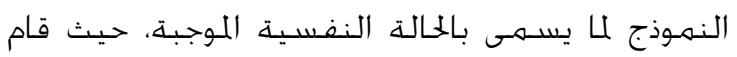

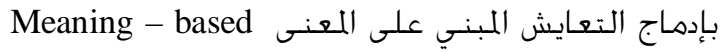
كاستجابة للألم الناتج عن الموقف، مضعمناً

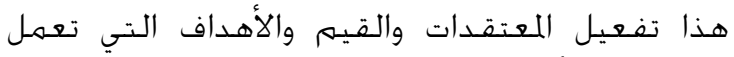
وتسـاعد في أن يقوم الفرد بالبحثن، وإيجاد معنى موجبـ 
قيام هذه العوامل بـــورها في التخـفيـف للأثـر الســلبـي

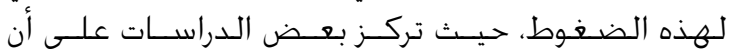

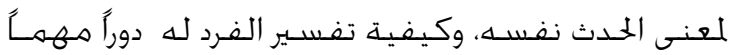

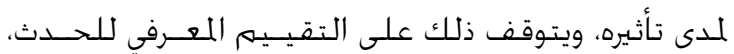

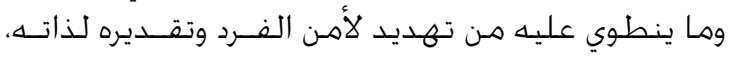

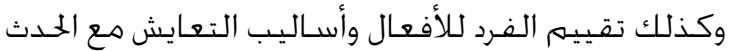
الضـاغط .

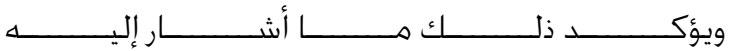

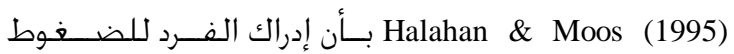

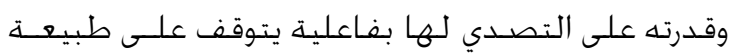

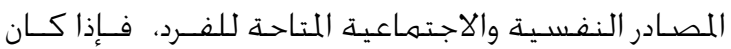

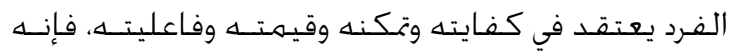

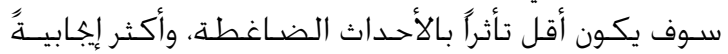

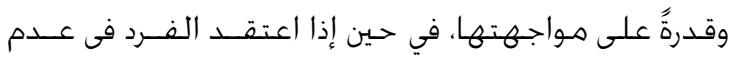

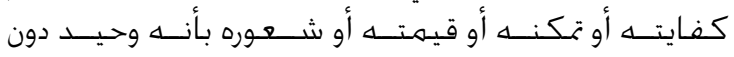

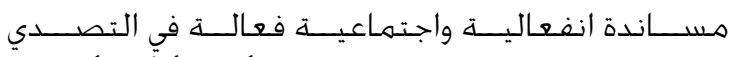

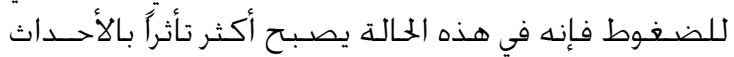

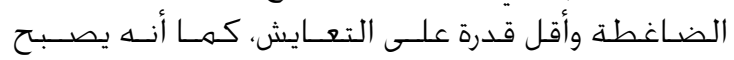
عرضـة للاضـطرابات النفسـيـة والسـلوكية.

وتعد فعالية الذات مـن المكونات المهمهة للنظرية المعرفية

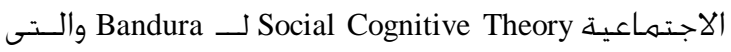

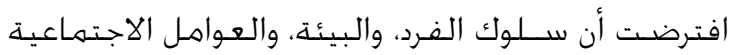

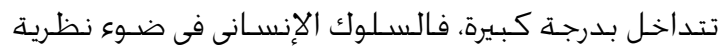

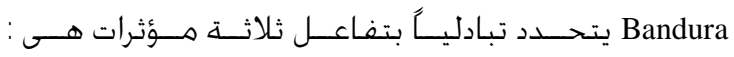

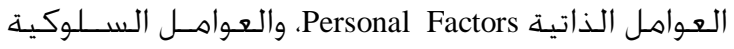
Environmental Behavioral Factors Factors

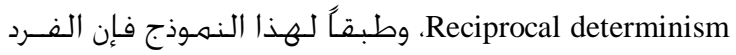

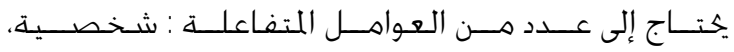

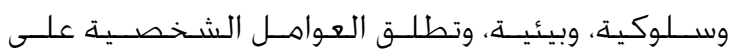

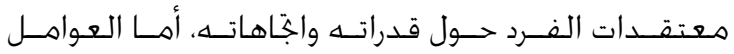

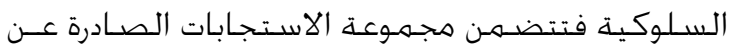

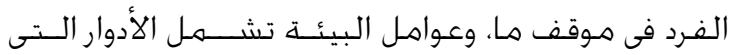

يقومـون بها كمعلمين (Zimmerman, 1989).

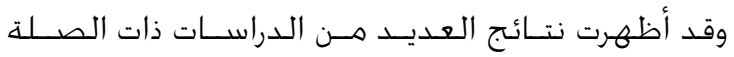

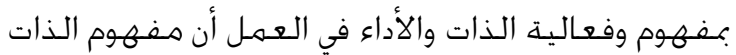

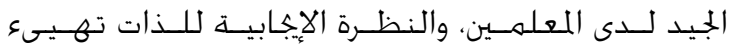

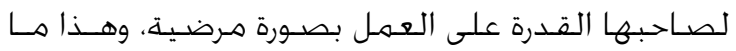

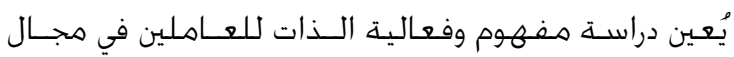

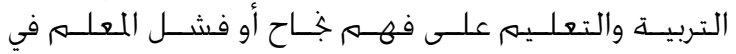

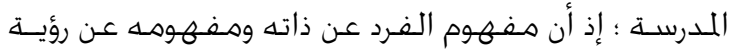

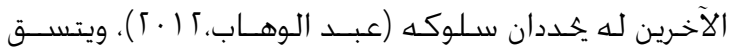

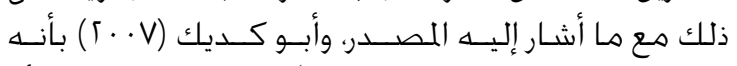

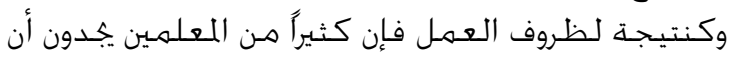

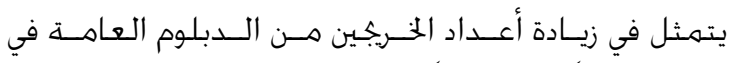

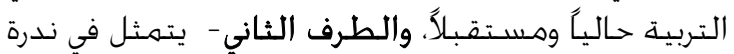

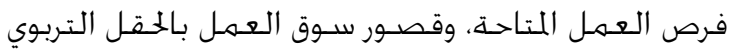

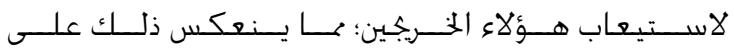

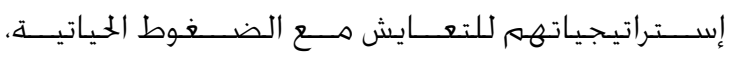
وتقديرهم لذواتهـم.

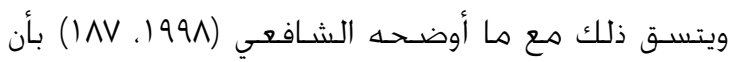

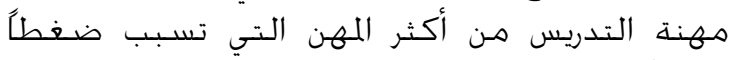

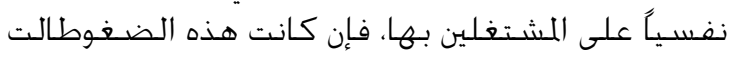

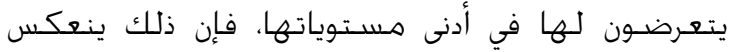

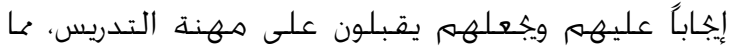

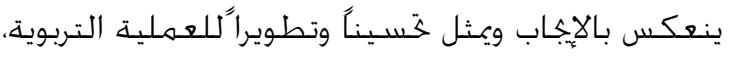

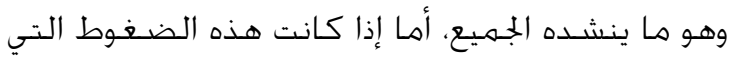

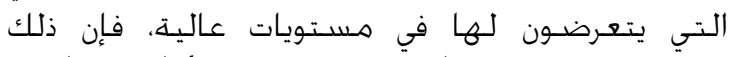

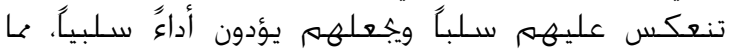

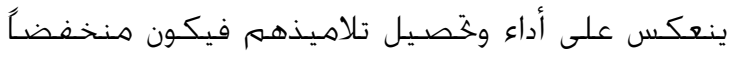

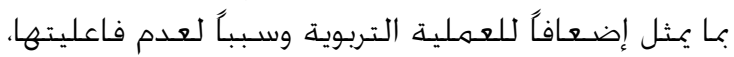

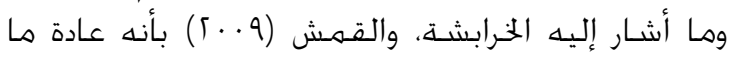

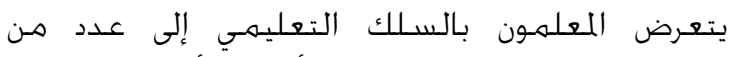

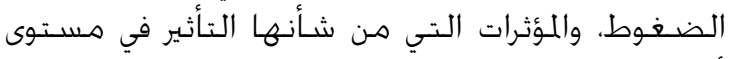

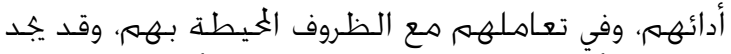

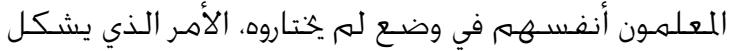

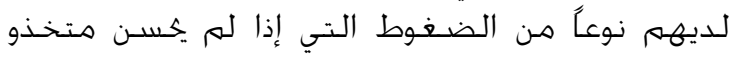

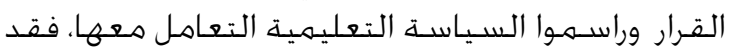

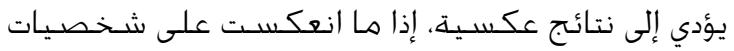

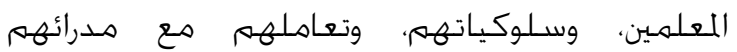
وزملائهم وطلابهـم وأفراد أسـرهم.

ويتماشـى ذلك مع ما قدم لضغوط أحسداث الخياة اليوهية

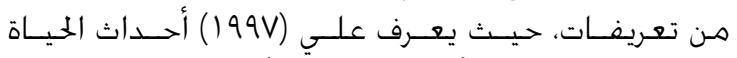

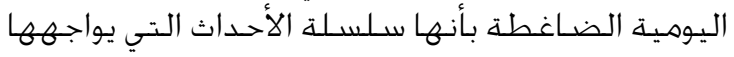

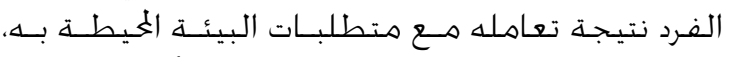

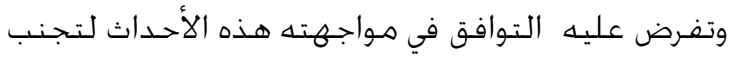

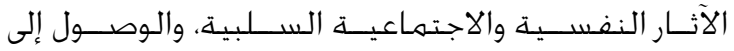

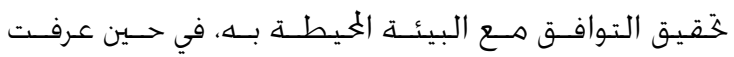

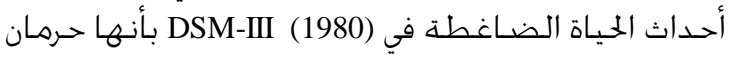

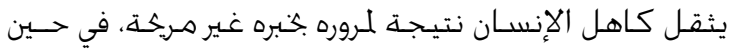

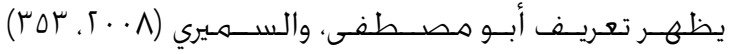

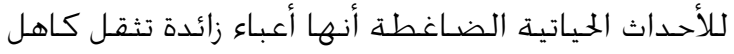

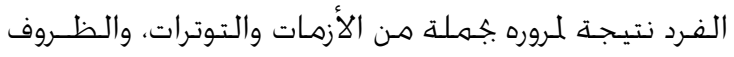

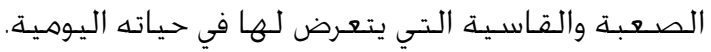

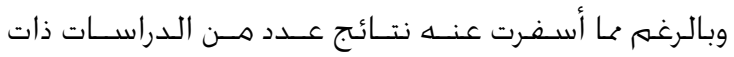

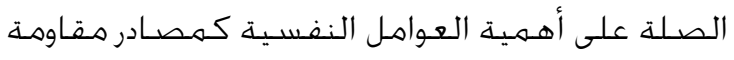

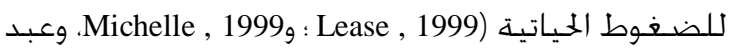

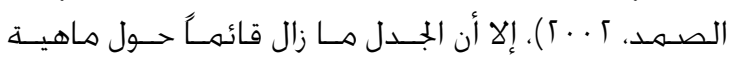




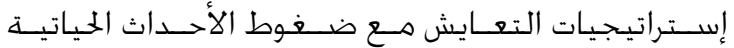

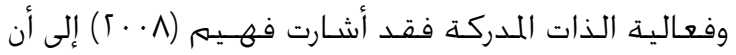

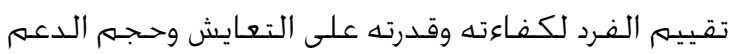

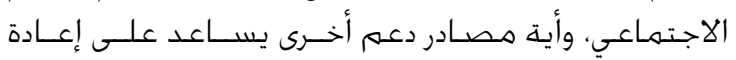

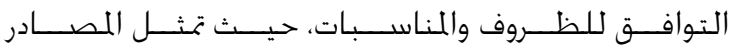
الشخصية Personal Resources قوة في عملية التعايش.

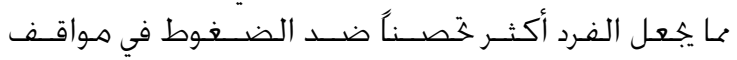

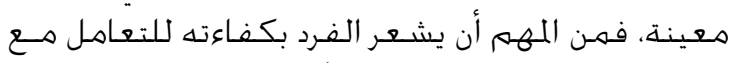

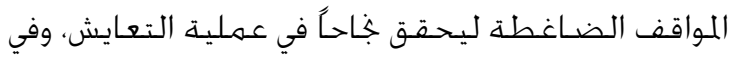

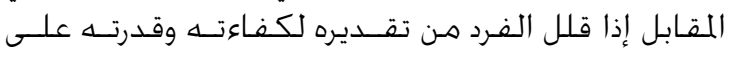

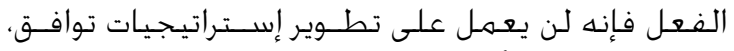

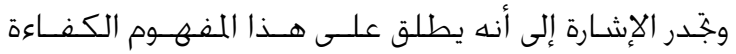

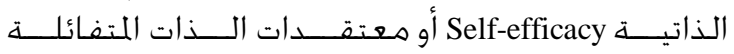
. Optimistic self-beliefs

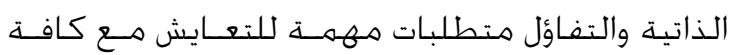

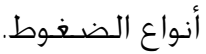

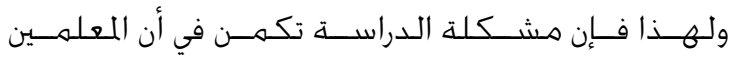

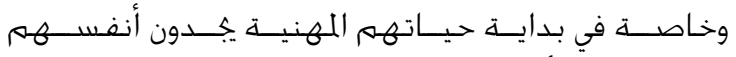

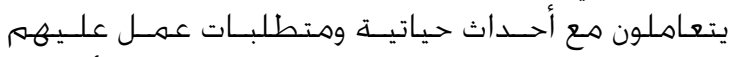

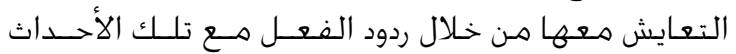

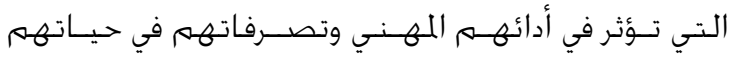

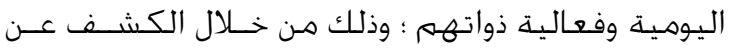

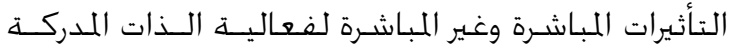

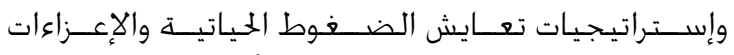

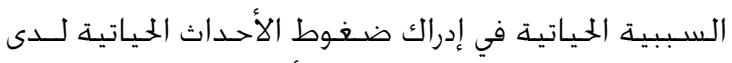
طلاب الدبلوم العامة في التربية بأسيوط إدرات

أسئلة الدراسـة الدبـ

يمكن أن تثير مشكلة الدراسـة الحالية الأسئلة التالية:

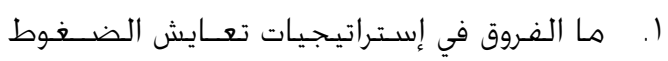

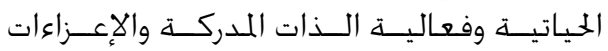

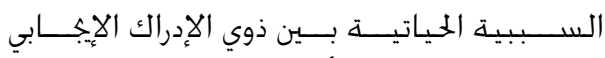

والسـلبي لضغوط الأحـداث الحياتية ؟ لإدرات الإن

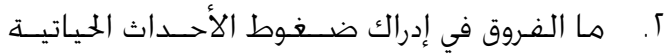

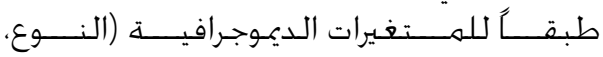
والتخصص الدراسي، ومنطقة السكن، والحالة الحئ

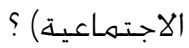

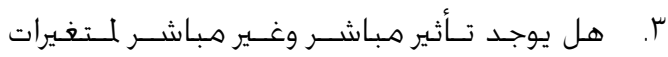

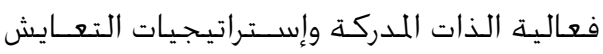

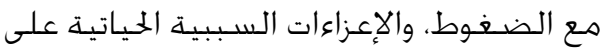
متغير إدراك ضغوط الأحداث الحياتية؟

أهداف الدراسـة تهدف الدراسـة الحالية إلى:

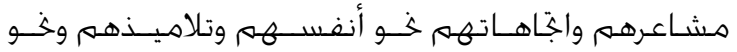

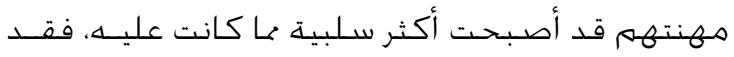
يظهر لديهم انفعالات نفسية مختلفة، مثل : الغضب.

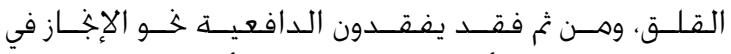

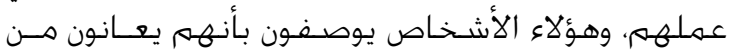

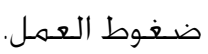

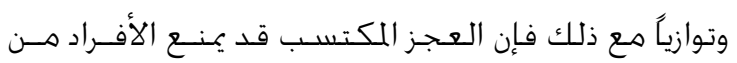

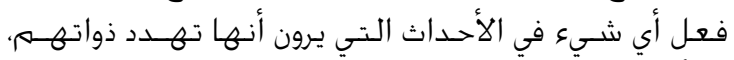

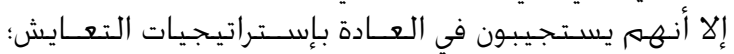

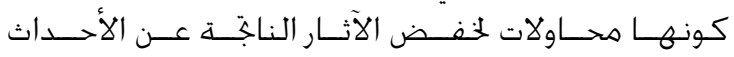

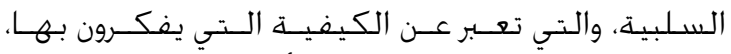

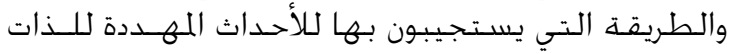

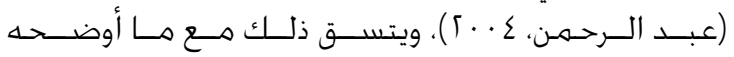

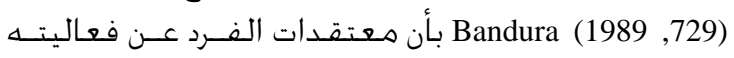

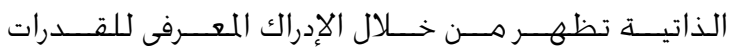

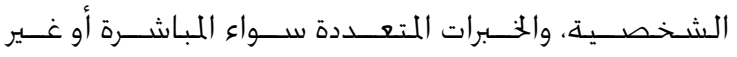

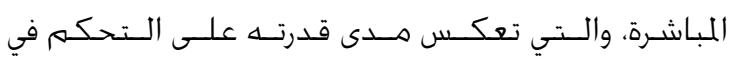

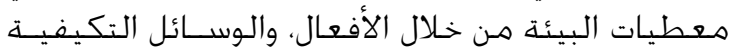

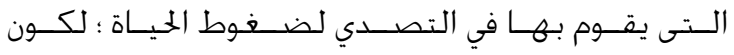

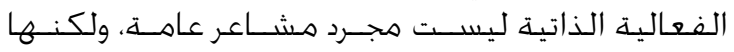

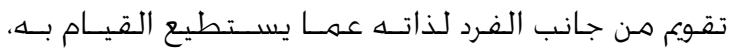

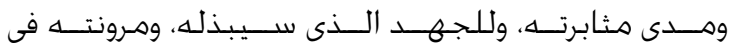

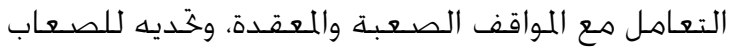

ومقاوهته للفشل.

ويؤكد ذلك Wasteson et al., (2006, 813 بأن هناك قدراً

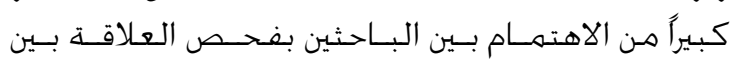

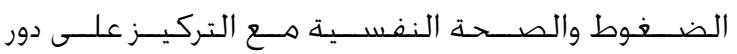

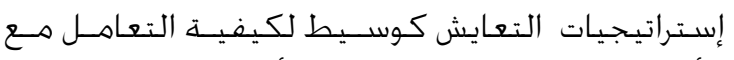

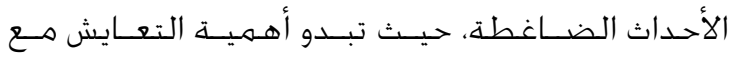

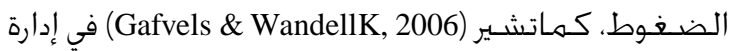

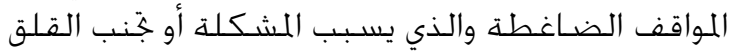

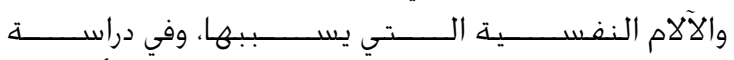
(Zeidner \& Saklofske, 1996)

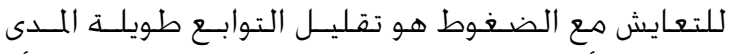

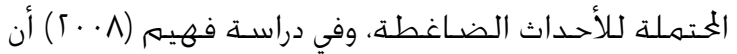

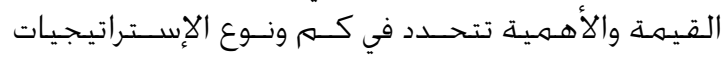

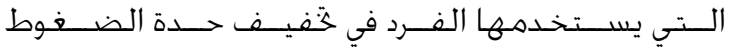

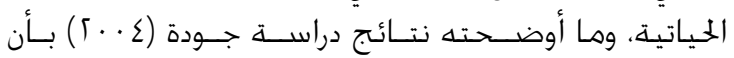

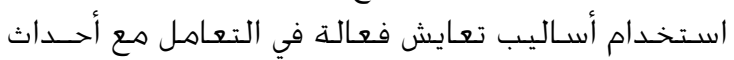

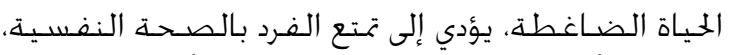

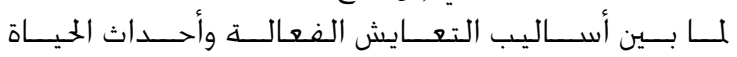
الضاغطة من ارتباط دال سـالب.

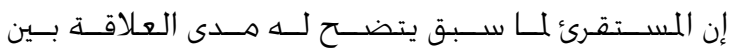

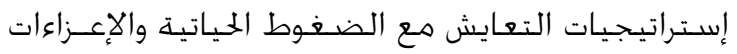

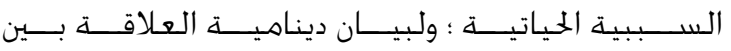




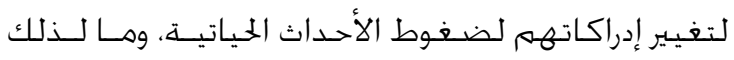

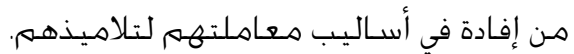

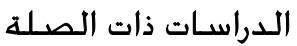

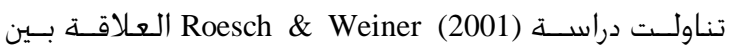

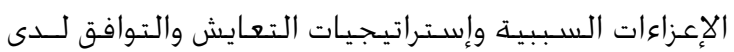

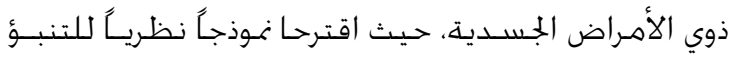

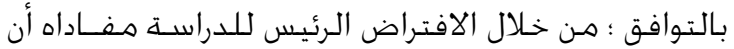

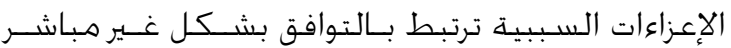

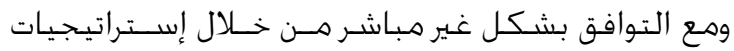

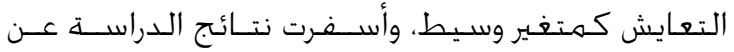

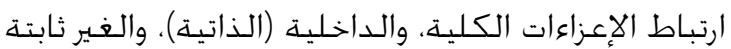

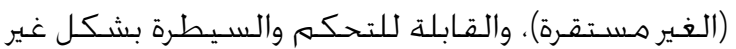

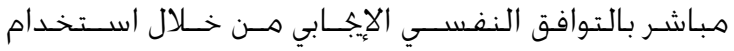

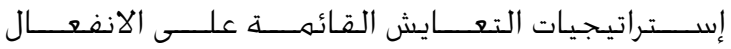

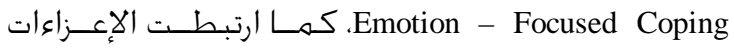

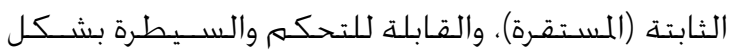

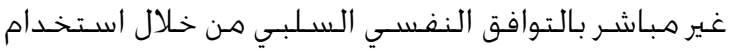

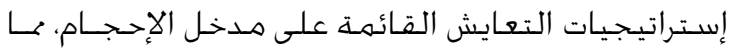

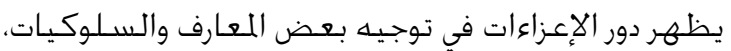
وارتباطها بإستراتيجيات التعايش.

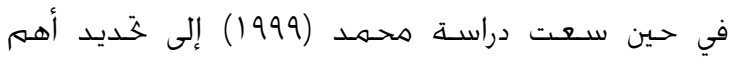

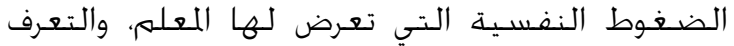

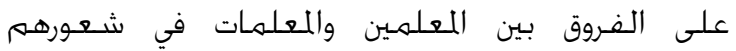

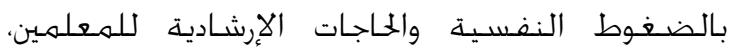

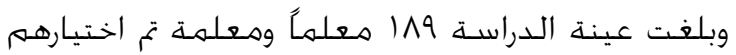

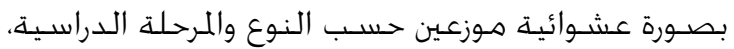

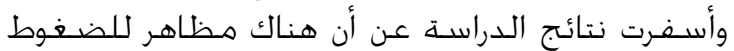

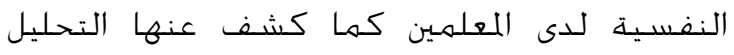

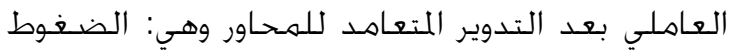

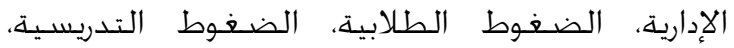

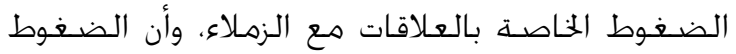

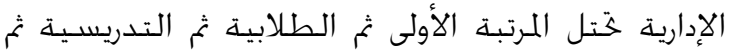

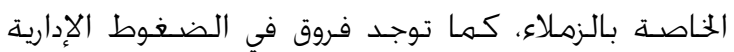

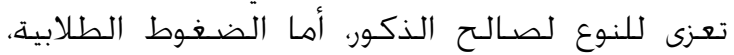

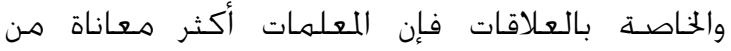

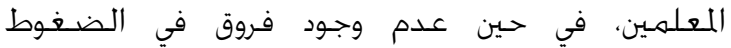
التدريسية تعزى للنوع.

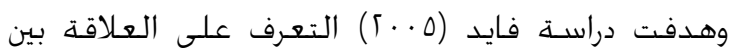

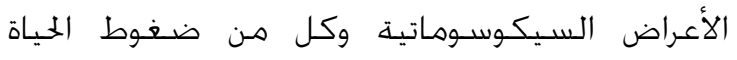
والضبط المدرك للحالات الذاتية والمساندة الاجتماعية،

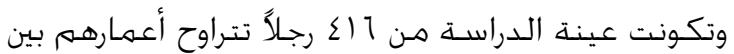

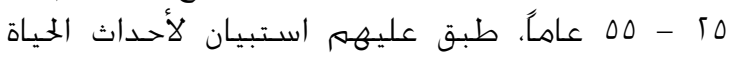

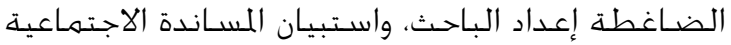

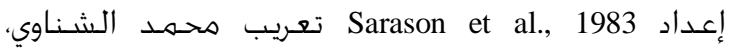

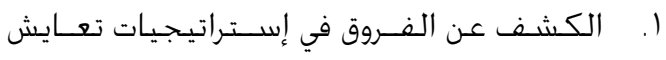

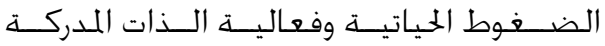

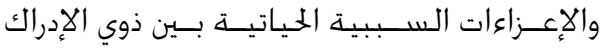

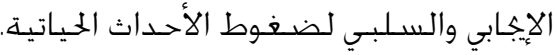
I الكشف عن الفروق في إدراك ضغوط الأحسداث الحياتية طبقاً للمتغيرات الديموجـرافيــة (النــوع. والتخصـص الدراسي، ومنطقة السكن، والحالة

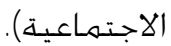

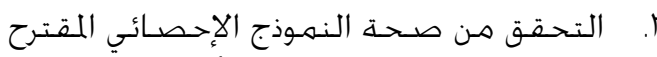

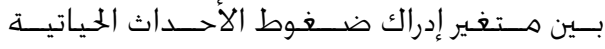

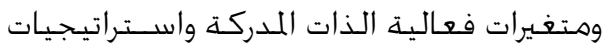

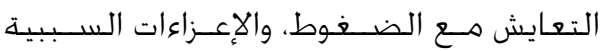

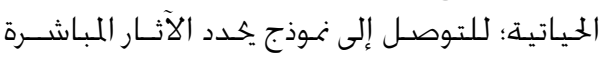

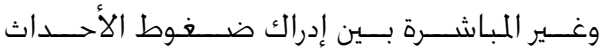

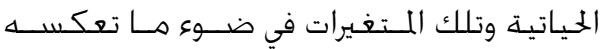
بيانات الدراسـة.

أهمية الدراسـة

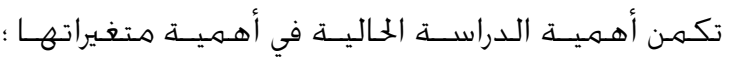

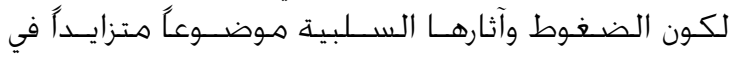

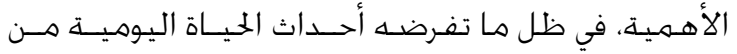

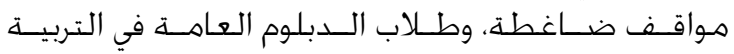

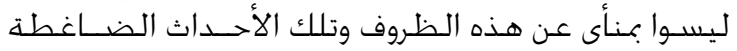

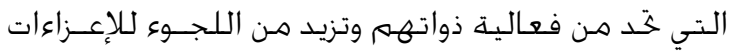

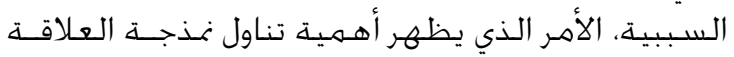

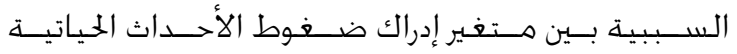

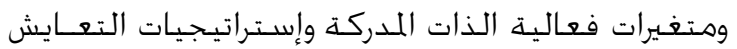

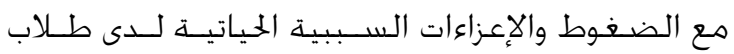

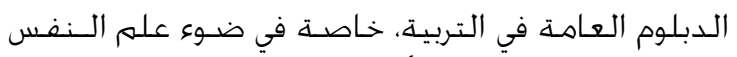

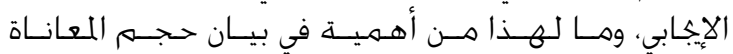

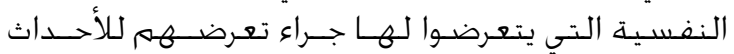

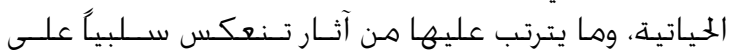

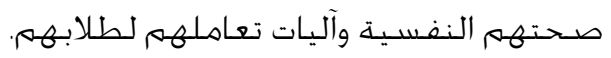
وتعزى الأهمية التطبيقية للدراسـة الحالية إلى الإســهام

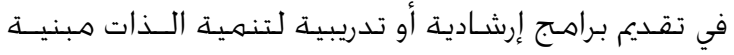

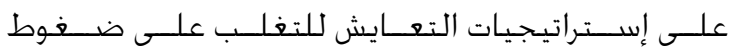

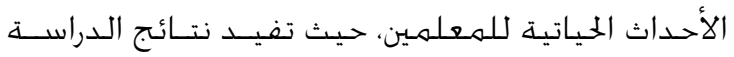

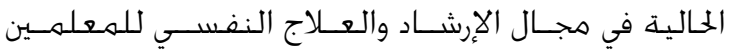

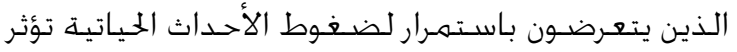

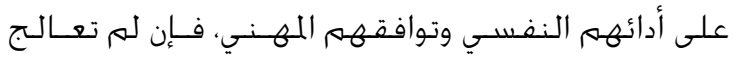

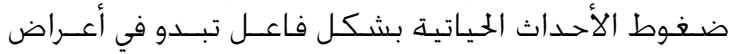

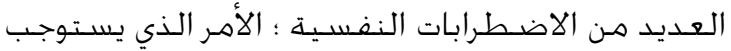

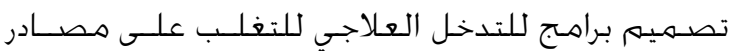

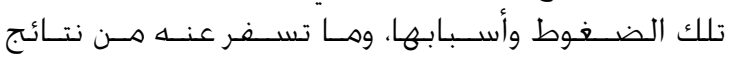

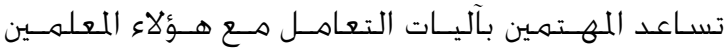


النوع (ذكور، إناث) لصالح الذكور في إستراتيجية

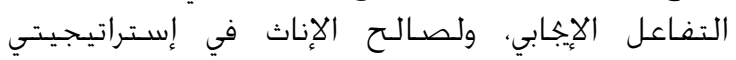
التفاعل السـلبـي والتصـرفات السـلوكية.

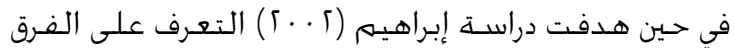

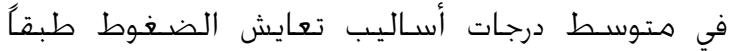

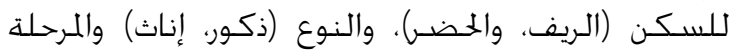

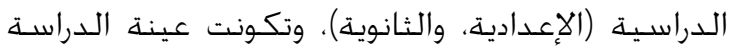

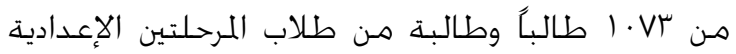

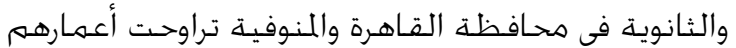

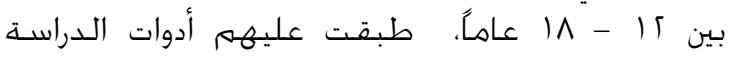

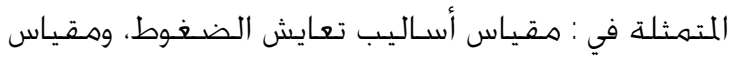

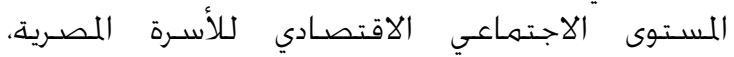

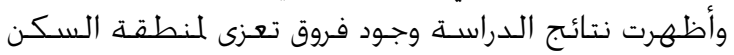

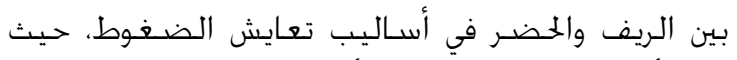

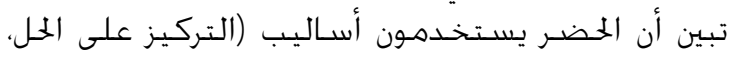

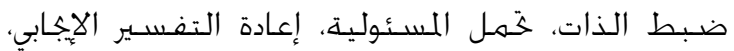

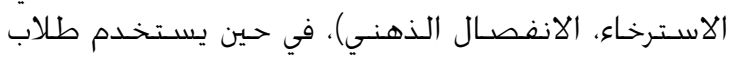

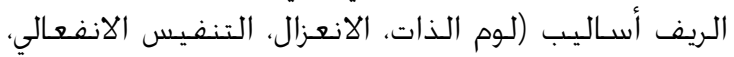

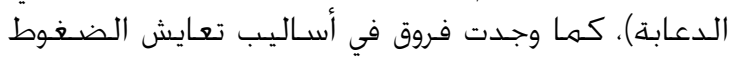

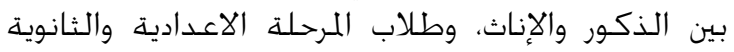

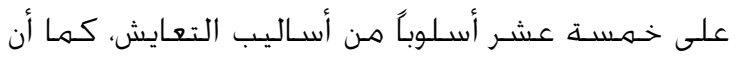

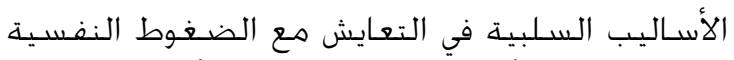

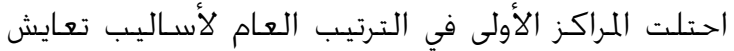

الضغوط (الإنكار، الاستسـلام، التنفيس الانفعالي).

وتناولت دراسـة Puskar \& Lamb أحداث الحياة

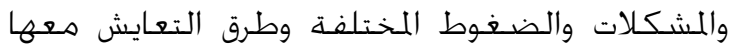

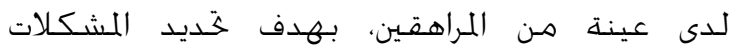
والضغوط النفسية التي يعاني منها المراهقون، ومعرفة المرفة

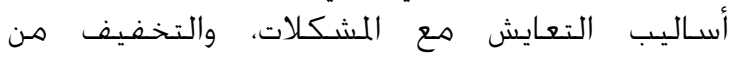
الضغوط النفسية، وتكونت عينة الدراسـة من التهات 19

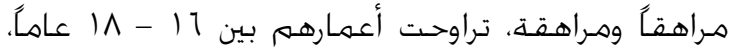

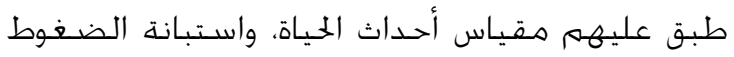

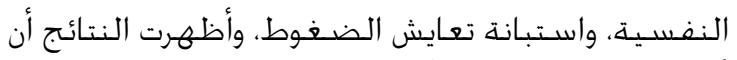

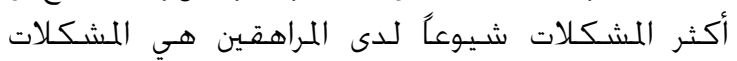

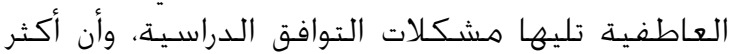

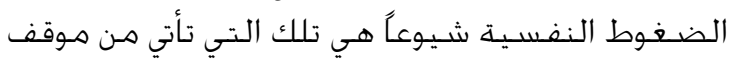

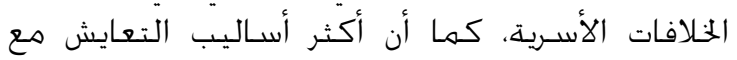

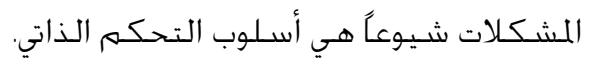

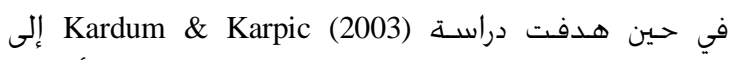

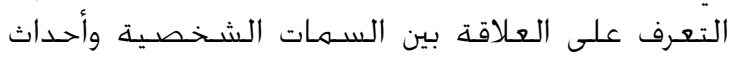

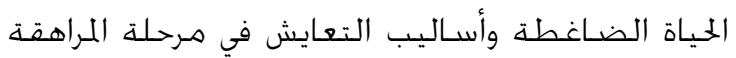

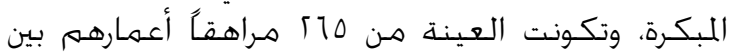

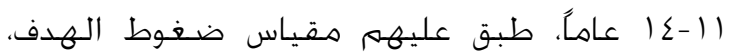

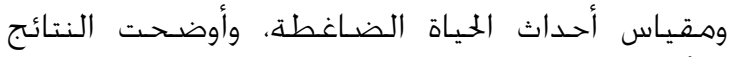
التأثير الإيكابي للانبساط في التعايش مع المشكلات.
وسامي أبو بيه، وهقياس الضبط المدرك للحالات الذاتية

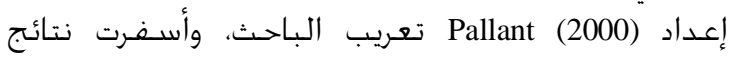

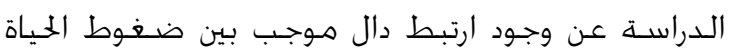

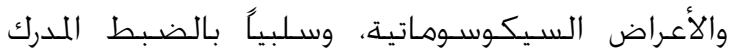
للحالات الذاتية والمساندة الاجتعاعية.

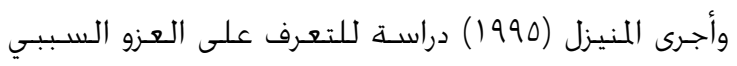

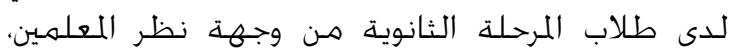

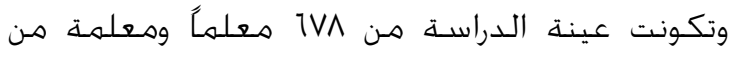

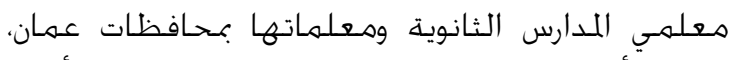

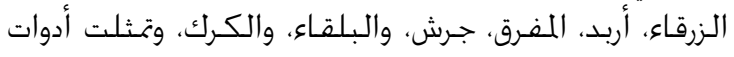

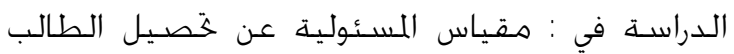

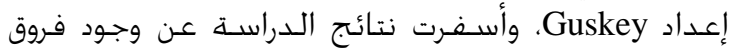

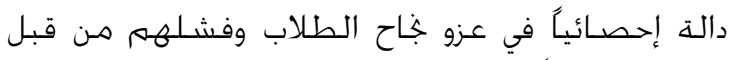

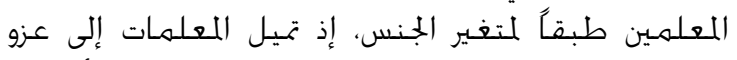

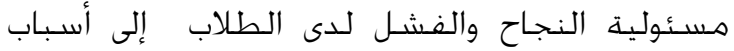

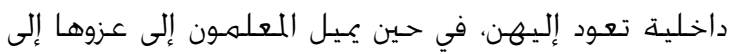

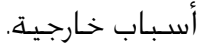

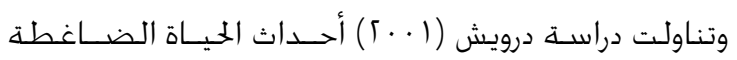

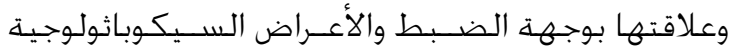

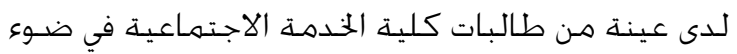

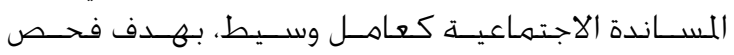

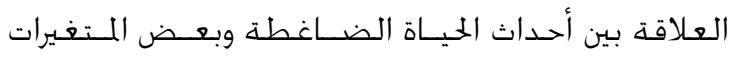

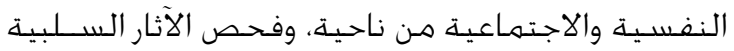

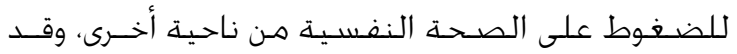

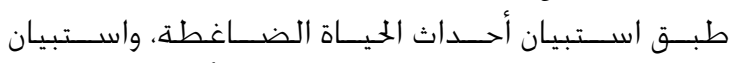

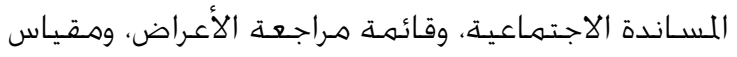

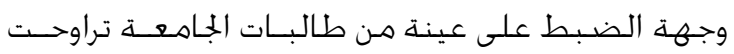

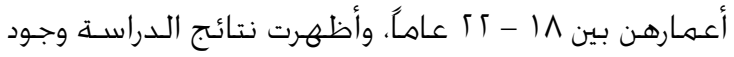

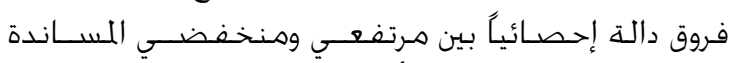

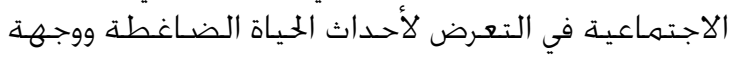

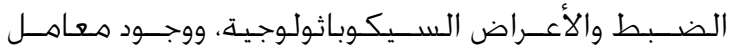

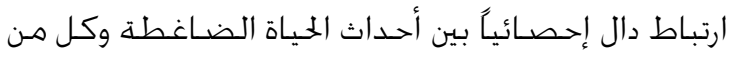

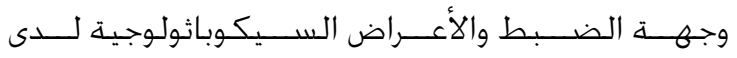

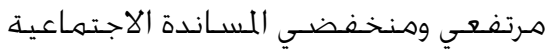

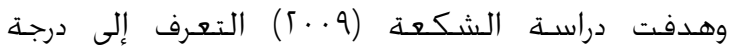

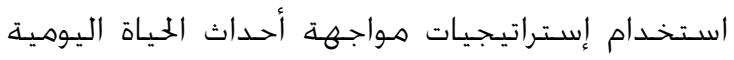

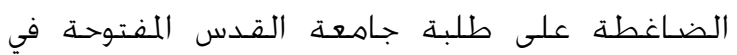
محافظة نابلس، والفروق فيها تبعاً لمتغيري الجنس ومكان العنان

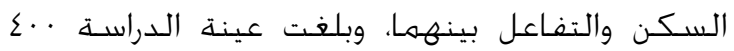

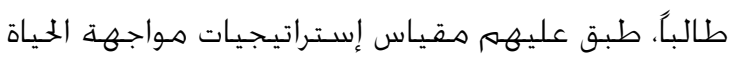

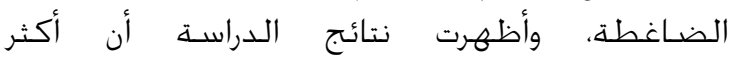

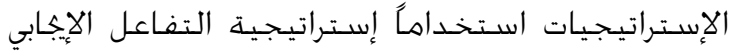

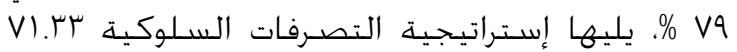

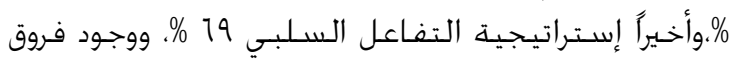

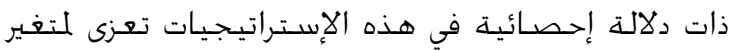




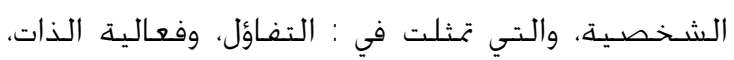

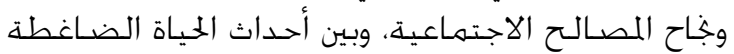

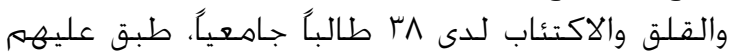

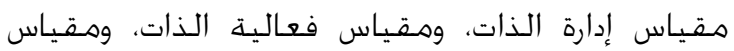
التوجه خو الحياة، ومقياس خجاح العلاقات الإنات الاجتهاعية،

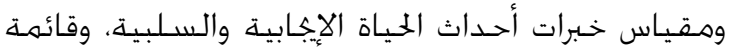
التعايش، وقائمة القلق، وقائمة الاكتئاب، وأشـارت نتائج الإنج

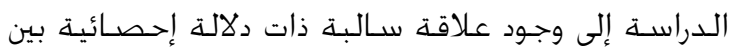

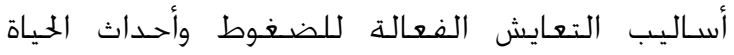

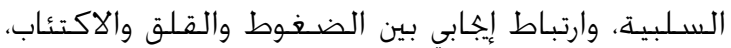

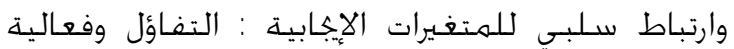

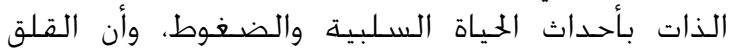

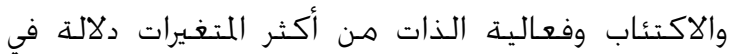

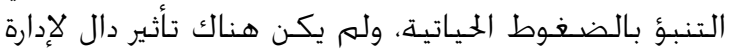

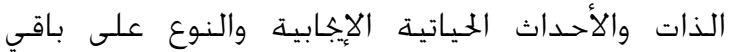

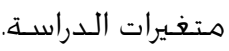

في حين هدفت دراسـة (2002) Marcotte خليل العلاقة بين

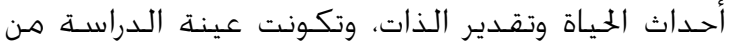

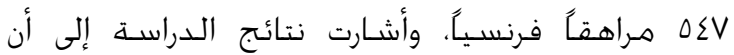
إخفاض تقدير الذات لهات له علاقة بأحداث الحياة السـلبية.

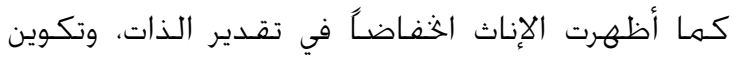

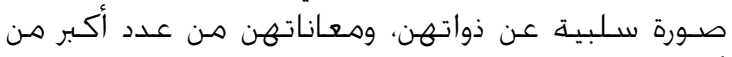
أحداث الحياة الضـاغطة مقارنة بالذكور.

وهدفت دراسـة عبد الوهاب (T) الـ) تعرف العلاقة بين

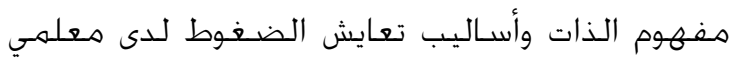

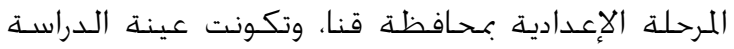

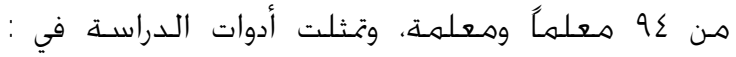

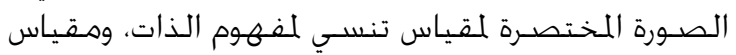

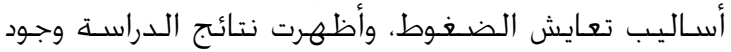

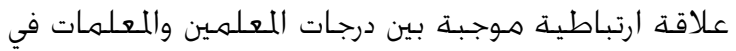

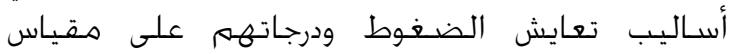

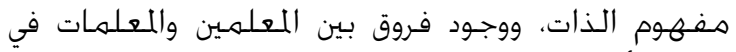
بعض أسـاليب تعايش الضغوط الضات تعزى للعمر والخبرة والحالة الاجتماعية لصالح المعلمات.

وتناولت دراسة Heiman العلاقة بين المصادر

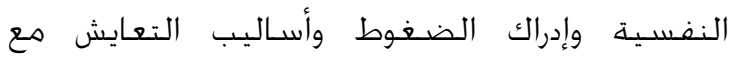

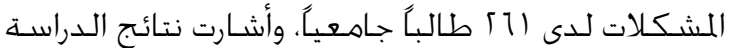

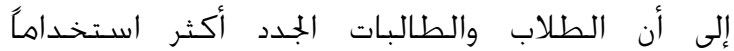

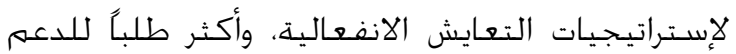

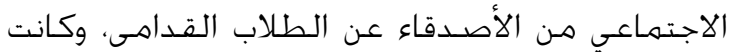

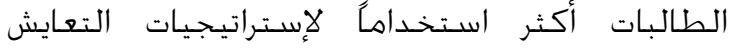

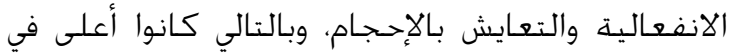

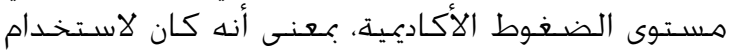

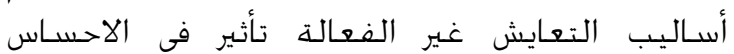

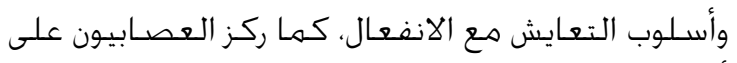

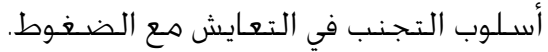

وتناولت دراســ (1992) Sharp \& Thompson إدراك المعلم

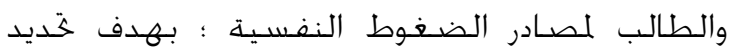

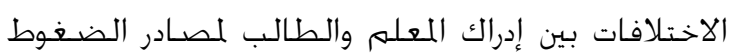

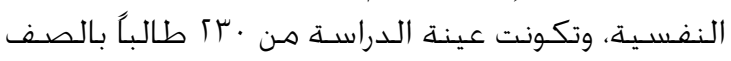

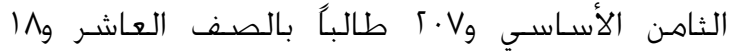

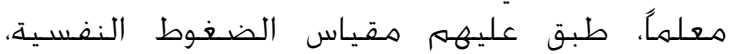

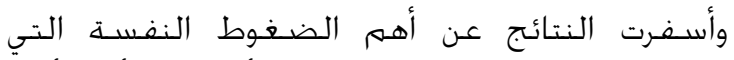

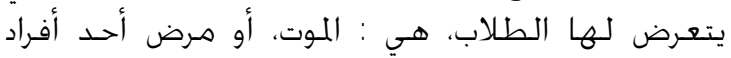

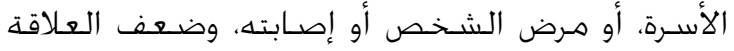

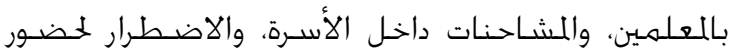

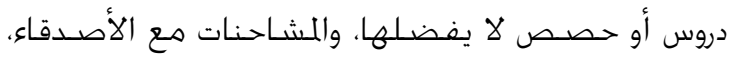

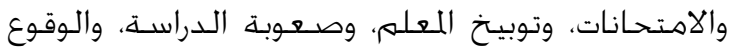

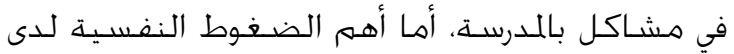

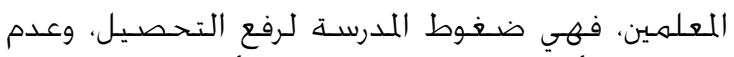

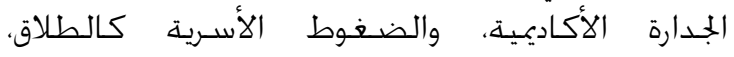
والانفصال.

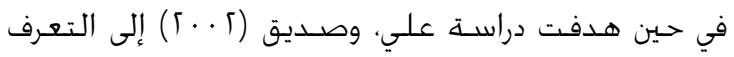

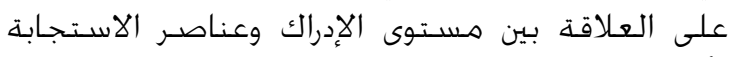

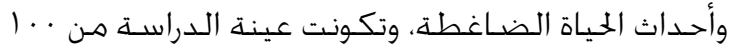

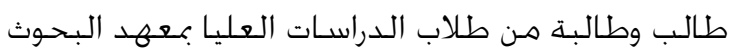

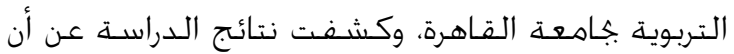

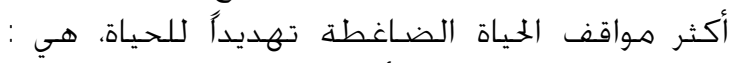
الفصـل من العمل، وهوت أحسد الوالدين.

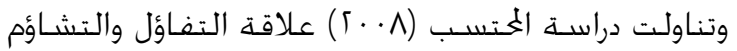

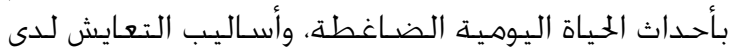

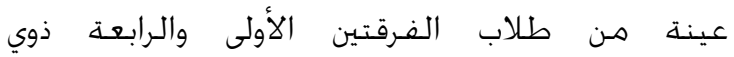
التخصصات العلمية والأدبية بجامعة القدس، وأشارت القابن

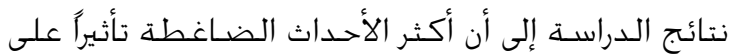

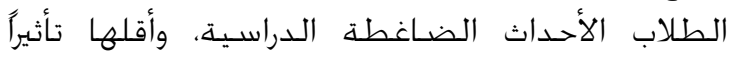

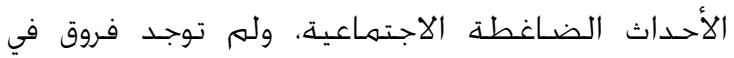

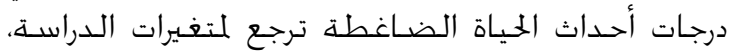

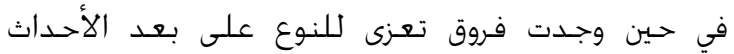

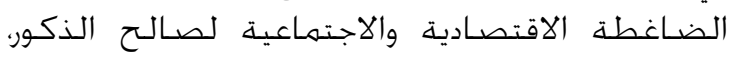

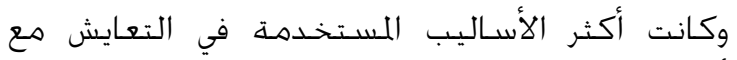

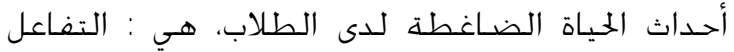

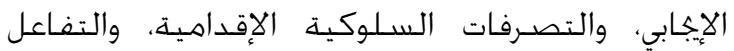

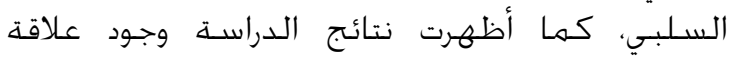
ارتباطية سالبة لأحداث الحياة الضاغطة باتهة بالتفاؤل.

وموجبة بالتشاؤم.

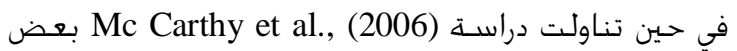

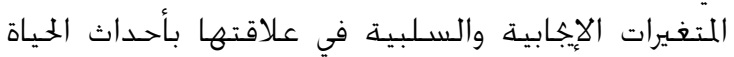
الضاغطة : بهدف تعرف العلاقة بين المتغيرات باتلات الماتيات 
المرتبة الأولى من حيث الأهمية النسبية، تلاها المواقف الدراسية والشخصية، ثم المواقف الصـية والهية والاقتصادية.

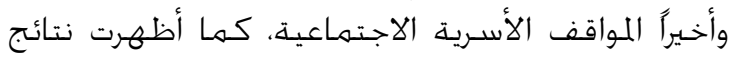

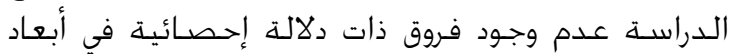

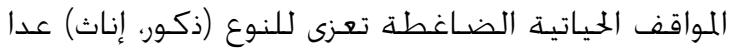
بعد المواقف الحياتية الصحية الضـاغطة لصالح الإناث.

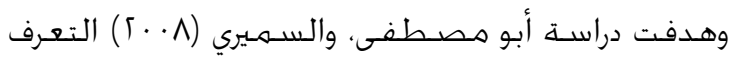

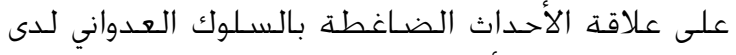

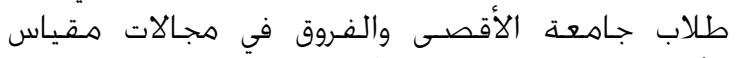

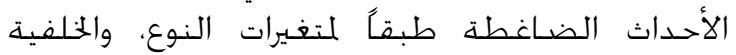

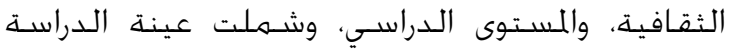

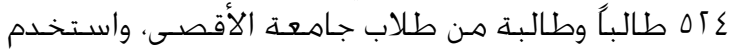

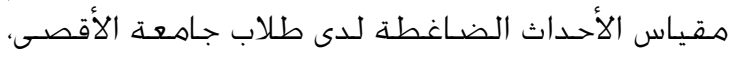

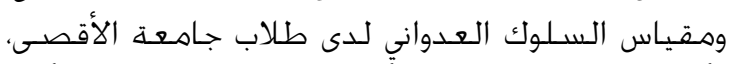

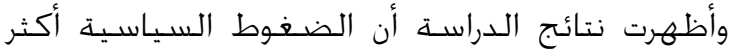

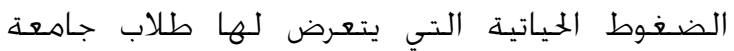

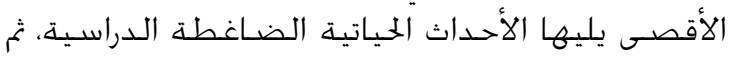

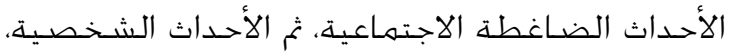

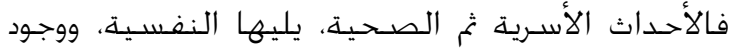
فروق ذات دلالة إحصائية تعزى للنوع في مجالات الأحداث الألاث

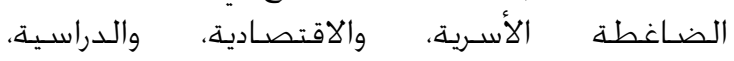

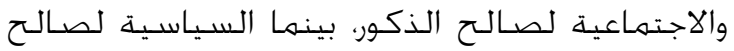

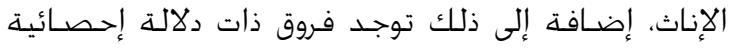

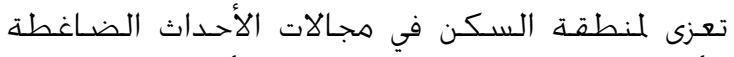

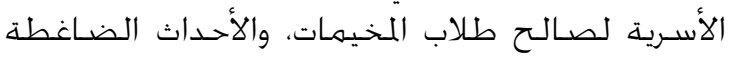
الاجتماعية والصحية لصالح طلاب المدن.

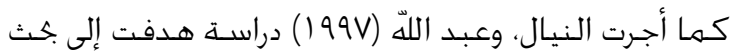

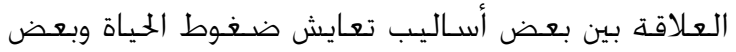

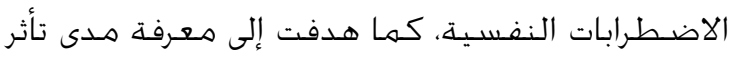

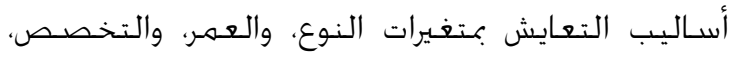

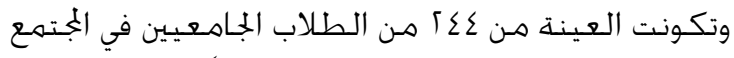

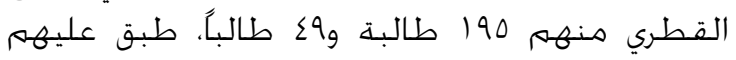

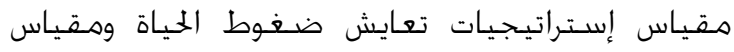

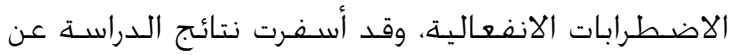

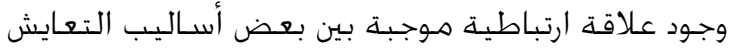

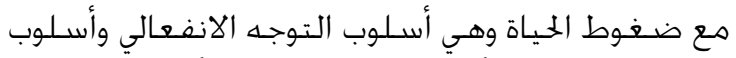

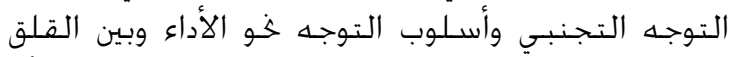

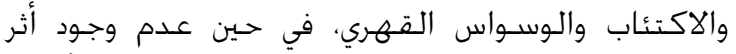

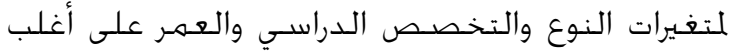

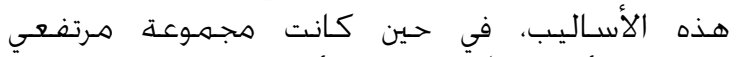

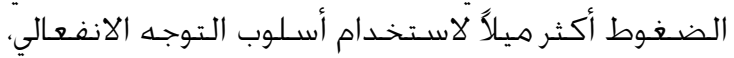

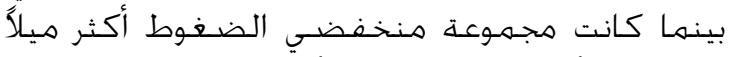
لاستـخدام أسـلوب التوجه خو الأداء.

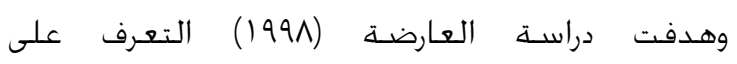

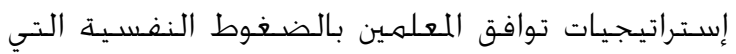

الضغوط الأكاديمية وضغوط العمل، وضغوط اللياة اليومية. - الصغو

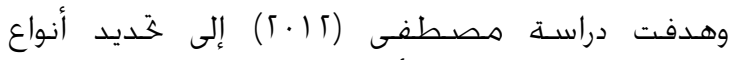

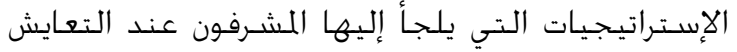

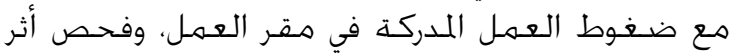

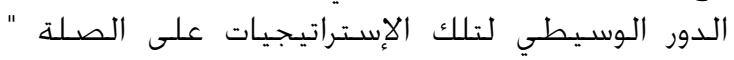

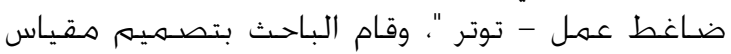

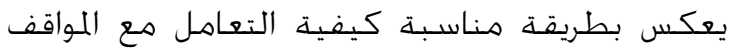

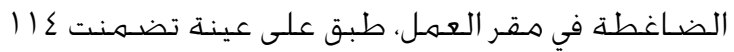

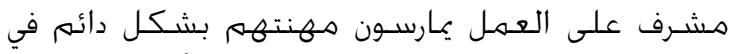

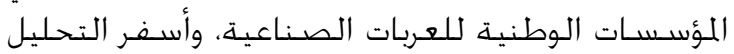

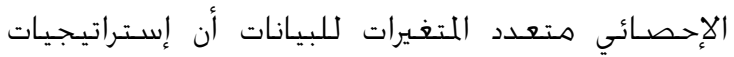

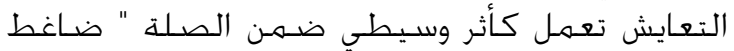

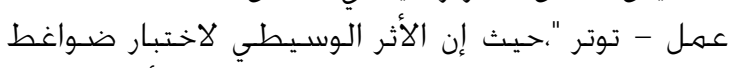

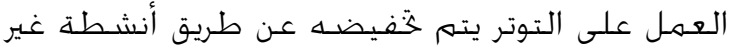
عملية ويتم تضخيمه عن طريق التفريغ الانفعالي. وتناولت دراسـة دسـوقي (990 () فعالية الذات وعلاقتها

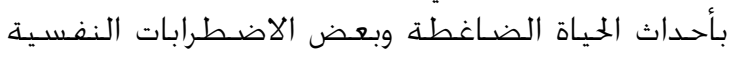

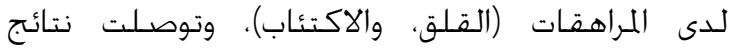

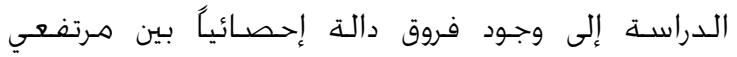

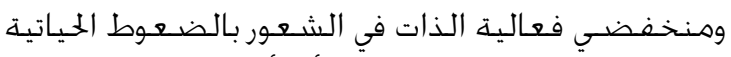

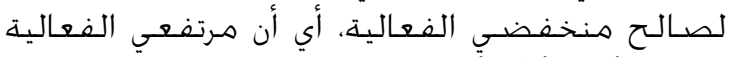

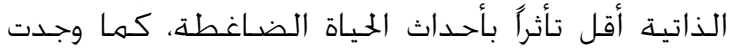

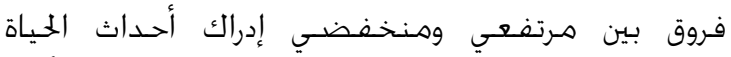

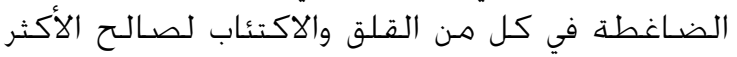

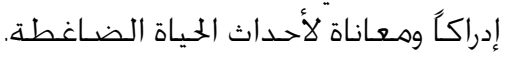

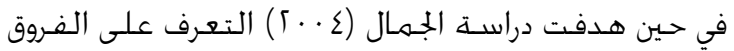
طبقاً للنوع في إدراك أحداث الحياة اليوهية (الضـاغطة الغية.

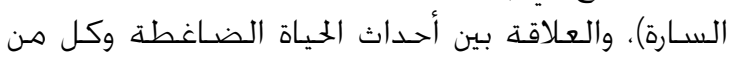

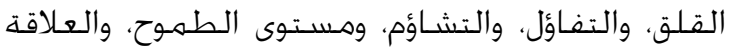

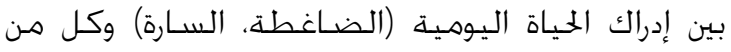

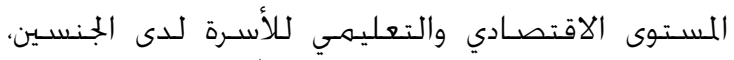

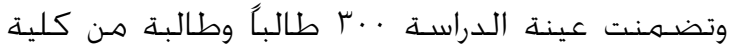

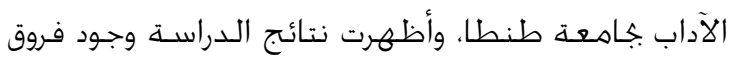

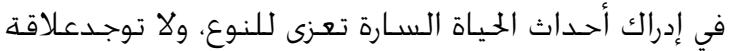

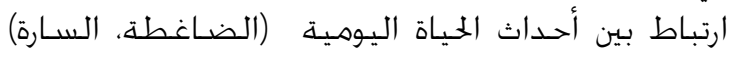

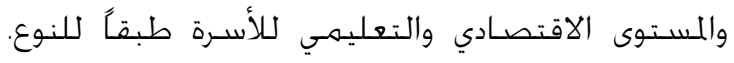

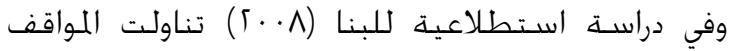

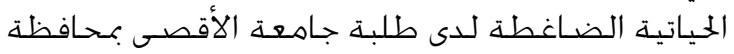

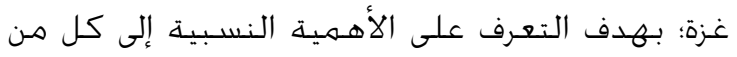

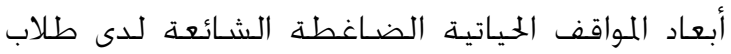

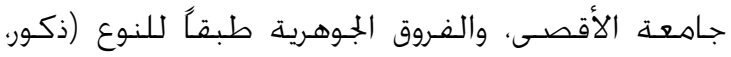

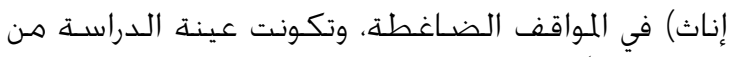

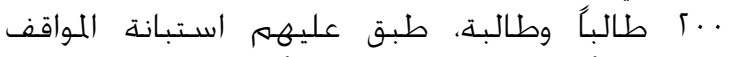
الحياتية، وأسـفرت نتائج الدراسـة أن المواقف الحينة الحياتية في 


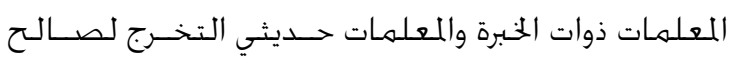

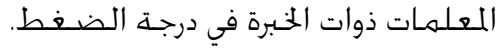

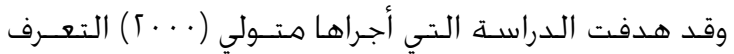

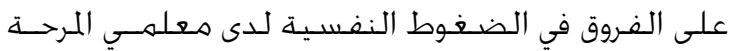

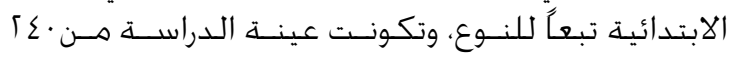

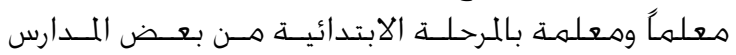

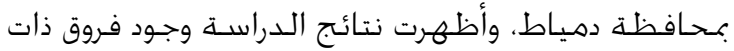

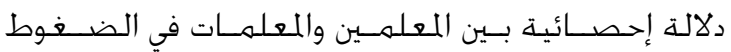

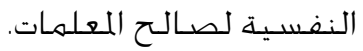

\section{تعقيب على الدراسـات ذات الصلـة}

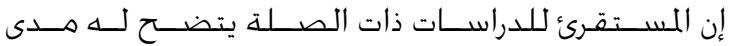

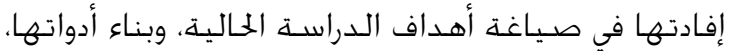
وصياغة فروضها، وذلك كما يلي:

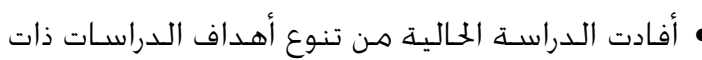

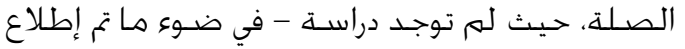

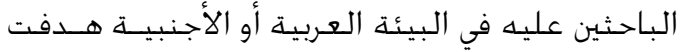

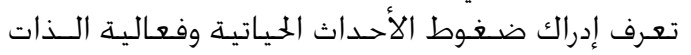

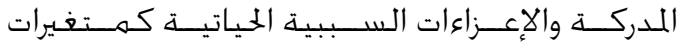

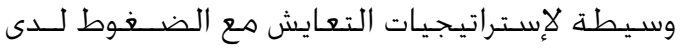

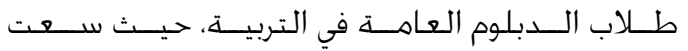

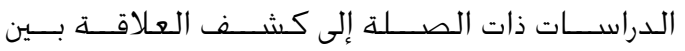

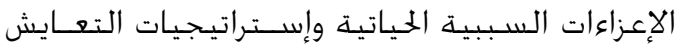

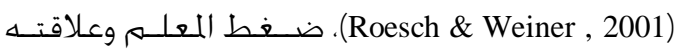

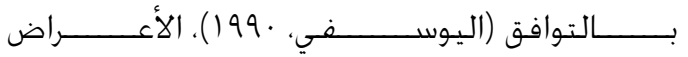

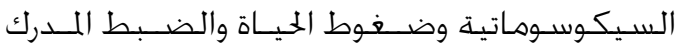

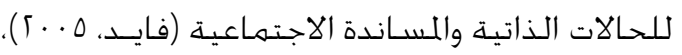

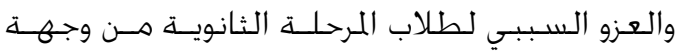

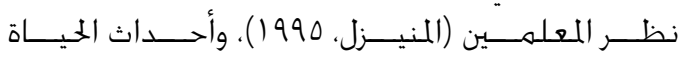

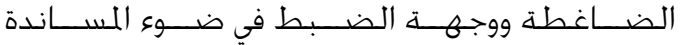

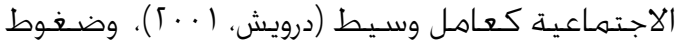

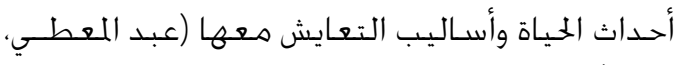

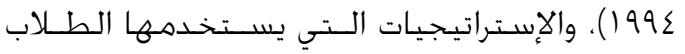

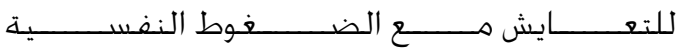

(Kardum \& Karpic, 2003. Puskar \& Lamb, 1991)

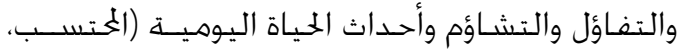

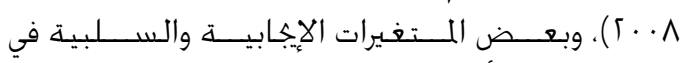

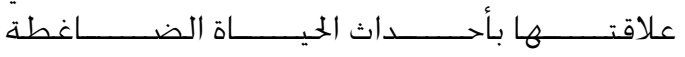

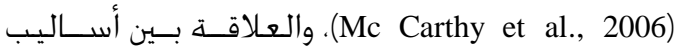

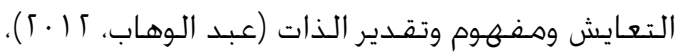

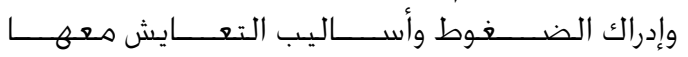

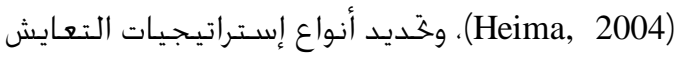

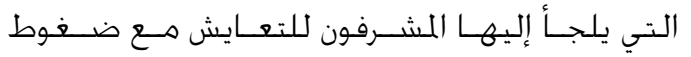

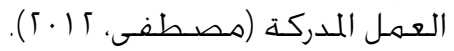

تواجههـم في المدارس الثانوية في محافظة نابلس، وأثر

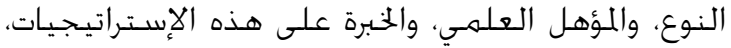

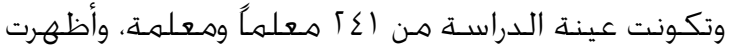

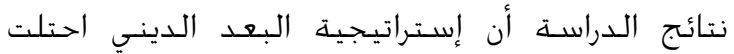

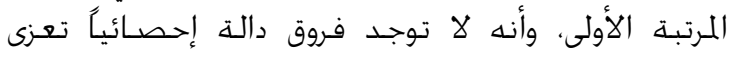

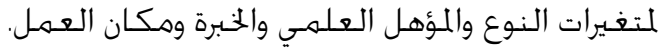

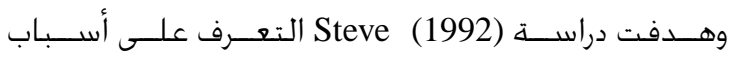

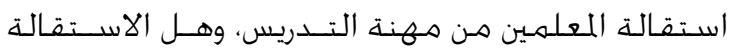

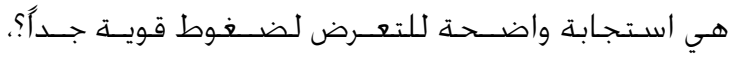

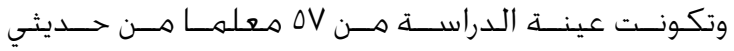

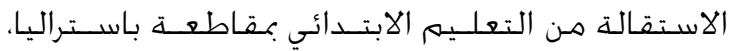

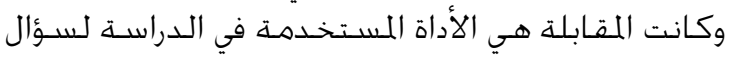

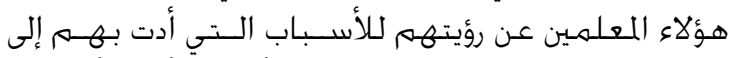

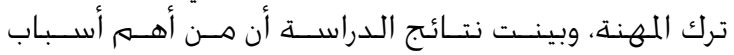

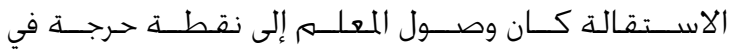
اجتاهـاته خو مهزنة التدريس تلك التي يعجز المدرس فيها

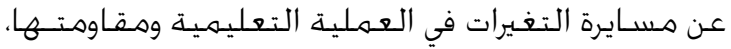

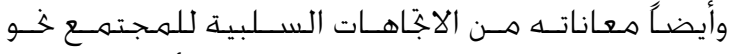

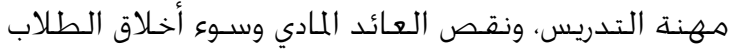
وسـوء العلاقة مع الزهـلاء.

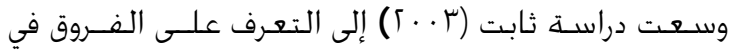

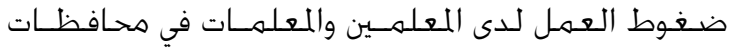

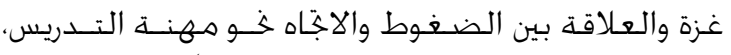

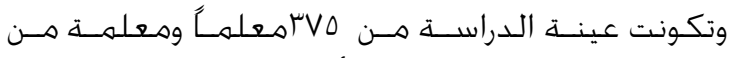

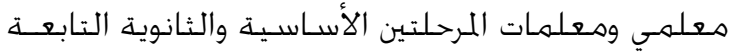

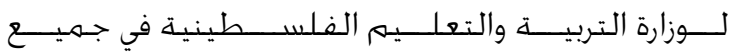

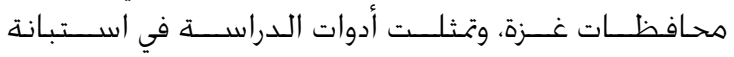

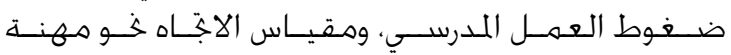

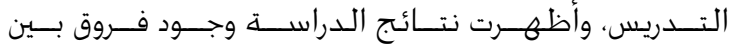

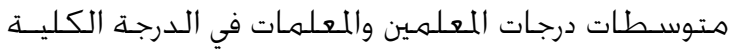

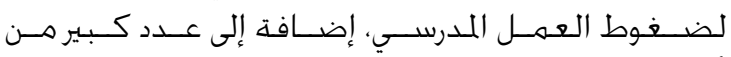

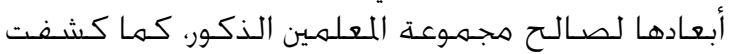

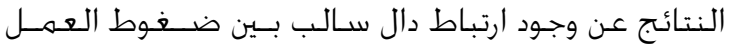

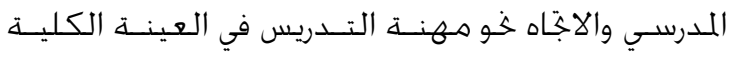

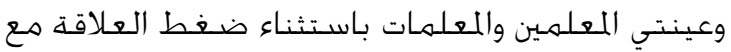

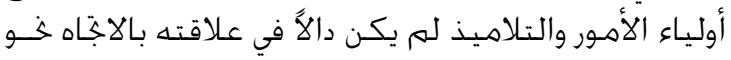

مهنة.

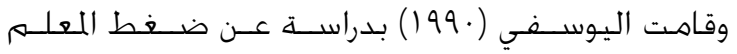

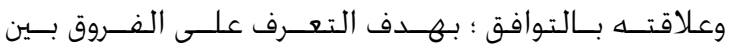

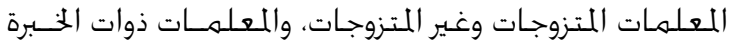

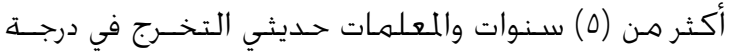

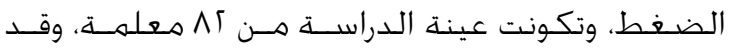

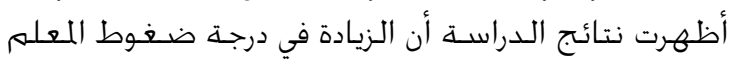

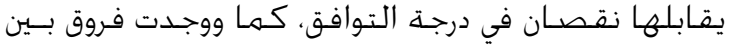




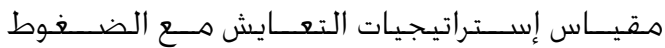

$$
\begin{aligned}
& \text { المستخــدم بالدراسـة. }
\end{aligned}
$$

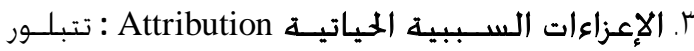

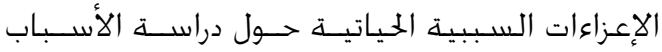

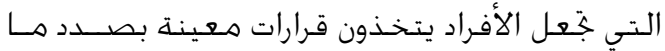

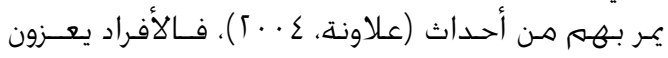

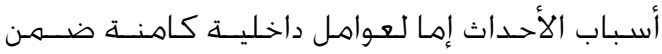

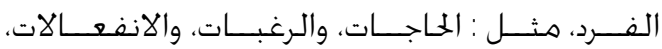

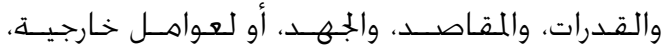

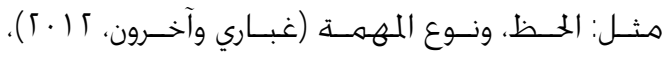

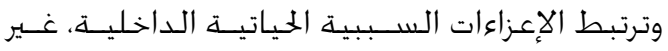

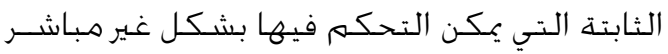

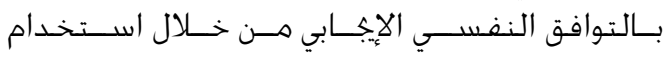

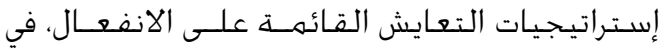

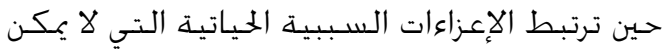

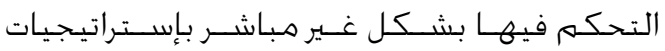

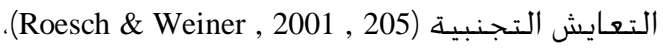

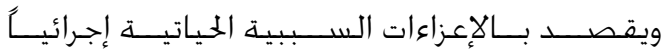

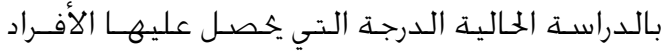

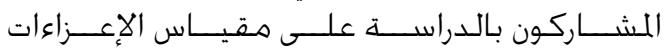

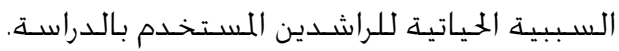
ع. إدراك ضـغوط الأحداث الحياتية :هدى وعي المعلمين

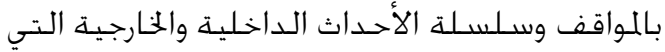

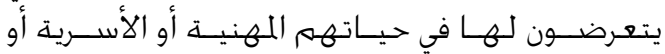

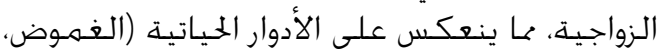

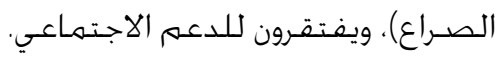

\section{الطريقة والإجراءات}

منههج الدراسـة

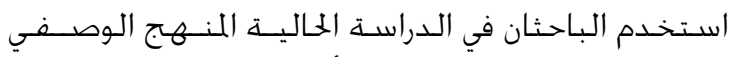

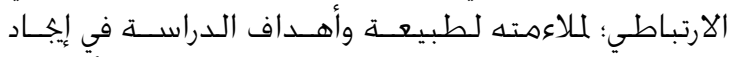

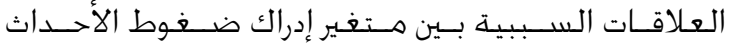

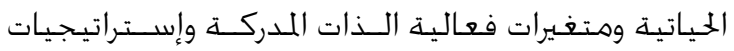

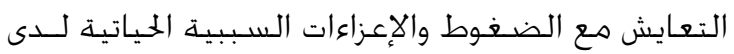

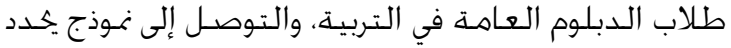

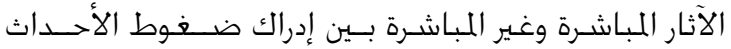

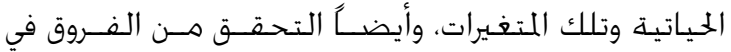

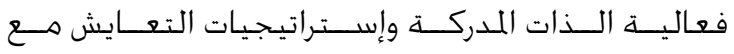

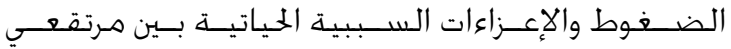

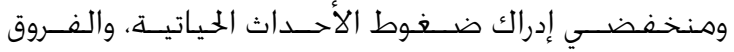

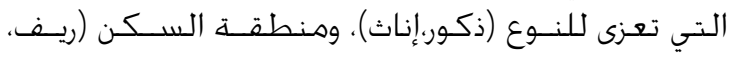

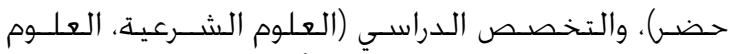

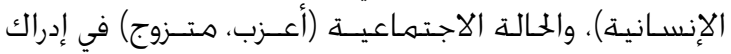
ضغوط الأحسداث الحياتية.
• تباينت الأدوات المسـتخدمة في الدراسـات ذات الصـلة

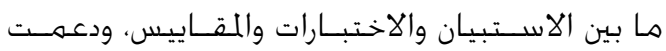

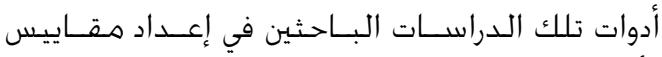

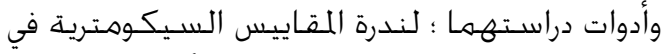

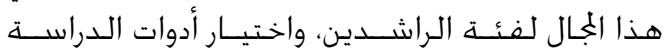

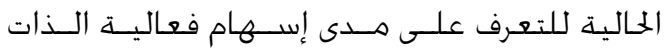

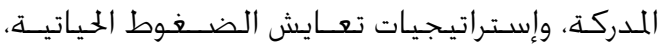

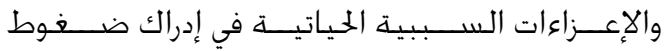
الأحسداث الحياتيـة للـراشـين.

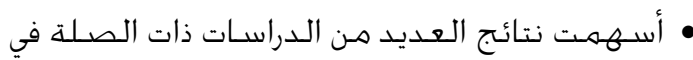

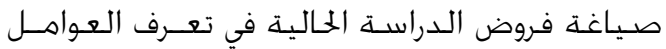

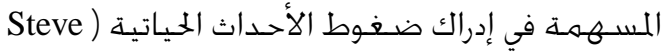
1992

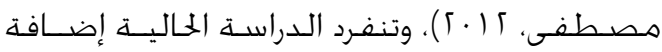

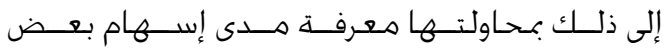

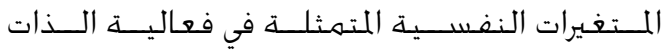

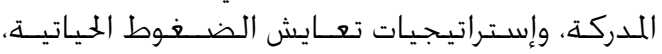

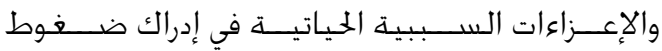

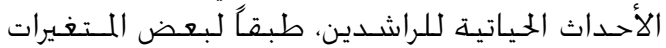

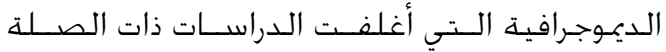

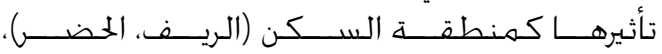

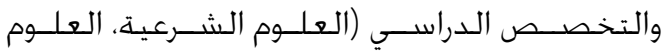

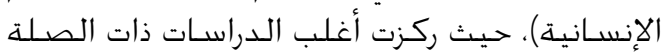

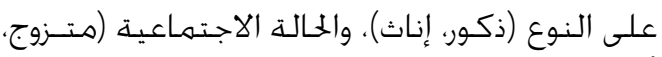

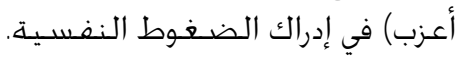
مصسطلحات الدراسـة

ا ـ فعالية الذات المدركة: Perception Self - Efficacy

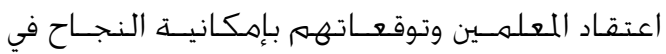

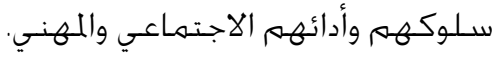

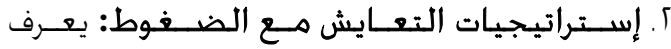

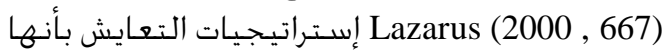

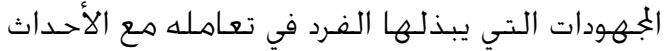

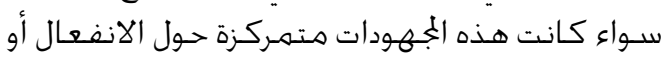

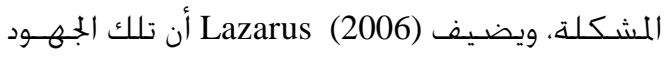

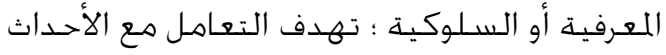

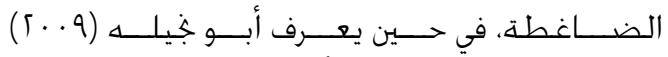

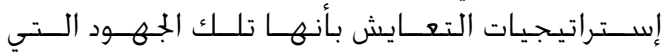

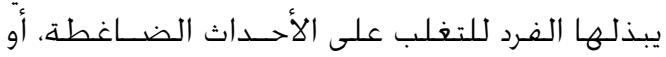

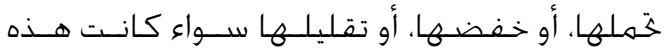

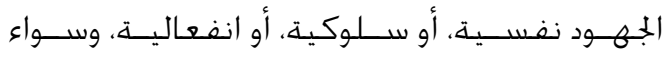

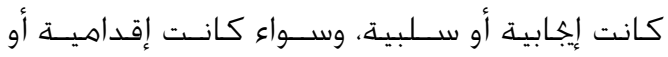

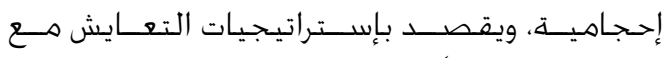

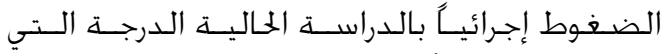

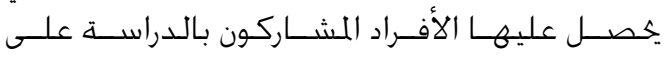


بهـدف التحققق من كفـاءة أدوات الدراسـة السـيكومترية،

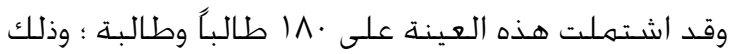

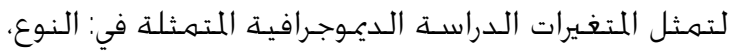

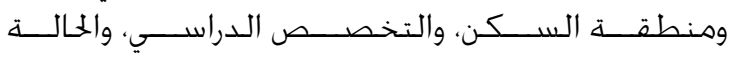

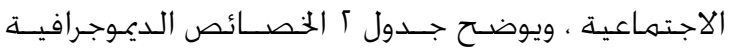

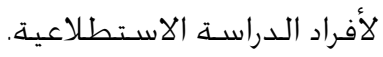

المشـاركون بالدراسـة

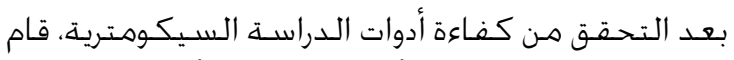

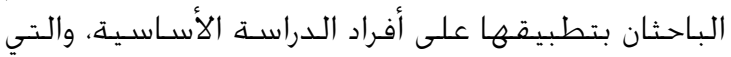

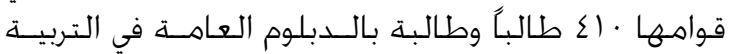

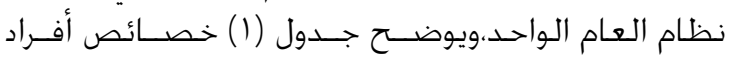
الدراسـة الأسـاسـيـة.

أدوات الدراسـة أد

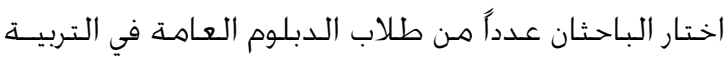

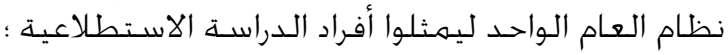

جدول الجاد

الخصائص الديموجرافية لأفراد الدراسـة الأساسية (ن= - (ع)

\begin{tabular}{|c|c|c|c|c|c|c|c|c|c|}
\hline \multirow[t]{3}{*}{ 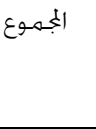 } & \multicolumn{4}{|c|}{ 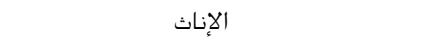 } & \multicolumn{4}{|c|}{ الذ الذكور } & \multirow{3}{*}{ 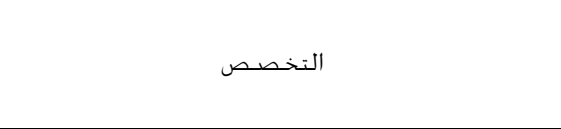 } \\
\hline & & الحضـر & & الريف & & الخضـر & & الريف & \\
\hline & متزوج & 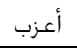 & متزوج & 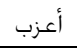 & متزوج & 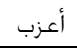 & متزوج & 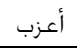 & \\
\hline$\wedge 1$ & 1. & 11 & 14 & 1. & V & 1. & 15 & $\wedge$ & أصــول الدين والدعـوة الإسـلامية \\
\hline$\sum 9$ & 0 & 0 & $\varepsilon$ & $\wedge$ & $\varepsilon$ & $\wedge$ & 10 & - & الشـريعة الإسـلامية \\
\hline V1 & 11 & it & 0 & IV & r & 0 & 1 & v & اللغة العربية والـراسـات الإسـلامية \\
\hline$\Gamma \cdot 1$ & $\lceil 1$ & $\lessdot \wedge$ & it & ro & $1 \varepsilon$ & $r \mu$ & $r r$ & 10 & إجـــالي عينة الدراسـة الاســطلاعية للعلوم الشـرعية \\
\hline$\Delta 1$ & 0 & 9 & 0 & $\vee$ & 0 & r & V & 10 & واللترجـــة (الإجذليزية، الفرنسـية، الشـرقية، الأوروبية \\
\hline$r \wedge$ & $\Delta$ & 广 & r & $\Delta$ & 广 & $\Delta$ & $\wedge$ & $\wedge$ & علم النفس والخدمة الاجتماعية \\
\hline iv & 广 & $\varepsilon$ & v & - & 1 & 1 & 广 & 0 & الإعلام \\
\hline$\varepsilon$ & $r$ & $\varepsilon$ & 0 & 1 & $\varepsilon$ & 1 & 0 & - & التاريخ والجغرافيا \\
\hline iv & 广 & 1 & $r$ & $r$ & 0 & $\varepsilon$ & $\varepsilon$ & 0 & الخـــوق والتـجـارة \\
\hline$\lceil\mu$ & r & 1 & 广 & 广 & $r$ & $\varepsilon$ & $r$ & 0 & الهنـدسـة والزراعـة \\
\hline$\Sigma \cdot \Sigma$ & $\Gamma \cdot$ & 11 & 10 & ir & 「. & $\lceil\wedge$ & 19 & $r \wedge$ & إجـمالي عينة الدراسـة الاسـطـلاعية للعلوم الإنسـانية \\
\hline$\Sigma 1$. & $\Sigma 1$ & $\Delta 9$ & $\varepsilon V$ & $\Delta \wedge$ & $r \varepsilon$ & 01 & 11 & $\Delta r$ & إجـــالي عينة الدراسـة الاسـطلاعية \\
\hline
\end{tabular}

جدولr

الخصـائص الديموجـرافية لعينة الدراسـة الاســطلاعية (ن = •^ال)

\begin{tabular}{|c|c|c|c|c|c|c|c|c|c|}
\hline \multirow{3}{*}{ الجمهـوع } & \multicolumn{4}{|c|}{ 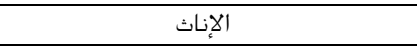 } & \multicolumn{4}{|c|}{ الذكور } & \multirow{3}{*}{ 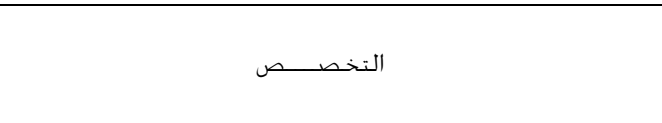 } \\
\hline & & & الخضر & الريف & & & الخضر & الريف & \\
\hline & متزوج & أعزب & متززوج & أعزب & متزوج & أعزب & متزوج & أعزب & \\
\hline 14 & - & 1 & $r$ & $\Gamma$ & - & $\mathrm{V}$ & 0 & - & أُصـول الدين والدعوة الإسـلامية \\
\hline 1. & r & 1 & - & r & - & r & - & r & 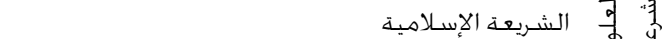 \\
\hline VI & 9 & r. & r & 19 & r & 1 & 0 & r & اللغـة العربية والـراسـات الإسـلامية \\
\hline 90 & 15 & re & 1 & $\lceil r$ & 广 & 0 & 1. & 0 & إجـــالي عينة الدراسـة الاسـطلاعية للعلوم الشـرعية \\
\hline iv & 0 & 9 & 广 & $\wedge$ & 1 & 1 & - & 1 & اللغات (الإجذليزية، الفـرنسية، الشـرقية، الأوروبية والترجـمة) \\
\hline $\mathrm{v}$ & 广 & - & - & 「 & - & 广 & - & 1 & علم النفس والخدمة الاجتماعية \\
\hline$\varepsilon$ & - & 1 & - & - & - & 1 & - & 广 & 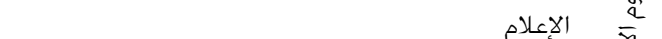 \\
\hline r. & r & 1 & r & 1 & - & 1 & 0 & 广 & التاريخ والجغرافيا \\
\hline 1. & r & r & - & $r$ & - & r & - & - & اللحقـوق والتجـارة \\
\hline $\mathrm{v}$ & r & 1 & 1 & 1 & - & - & r & - & الهزندسـة والزراعة \\
\hline ^o & 14 & 19 & 1 & 「. & 1 & $1 \%$ & v & 1 & إجـمالي عينة الدراسـة الاســطلاعية للعلوم الإنسـانية \\
\hline $1 \wedge$ & 10 & 01 & 15 & $\Sigma r$ & r & 11 & IV & 11 & إجـــالي عينة الدراسـة الاستطلاعية \\
\hline
\end{tabular}


وخليل، (1 ( ) )، اسـتبيان أحسداث الحياة الضـاغطـة (Roohafza et al., 2012)

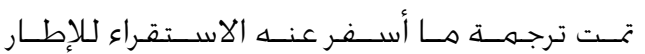

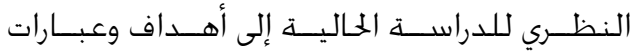

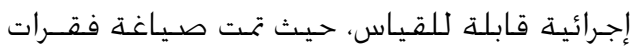

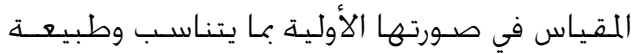

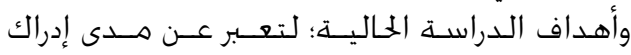

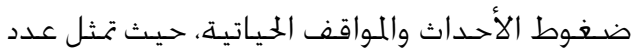

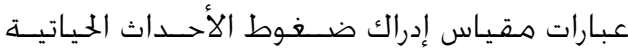

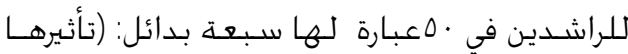

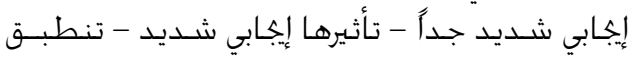

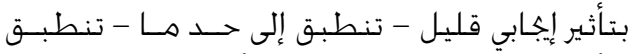

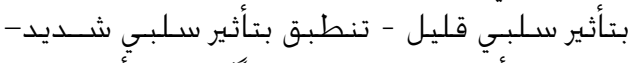

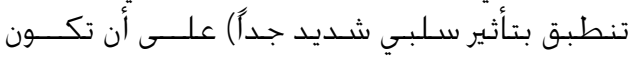

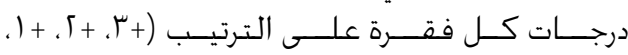

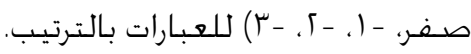

كفاءة مقياس إدراك ضغوط الأحداث الحياتية للراشـدين: الصـدق: اعتهـد الباحثان في حسـاب صـدق المقياس علـى ما يلي:

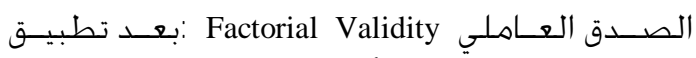

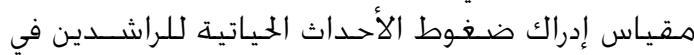

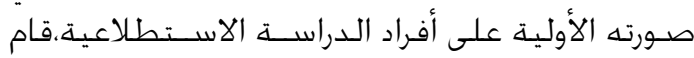

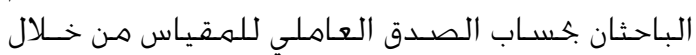

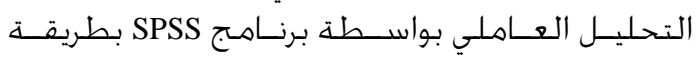

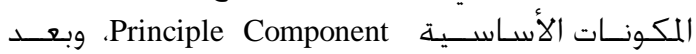

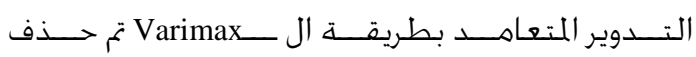

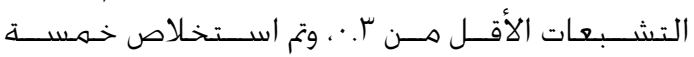

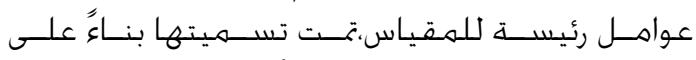
طبيعة ومعنى إدراك ضـغوط الأحسداث الحياتية بالإطار

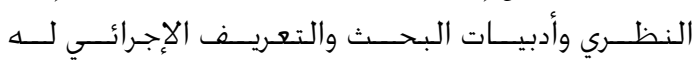

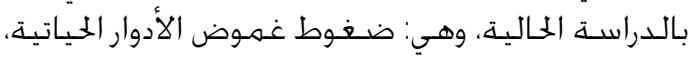

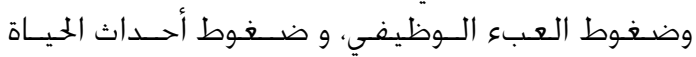

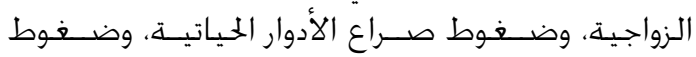

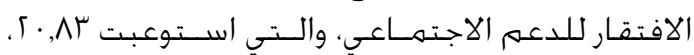

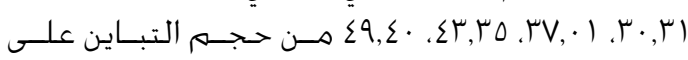
التـرتيـ. (الب.

الثبات: طريقـة ألفـا كرونباخ:اسـتخـدم الباحثان معـادلة

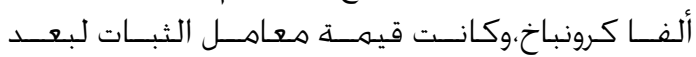

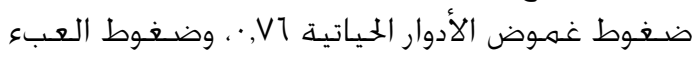

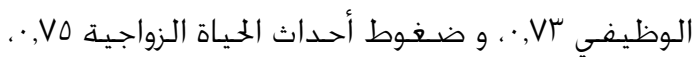

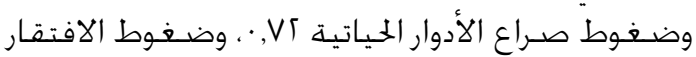

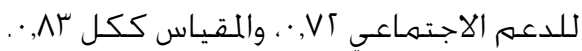

\section{مقياس إدراك ضغوط الأحداث الحياتية للراشـدين :}

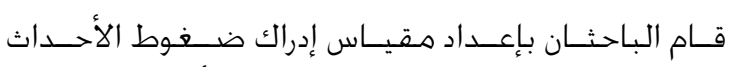

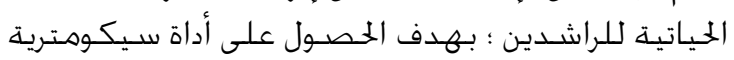

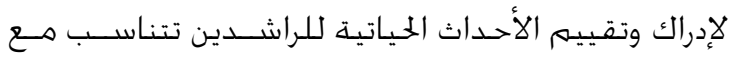

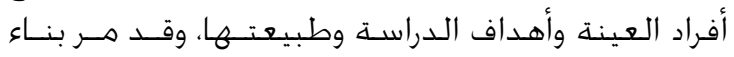
المقياس بالخطوات التالية:

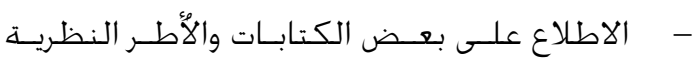

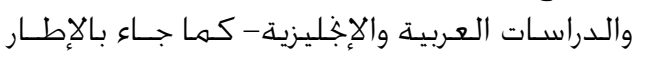

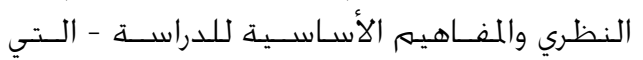

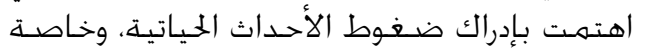

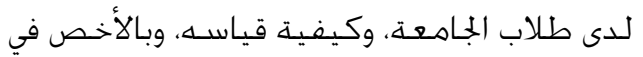

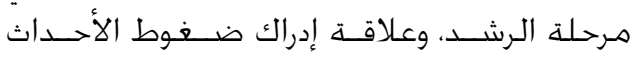

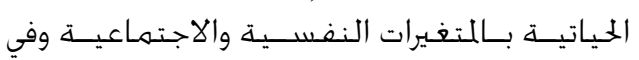

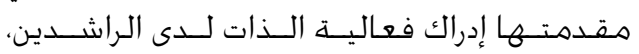

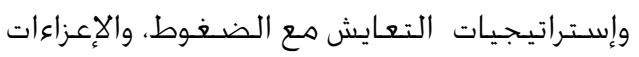
السـببية الخياتية.

الاطلاع على بعض المقاييس العربيـة والإجنليزيـة،

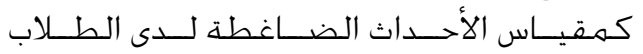
(Richard et al., 1999)

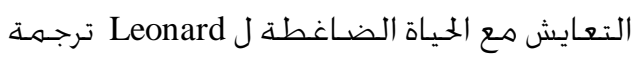

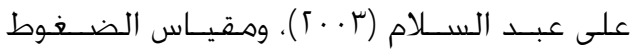

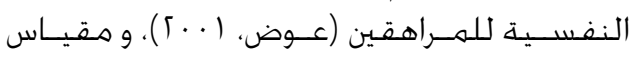

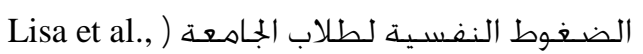

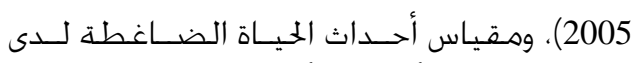

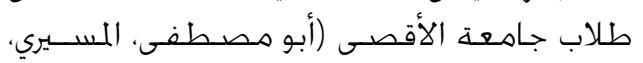

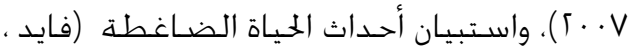

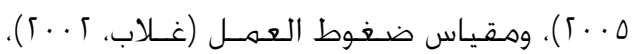

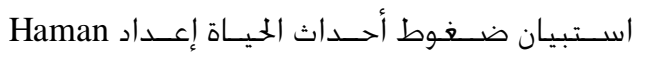

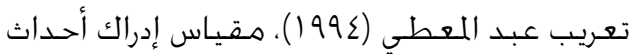

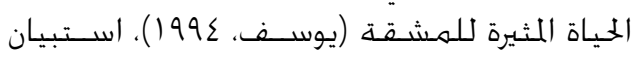

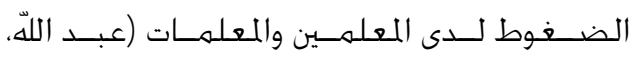

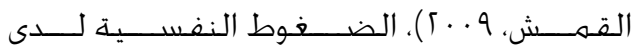

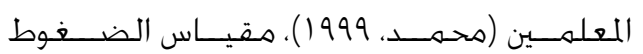

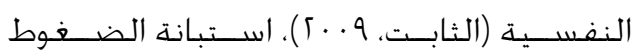

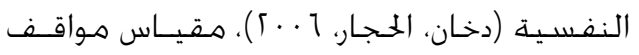

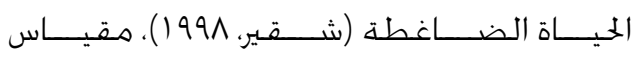

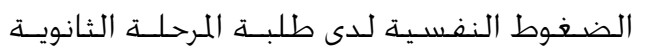

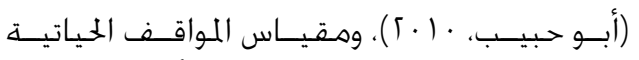

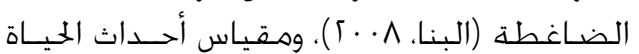

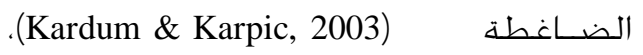

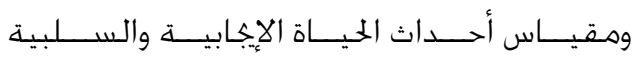

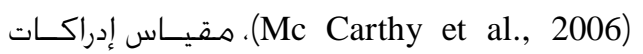

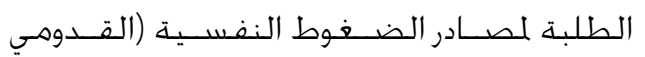


Principle Component

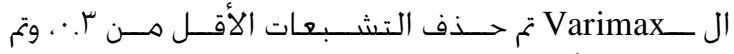

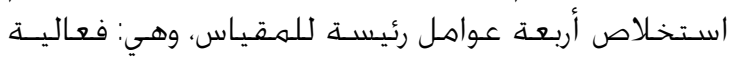

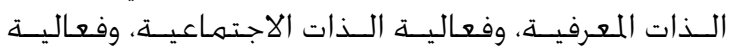

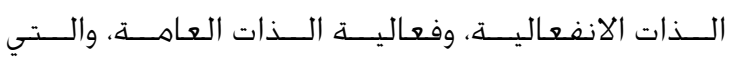

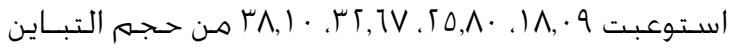
على التـرتيب.

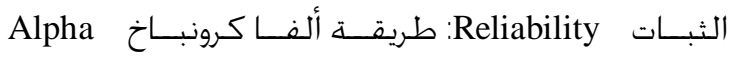
Cronbach Method

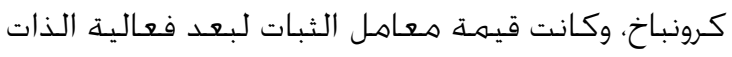

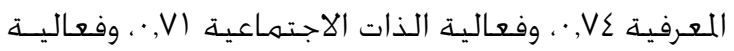

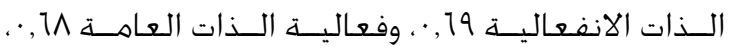

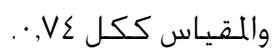

مقياس الإعـزاءات الحياتيـة السـبـيـة للراشـدين:قـام

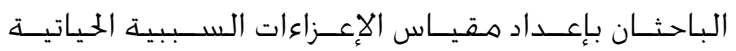

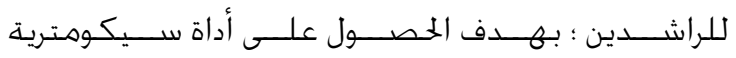

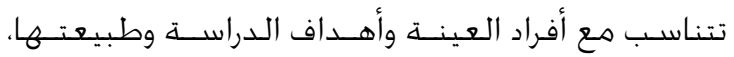

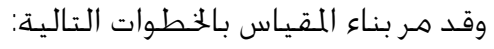

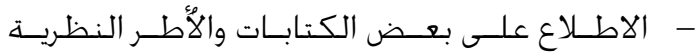

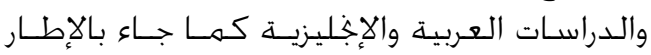

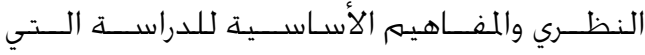

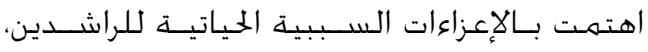

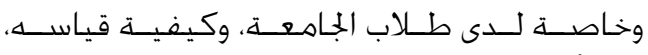

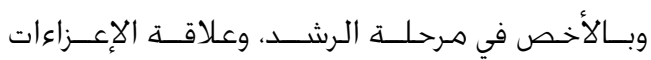

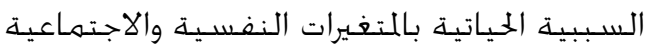

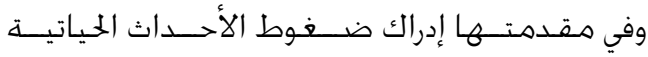

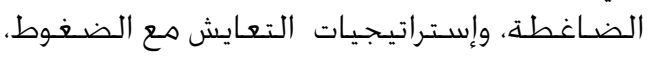

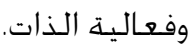

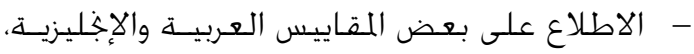

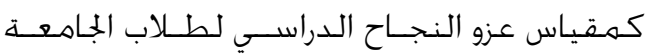

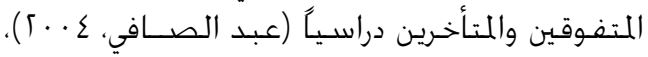

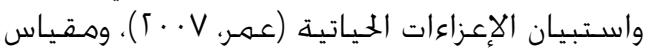

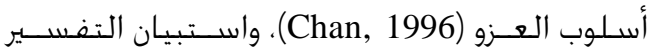

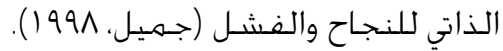

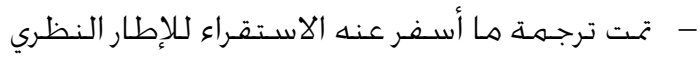

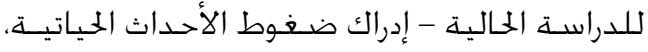

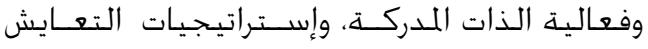

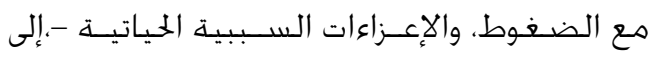

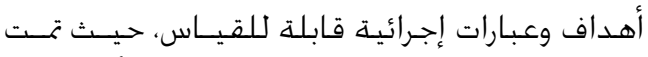

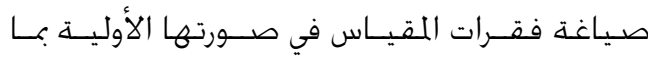

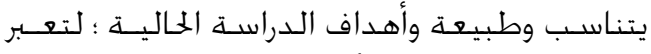

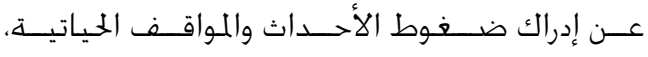

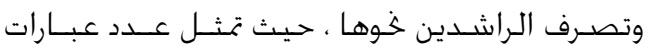

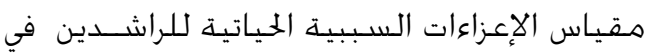

مقياس فعالية الذات المدركة للراشـدين: قام الباحثان

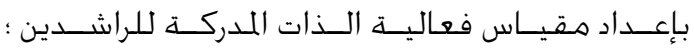

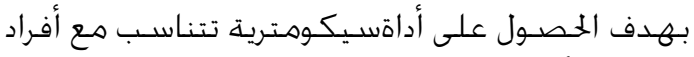

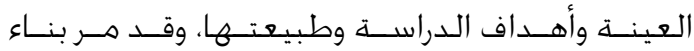
اللقياس بالخطوات التالية:

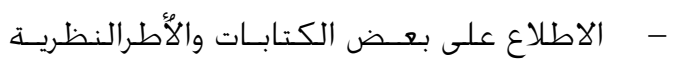

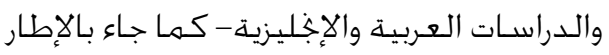

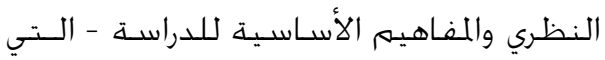

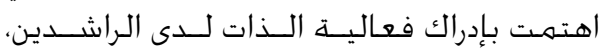

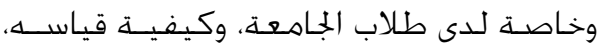

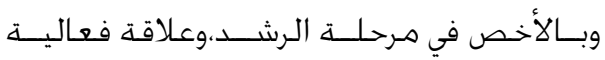

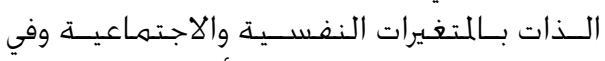

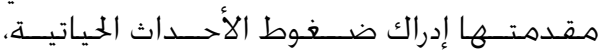

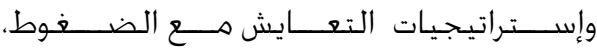
والإعزاءات السببيـة الحياتيـة.

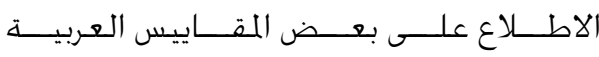

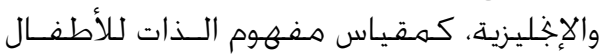

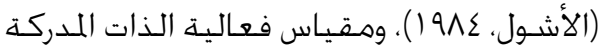
Measurement of Perceived Self-Efficacy

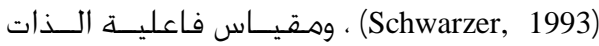

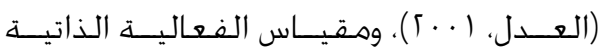
Tiptan \& Worthinghton

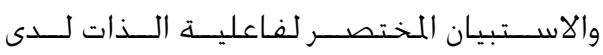
الشـباب (Muris, 2001).

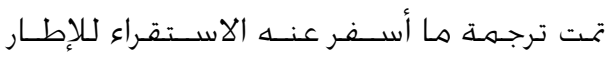

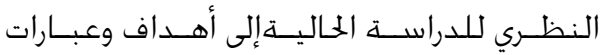

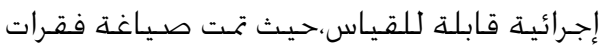

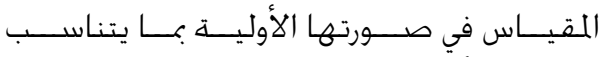

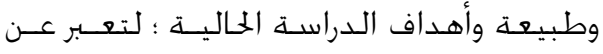

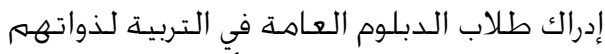

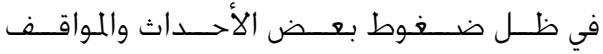

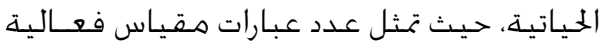

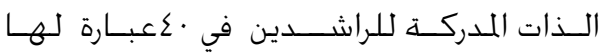

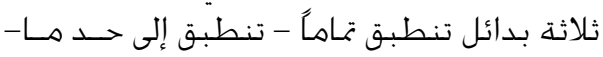

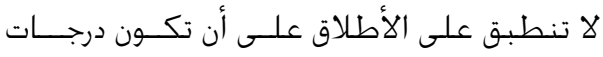

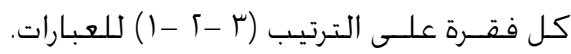

كفاءة مقياس فعالية الذات المدركة للراشدينن

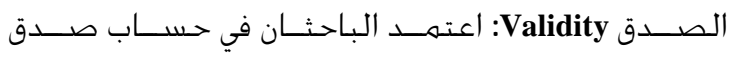
المقياس على ما يلي:

الصـدق العـاملي Factorial Validity بعـد تطبيق مقياس

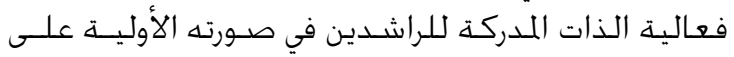

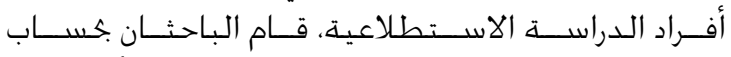

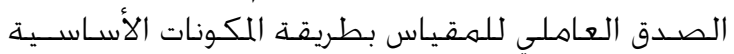


وقائمة فحــص إســـراتيجيات التعـايش للأطفــال (CCSC) Children's Coping Strategies Checklist

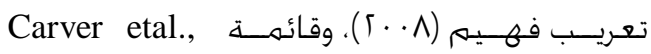

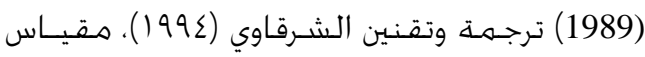

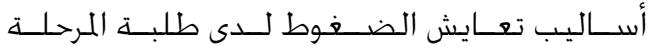

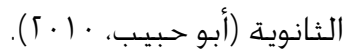

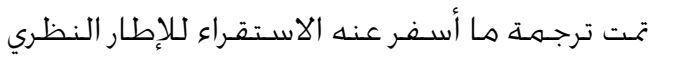

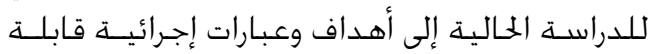

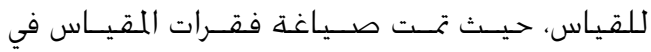

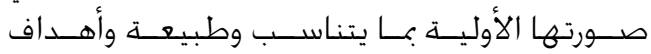

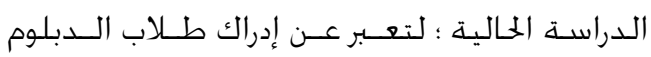

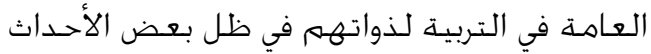

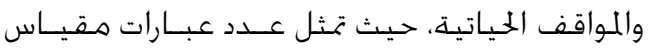

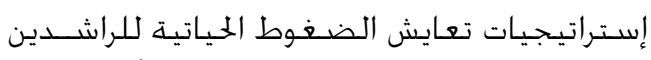

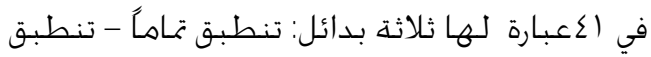

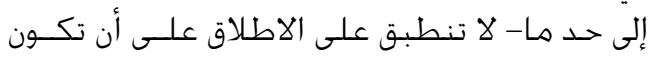

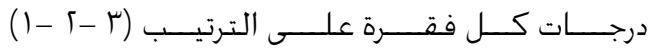

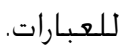

\section{كفاءة مفياس إستراتيجيات تعايش الضغوط الحياتية} للراشدين:

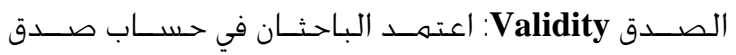

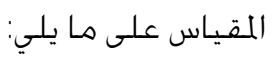

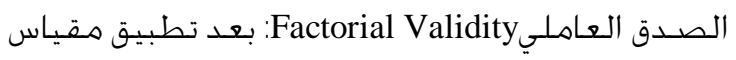

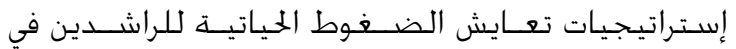

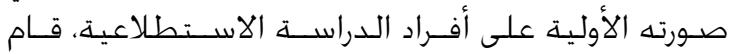

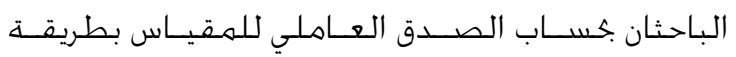
المكونات الأسـاسية Principle Component، وبعد التدوير المتعامد بطريقة ال Varimax تم حذف التشبعات الأقــل التحل

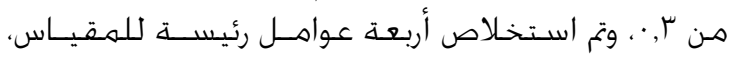

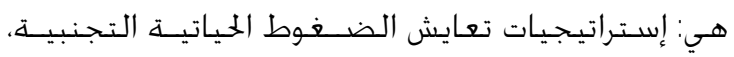

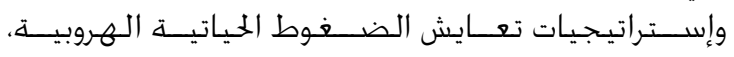

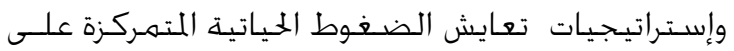

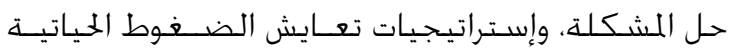

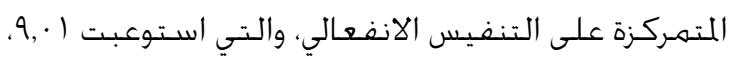

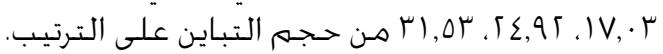

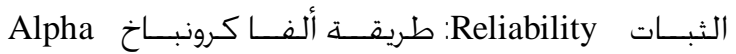
Cronbach Method

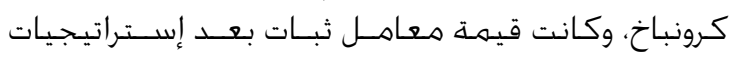

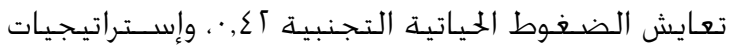

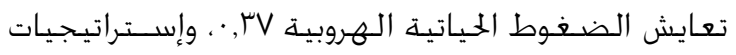

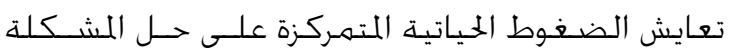

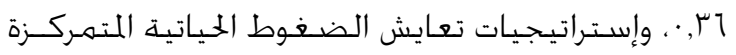

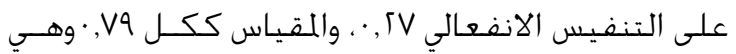
قيم مرتفعة تدل على ثبات المقياس.

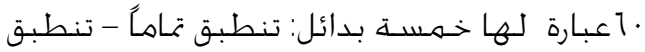

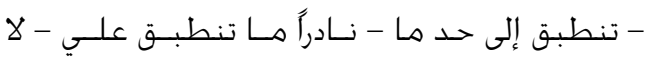

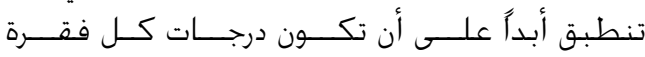

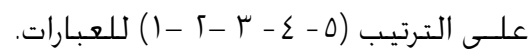

كفاءة مفياس الإعزاءات الحياتية السببية للراشـين:

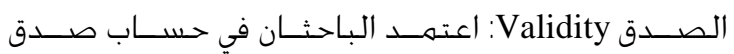
المقياس على ما يلي:

الصـــق العـاملي: Factorial Validity بعـد تطبيـق

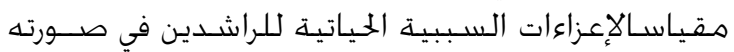

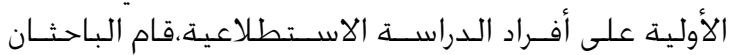

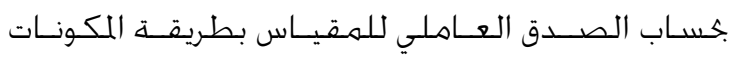

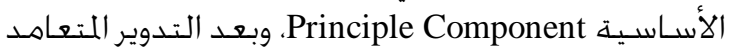

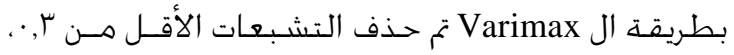

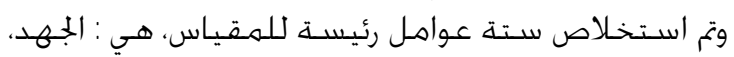

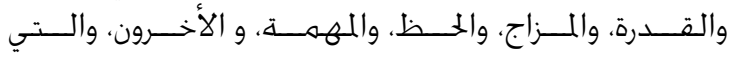

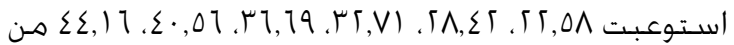

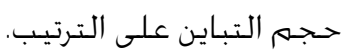

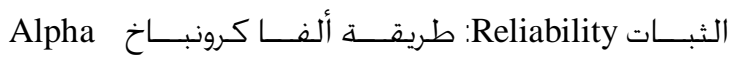
Cronbach Method

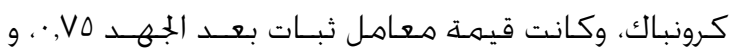

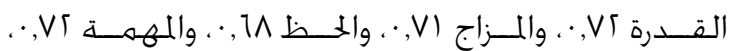

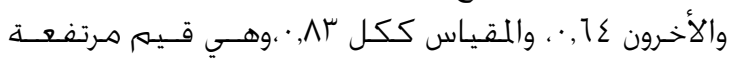
تدل على ثبات المقياس.

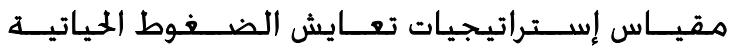

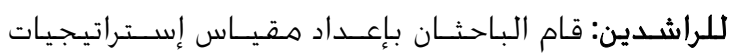

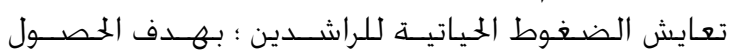

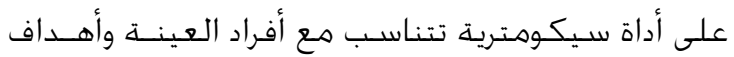
الدراسـة وطبيعتها، وقد مـر بناء المقياس بالخطوات التالتالية:

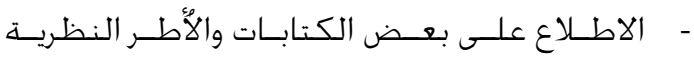

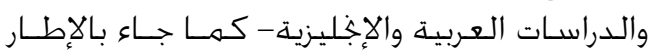

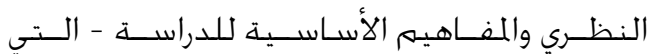

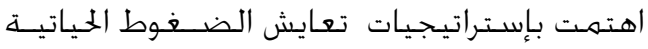

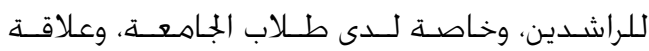

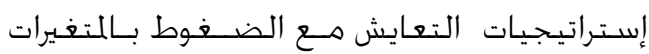

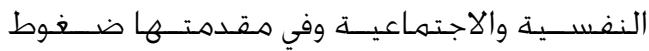

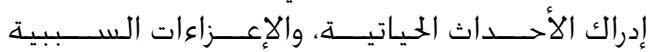

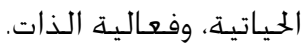

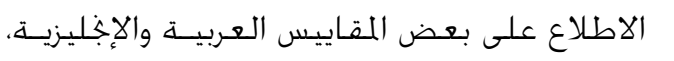
كمقيـاس (Litt et al., 2003) لإبســتراتيجيات

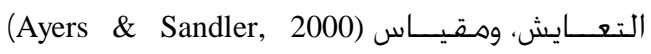

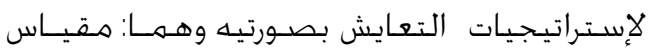

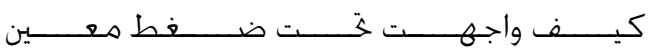
.How I Coped Under Pressure Scale (HICUPS) 


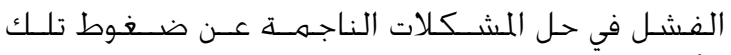

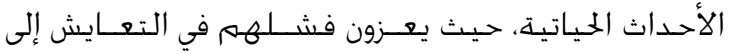

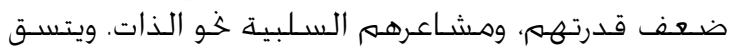

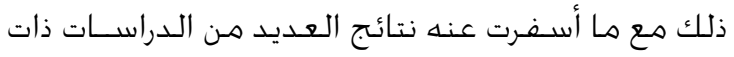

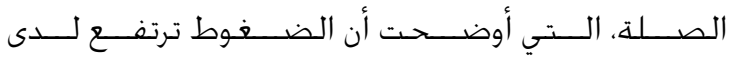

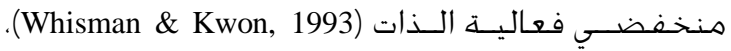

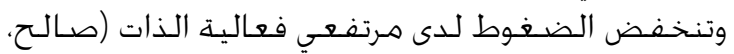

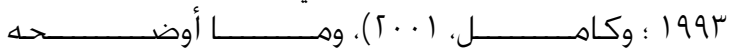
Somerfield \& Mccrea

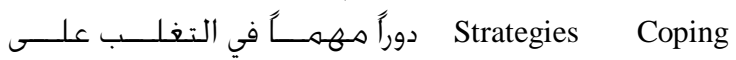

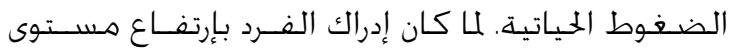

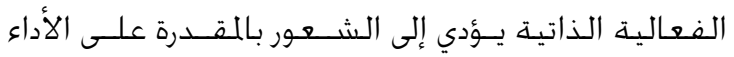

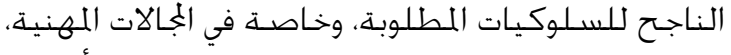

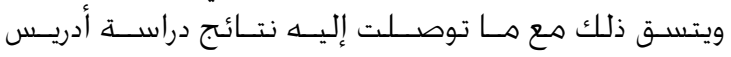

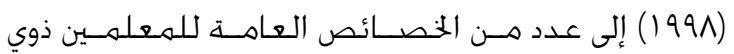

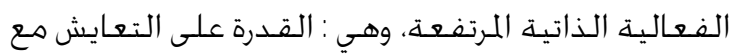

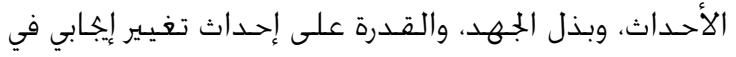

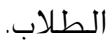

نتائج الفـرض الثاني ومـناقشـهـا: يـــص الفــرض الثـاني

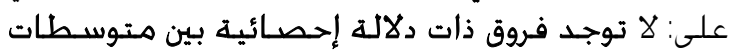

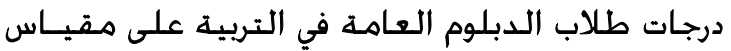

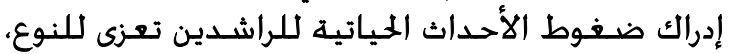

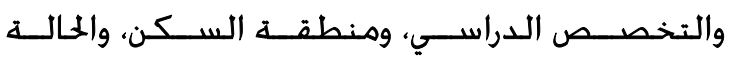
الاجتماعيـة.
نتائج الدراســـــ ومناقشـتها

نتائج الفـرض الأول ومناقشــها: ينص الفـرض الأول على فئل

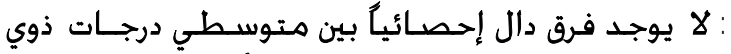

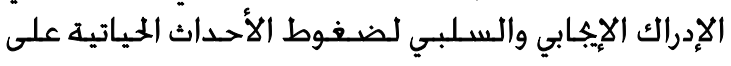

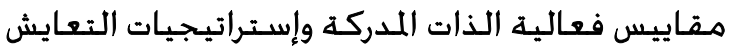

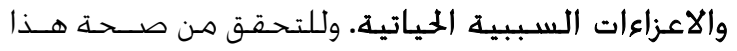

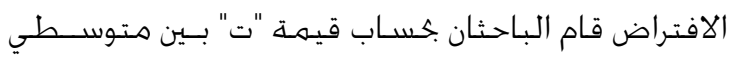

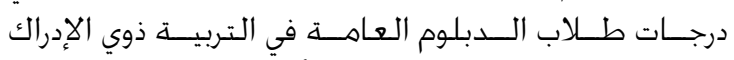

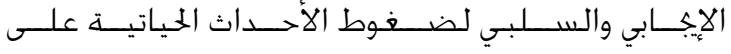

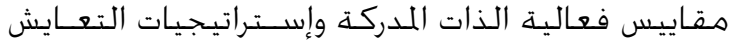

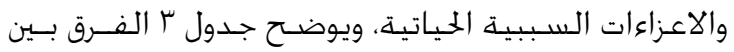

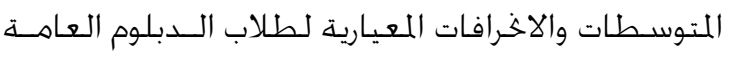
في التربيـة على مقاييس الـدراسـة.

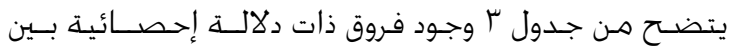

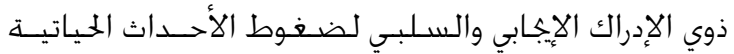

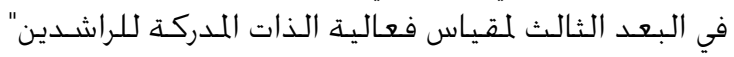

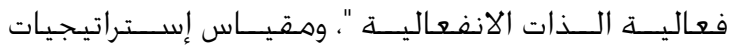

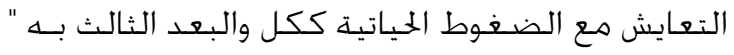

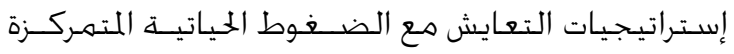

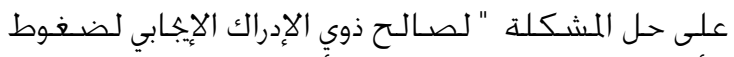

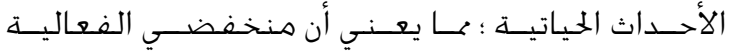

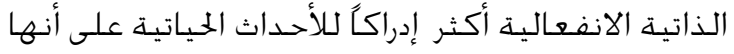

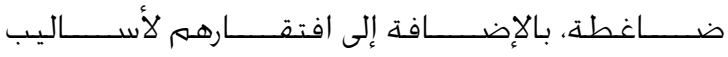

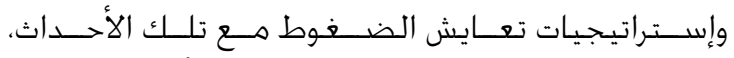

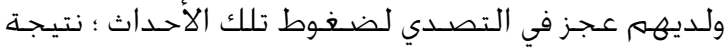

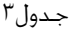

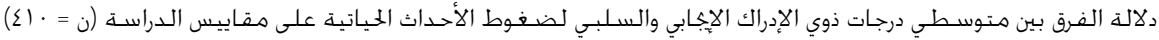

\begin{tabular}{|c|c|c|c|c|c|c|}
\hline \multirow[t]{2}{*}{ قيهة ت } & \multicolumn{2}{|c|}{ ذوي الإدراك السلبي لضغوط المباتية } & \multicolumn{2}{|c|}{ ذوي الإدراك الإيجابي لضغية الضوط } & \multicolumn{2}{|l|}{ الجمهوعات البجات } \\
\hline & $\varepsilon$ & p & $\varepsilon$ & p & & المقاييس وأبعادها \\
\hline$\cdot, \cdot 1$ & $\Lambda, 19$ & $\varepsilon \Gamma, 1 \varepsilon$ & 1,09 & $\sum\lceil, V)$ & فعالية الذات العرفية & فعالية الذات \\
\hline$\cdot, \mathrm{VA}$ & $\Gamma, 09$ & $11, \mathrm{~V} \varepsilon$ & 「,V1 & $1[1, \Gamma 1$ & فعالية الذات الاجتماعية & 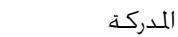 \\
\hline 1,90 & $\varepsilon, \wedge$ & $\mid \wedge, 0 \Gamma$ & $\varepsilon, 10$ & $19,9 \wedge$ & فعالية الذات الانفعالية & \\
\hline$\cdot, \Gamma \wedge$ & $\Gamma, \varepsilon$ & $1 \cdot, \mathrm{V} r$ & $\ulcorner, \cdot \wedge$ & $1 \cdot, \wedge r$ & فعالية الذات العامة & \\
\hline $1, \cdot 1$ & $1 \cdot, \mathrm{V} 1$ & $\wedge ץ, 1 \varepsilon$ & $9, \sum \pi$ & $\wedge 0,1 \varepsilon$ & فعالية الذات المدركة للراشــين & \\
\hline $1, \cdot 0$ & $0, \Sigma \mathrm{V}$ & $\lceil 9,1 \mathrm{~V}$ & $r, \wedge 9$ & $r \cdot, 1 \varepsilon$ & إستراتبجيات التعايش مع الضـغوط الحياتية التجنبية & إســـراتيجيـات \\
\hline $1,7 \mathrm{~V}$ & $r, \mathrm{Tr}$ & $19, \cdot 1$ & $r, \mathrm{vr}$ & $\lceil\cdot, \mathrm{V})$ & إستراتبجيات التعايش مع الضغوط الحياتية الهروبية & 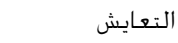 \\
\hline$*\lceil, 1 \leq$ & $0,5 \mathrm{~V}$ & $r o, v \varepsilon$ & $\varepsilon, \Sigma \mu$ & $r V, 19$ & على حلـ المشيكلة التعايش مع الضغوط الحياتية المتمركزة & \\
\hline$\cdot, \pi$ & $\mathrm{V}, \varepsilon \varepsilon$ & $\Gamma 0, \mathrm{~V} \Gamma$ & $\cdot, \cdot \cdot 1$ & $10, \cdot \cdot$ & على التنفيجيس الانفعايش مع الضـفوط الحياتية المتمركزة & \\
\hline$*\lceil, 11$ & $\Lambda, \vee 1$ & $11 \cdot, 19$ & $\Lambda, 11$ & $11 \%, 0$. & إستراتيجيات التعايش مع الضغوطو للراشـدين & \\
\hline$\cdot, \wedge)$ & $1 \wedge, \cdot 1$ & $\wedge 1,0 \Gamma$ & $\lceil r, \Gamma \Lambda$ & $\wedge \mu, 1 \varepsilon$ & الجهـ & 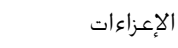 \\
\hline $1, \Gamma \mu$ & 11,00 & $r \mu, r]$ & $\wedge, 19$ & $r \cdot, \mu r$ & القدرة & السـببية الحياتية \\
\hline $1,1 \varepsilon$ & $\varepsilon, 1 \varepsilon$ & $I V, \Sigma 9$ & $V, \Sigma 1$ & $1 \wedge, 09$ & المزاج & \\
\hline$\cdot, 0 \Sigma$ & $0, \Lambda 1$ & 10,95 & $\varepsilon, \Sigma \varepsilon$ & $10, r \wedge$ & الخا & \\
\hline $1, \cdot 5$ & $\varepsilon, \Sigma 0$ & $17,1 \%$ & $\varepsilon, 1 \mathrm{~V}$ & $10, \Sigma 1$ & المهمة & \\
\hline $1,0 \wedge$ & $\lceil, 9 \uparrow$ & $|\varepsilon, 1|$ & $\Sigma, \Sigma 0$ & 10.9 & الآخرون & \\
\hline$\cdot, 11$ & $r \mu, 99$ & $1 \wedge r, 1 r$ & $\varepsilon 0,79$ & $1 \vee \wedge, 90$ & الإعزاءات السـبـية الحياتية للراشـدين & \\
\hline
\end{tabular}

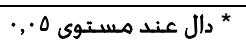




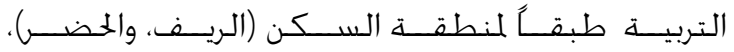

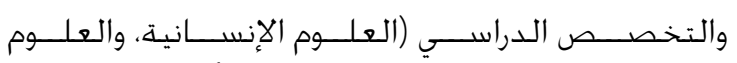

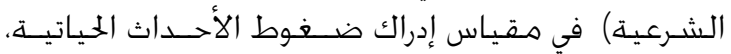
ويوضح جدول ه قيمة "ت" ودلالتها الإحصائية.

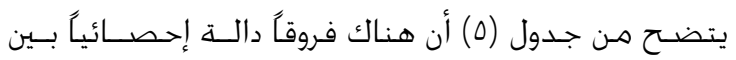

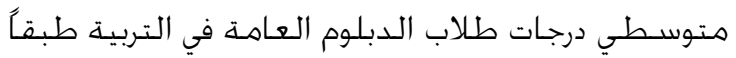

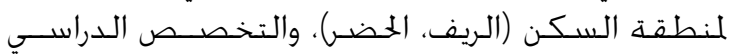

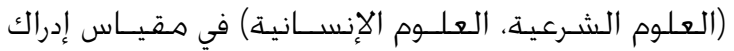

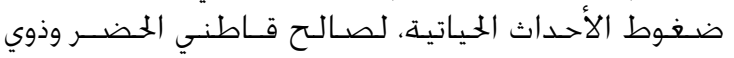
غتص ضص العلوم الإنسانية.

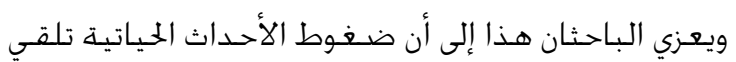

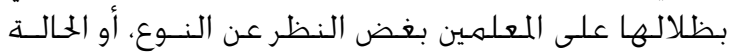

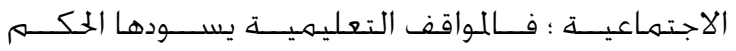

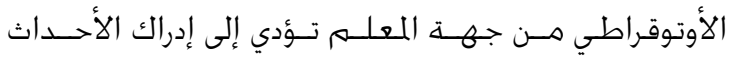

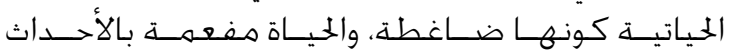

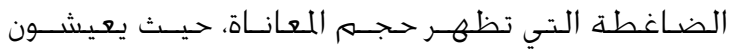

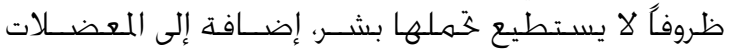

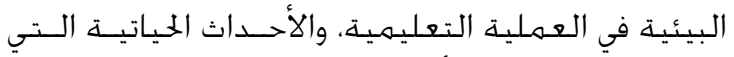

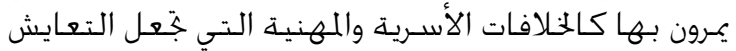

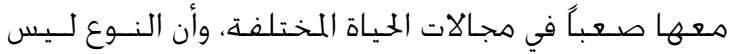

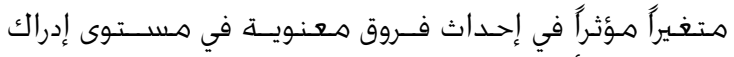

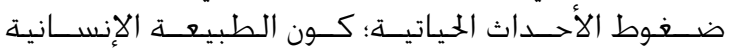

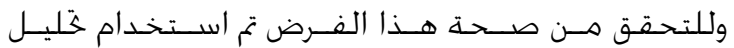

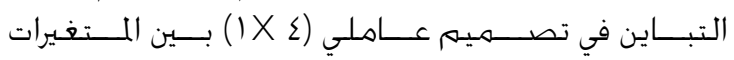

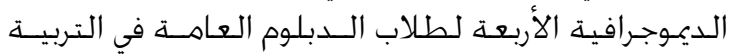

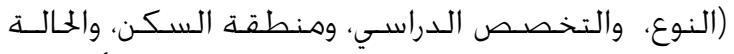

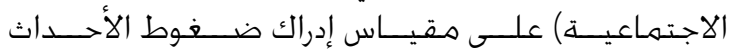

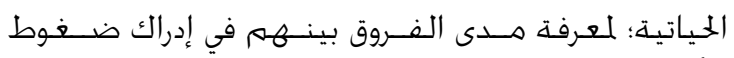

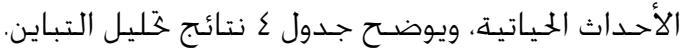

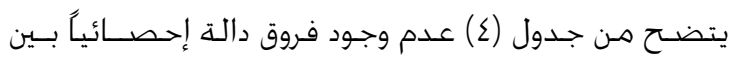

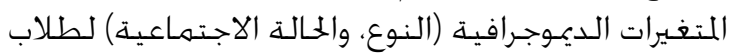

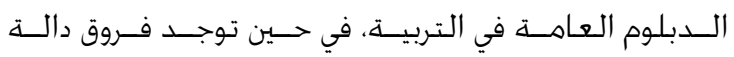

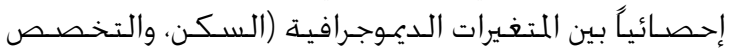

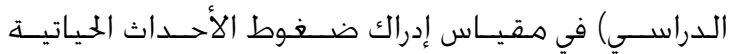

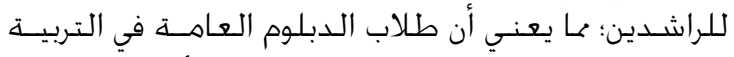

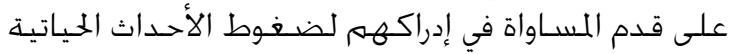

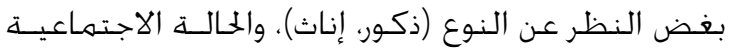

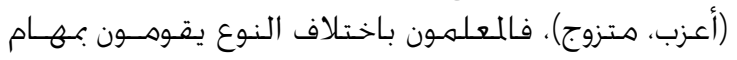

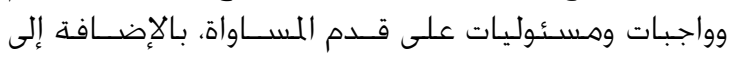

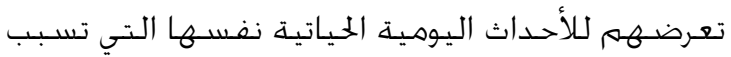

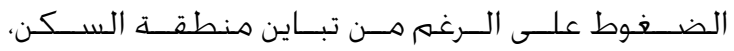

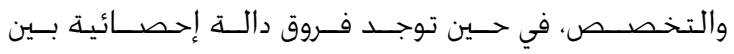
المتغيرات الديموجرافية (السكن، والتخصص فئس الدراسي).

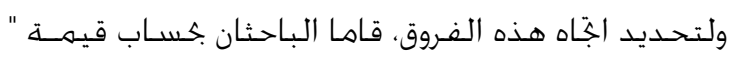

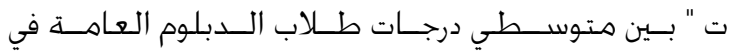

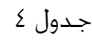

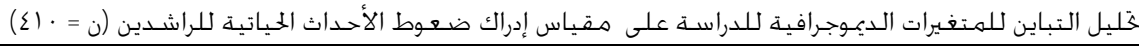

\begin{tabular}{|c|c|c|c|c|c|}
\hline قيمة "ف " & متوسعات & 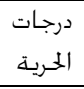 & مجهموع المربعات & مصــدر التباين & بصـياً المغرات الديموجرافية للمراهقين المعوقين \\
\hline \multirow{3}{*}{1,10} & $\cdot, \Gamma \varepsilon$ & 1 & $\cdot \Gamma \varepsilon$ & بين الجهموعات & \multirow{6}{*}{ الحالة الاجتماعية (أعزب، متزوج) } \\
\hline & $\cdot, 1 \varepsilon$ & $\varepsilon \cdot \Lambda$ & $\Delta \wedge, \Sigma \vee$ & داخل الجُمـوعات & \\
\hline & & $\varepsilon \cdot 9$ & $\Delta \wedge, \vee)$ & الكلي & \\
\hline \multirow{3}{*}{$\cdot, \mathrm{V} \varepsilon$} & $\cdot, \cdot 10$ & 1 & $\cdot, \cdot 10$ & بين الجُمــوعات & \\
\hline & $\cdot, 199$ & $\varepsilon \cdot \Lambda$ & $\Lambda 1, r q$ & داخل الجُمهوعات & \\
\hline & & $\varepsilon \cdot 9$ & $\wedge 1, \Sigma 1$ & الكلي & \\
\hline \multirow{3}{*}{$* * 1, \mathrm{VV}$} & 1,10 & 1 & 1,10 & بينالجـهــوعات & \multirow[t]{3}{*}{ السكن (ريف، حضر) } \\
\hline & $\cdot, \Gamma \varepsilon$ & $\varepsilon \cdot \Lambda$ & 99,07 & داخلالجمهـوعات & \\
\hline & & $\sum \cdot 9$ & $1.1,[1$ & الكلي & \\
\hline \multirow{3}{*}{$* * \Gamma \cdot, 0 \Gamma$} & $\langle, 9)$ & 1 & $\langle, 9)$ & بينالجُمهـوعات & \multirow{3}{*}{ علوم شـرعية) الدراسـي (علوم إنســــــــة. } \\
\hline & $\cdot, \Gamma \varepsilon$ & $\varepsilon \cdot \Lambda$ & $9 \mathrm{~V}, \Delta \wedge$ & ماخل الجُموعات & \\
\hline & & $\varepsilon \cdot 9$ & $1 \cdot \Gamma, \sum 9$ & 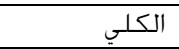 & \\
\hline
\end{tabular}

دلالة الفرق بين متوسـي درجات أفراد العينة الأسـاسية طبقًاً لنططقة السكن والتخصص الدراسي في مقياس إدراك ضغوط الأحداث الحياتية (ن (乏). =

\begin{tabular}{|c|c|c|c|c|c|}
\hline \multirow{2}{*}{ 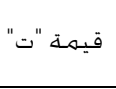 } & \multicolumn{2}{|c|}{ مقياس إدراك ضغوط الأحـداث الحياتي } & \multirow{2}{*}{ ن } & & \multirow{2}{*}{ المتغيرات } \\
\hline & $\varepsilon$ & e & & & \\
\hline \multirow{2}{*}{$* *\lceil, 1 \uparrow$} & $\cdot, \sum \wedge$ & $1,7 \mu$ & $\ln$ & الريف & \multirow{2}{*}{ منطقة السكن } \\
\hline & $\cdot, \sum \mu$ & I,Vo & 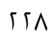 & الخضـر & \\
\hline \multirow{2}{*}{$* * \varepsilon, \Delta \mu$} & $\cdot, \Sigma 9$ & 1,09 & $\Gamma \cdot r$ & العلوم الشـرعية & \multirow{2}{*}{ التخصص الدراسي } \\
\hline & $\cdot, \Sigma 1$ & $1, \Lambda ז$ & $\Gamma \cdot V$ & العلوم الإنسـانية & \\
\hline
\end{tabular}




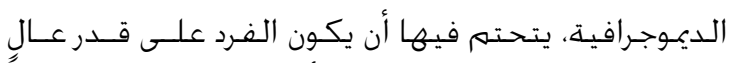

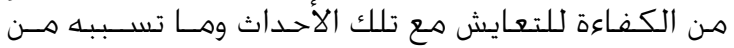

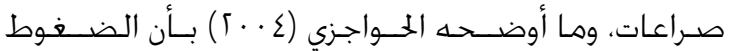

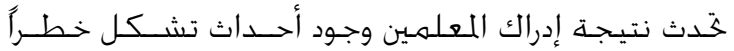

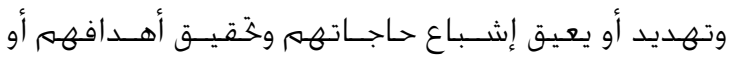

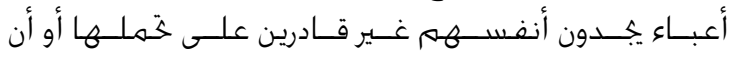
متطلباتها تفوق قدرته، فيشعر بحالة من عـدم الارتيـاح والعبء الذي يقع على كاهله.

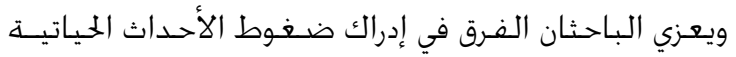

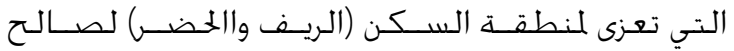

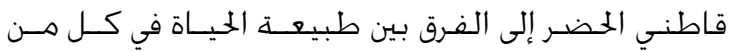

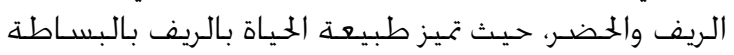

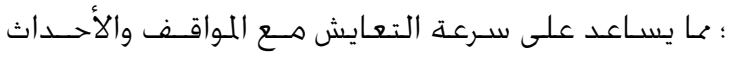

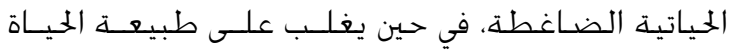

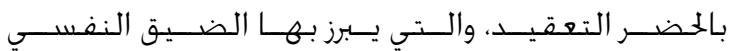
وجَعلهم أكثر إدراكاً للمواقف الحياتية الضـاغطة.

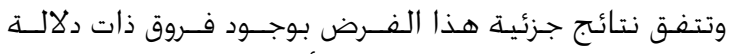

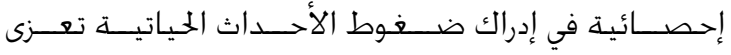

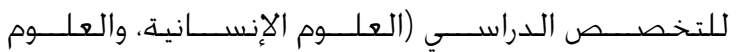

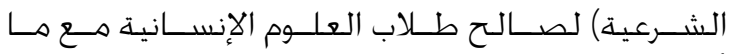

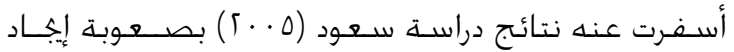

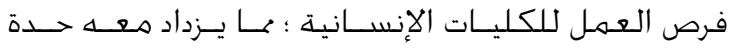

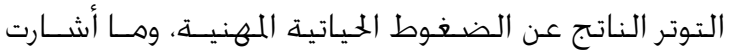

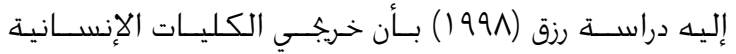

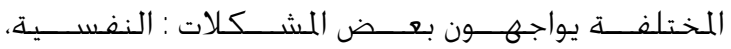

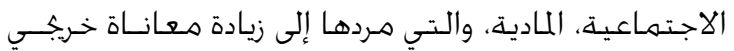

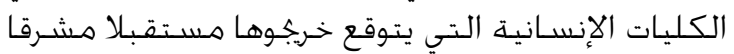

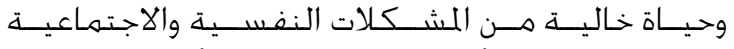

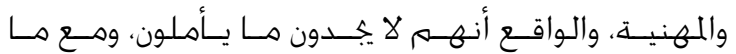

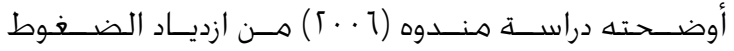

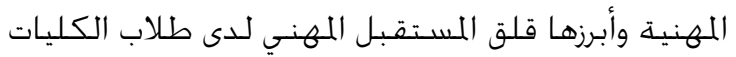

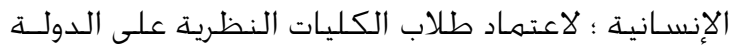

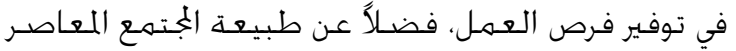

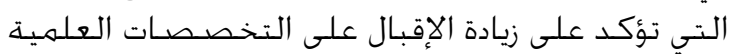

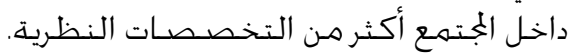

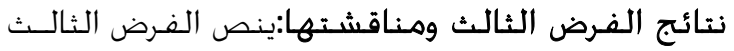

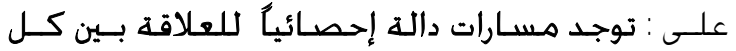

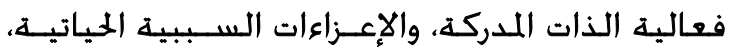

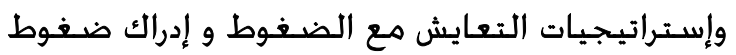
الأحداث الحياتية لدى طلاب الدبلوم العامة في التربية.

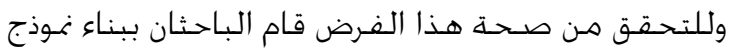

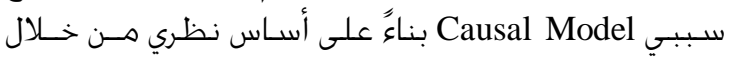

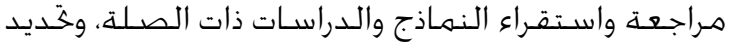

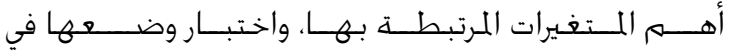

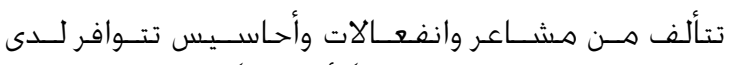

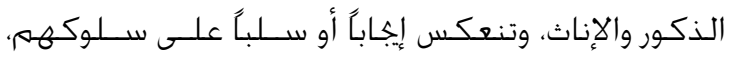

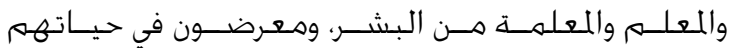

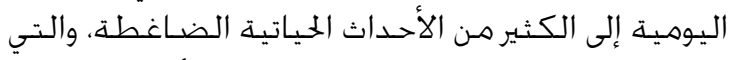

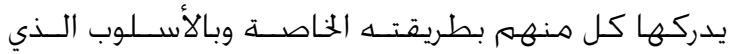

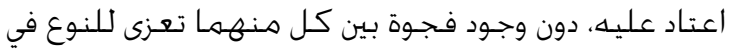
ذلك الإدراك لضغوط الأحداث الحياتية.

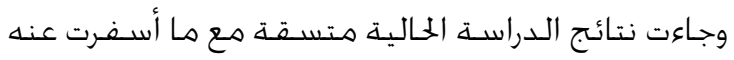

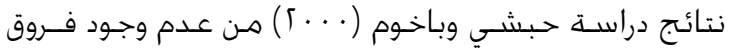

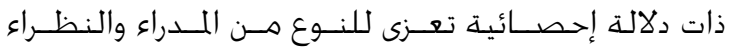

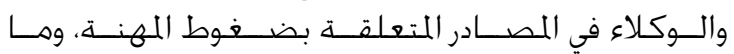

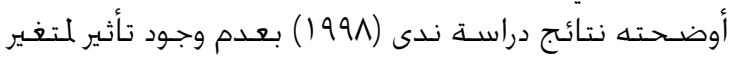

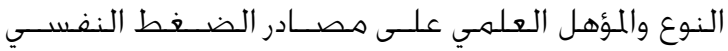

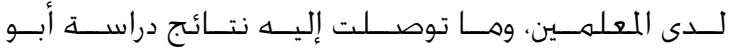

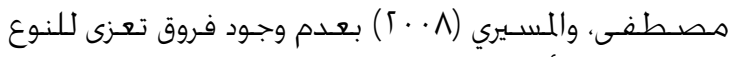

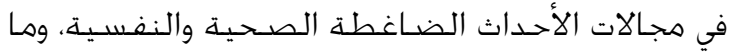

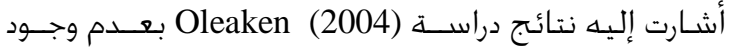

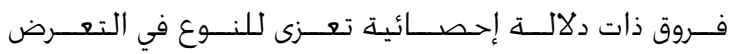

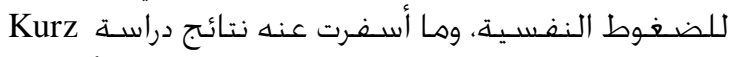

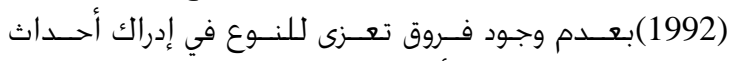

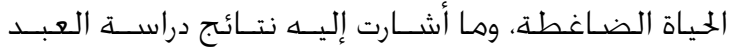

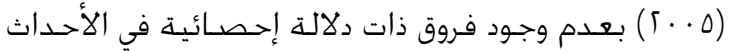

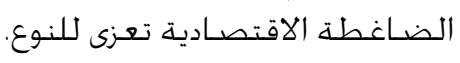

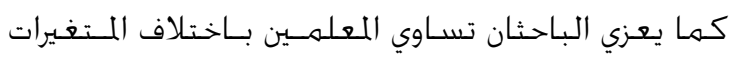

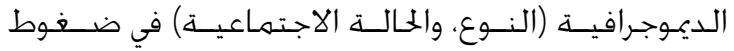

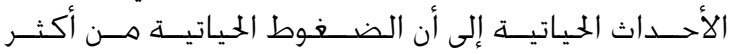

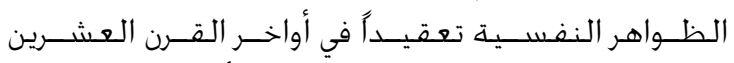

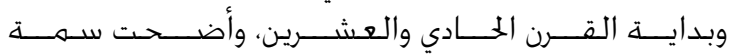

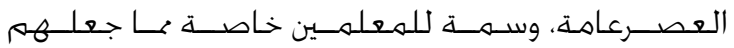
يواجهون الكثير من المشكلات والتحديات في طريق ختقيق

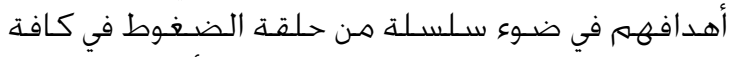

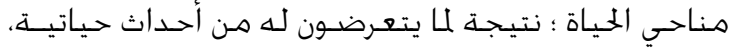

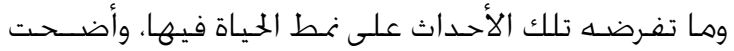

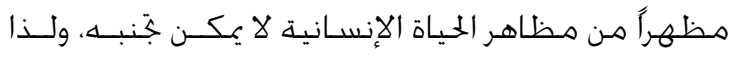

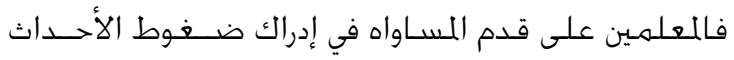

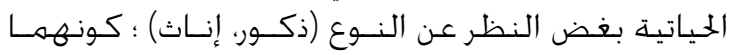

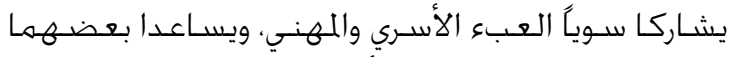

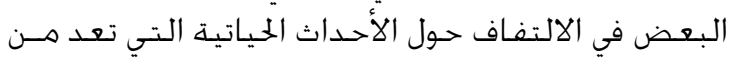

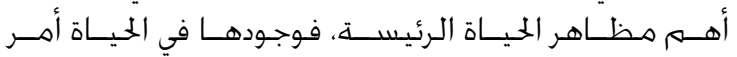
طبيعي لكل منهما.

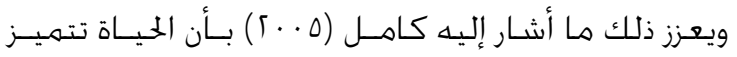

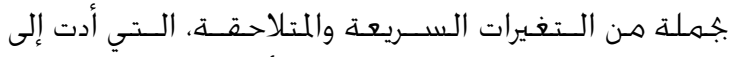

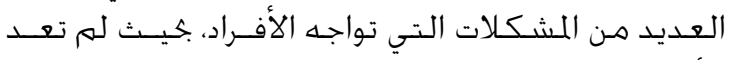

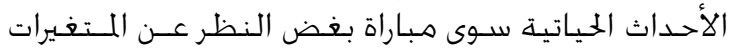




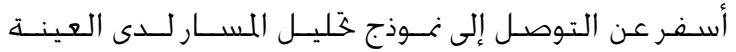

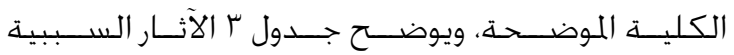

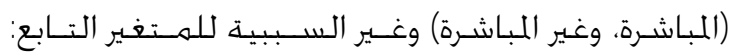

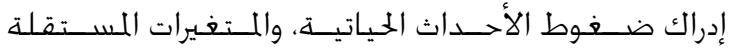

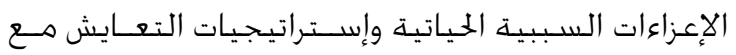

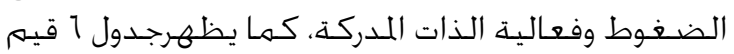

$$
\text { معامـلات المسـار ودلالتها. }
$$

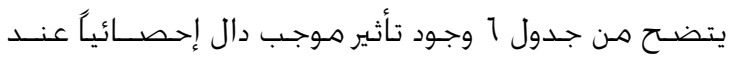

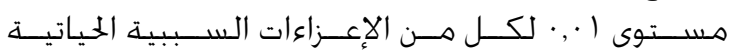

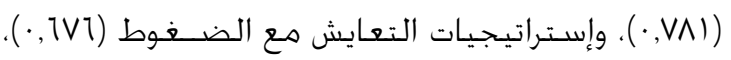

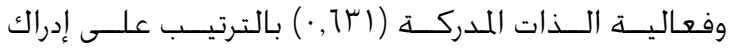

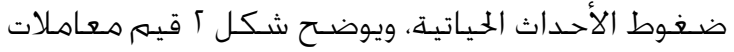
المسيار ودلالتها . - المال.

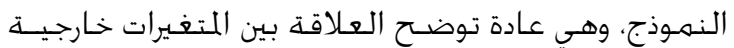

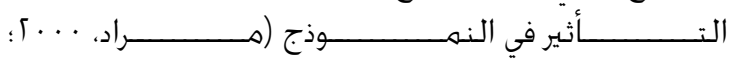

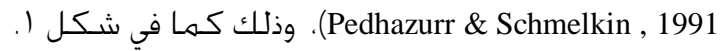
يتضـح هـن النهــوذج المقتــرح (شـــل ( ) أن إدراك الأفـراد

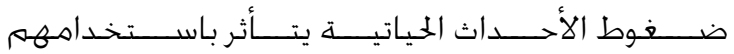

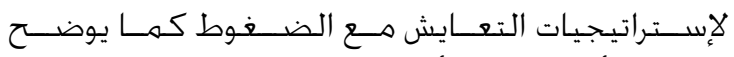

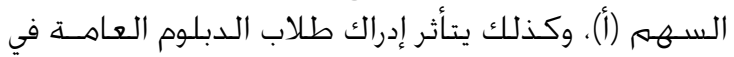

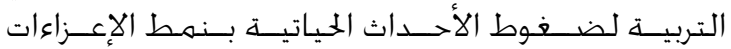

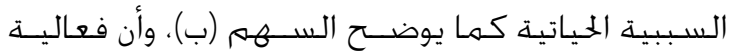

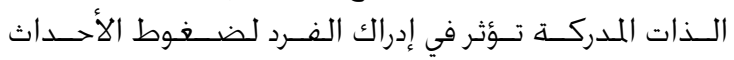

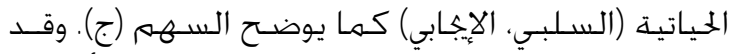

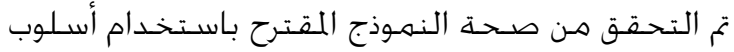

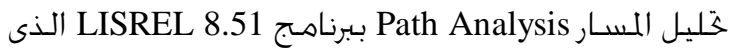

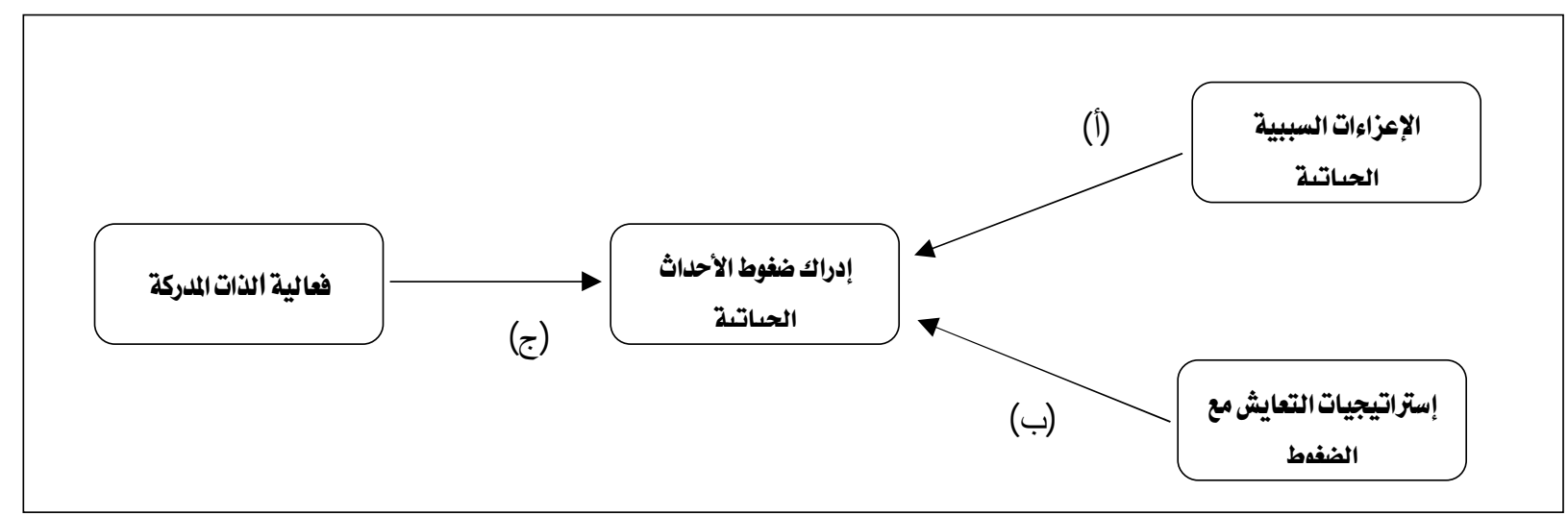

شكل 1

نموذج مقترح للعلاقة بين متغيرات الدراســ

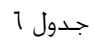

الآثار السـببية (المباشرة، وغير المباشـرة) وغير السببية للهتغير التابع إدراك ضغوط الأحداث الحياتية.والمتغيرات المستقلة الإعزاءات السببية الحياتية وإستراتيجيات

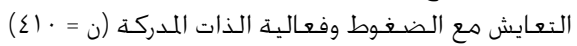

\begin{tabular}{|c|c|c|c|c|c|}
\hline الآثار غير السببية & الآثار الكلية & الآثار غير المباشـرة & الآثار المباشـرة & الارتباط بإدراك ضـغوط الأحـداث الحياتية & المتغيرات المستقلة \\
\hline$\cdot, \cdot \wedge$ & $\cdot, 995$ & $\cdot, \Gamma 11$ & $\cdot, \mathrm{V} \wedge \mathrm{I}$ & $\cdot, \Lambda \Lambda\ulcorner$ & الإعزاءات السببية الحياتية \\
\hline$\cdot, \cdot\lceil 1$ & $\cdot, 9 \wedge 9$ & $\cdot, \mu \mid r$ & $\cdot, 1 \mathrm{~V} 1$ & $\cdot, \mathrm{VV} 1$ & إسـراتيجيات التعايش مع \\
\hline$\cdot, \cdot 15$ & $\cdot, 9 \wedge \wedge$ & $\cdot, r \Delta V$ & $\cdot, 741$ & $\cdot, \mathrm{V} \Sigma \Gamma$ & فعالية الذات المدركة \\
\hline
\end{tabular}

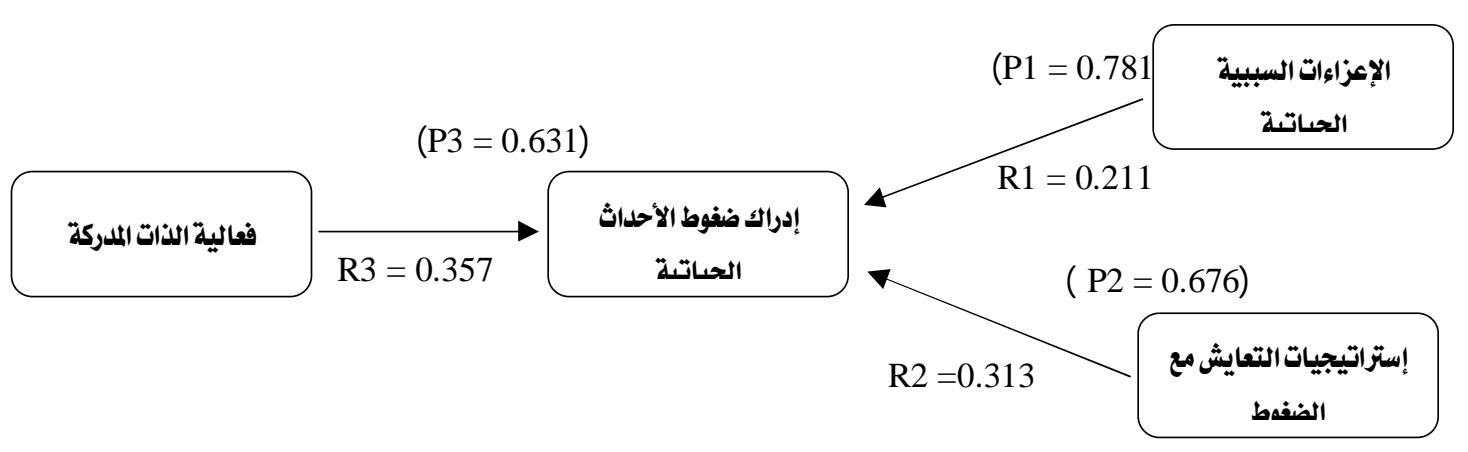

شكل

قيه معاملات المسار للمتغيرات ودلالتهيا 


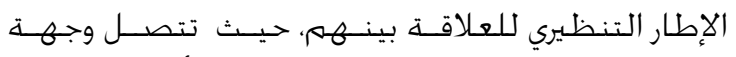

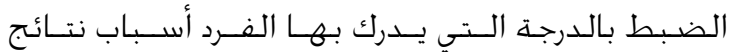

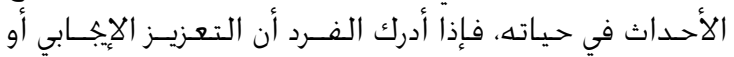

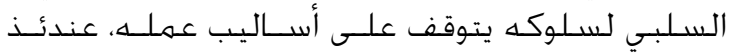

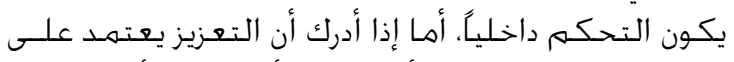

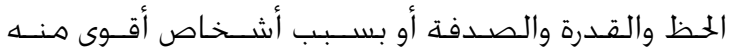

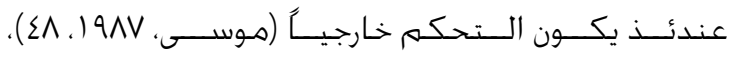

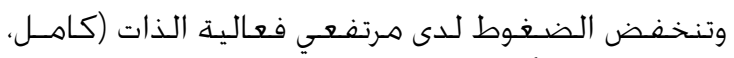

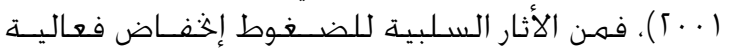

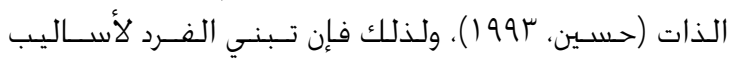

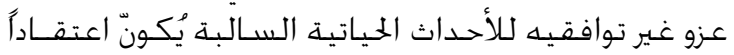

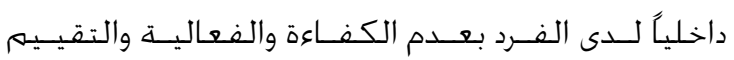
السـلبي للذات (Ruth \& Judy , 1995 , 375).

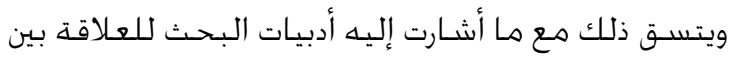

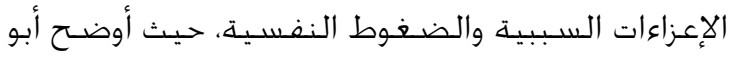

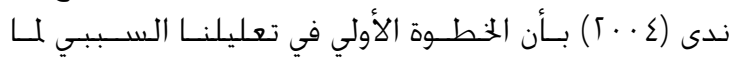

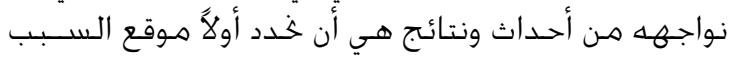

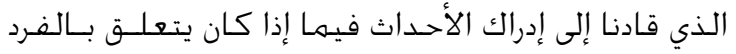

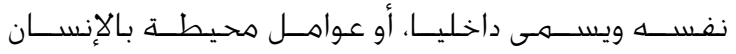

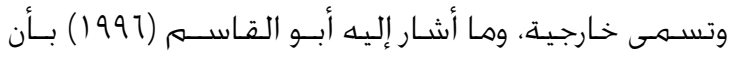

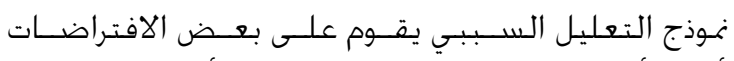

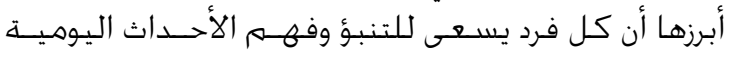

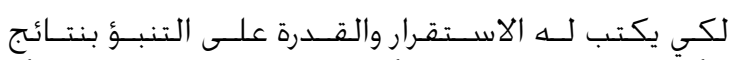

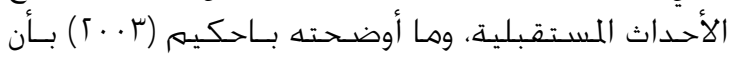

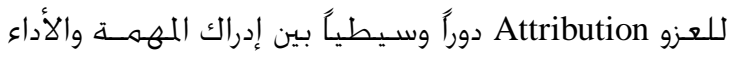

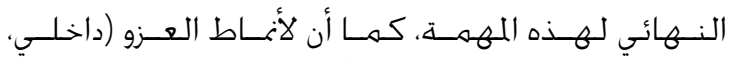

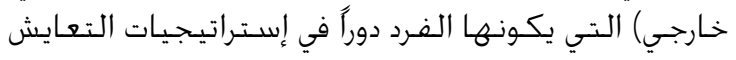
مع الضغنوط.

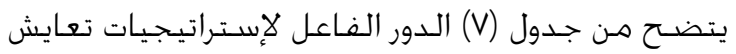

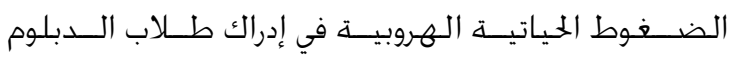

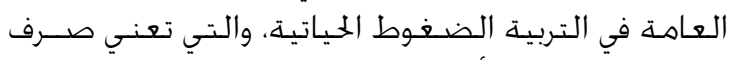

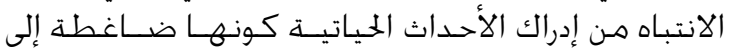

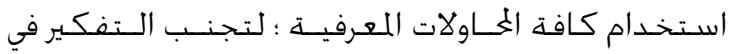

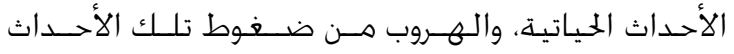

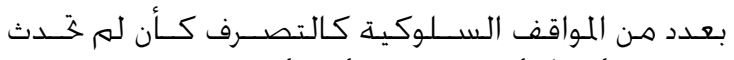

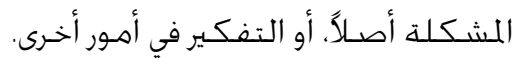

توصيات الدراســة ومقترحاتها

بناء على ما أسـفـرت الـراسـة عنـه مـن نتائج، صــــــت التوصيات كما يلي :

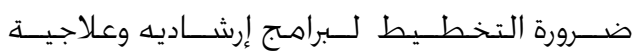

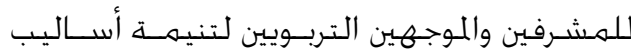

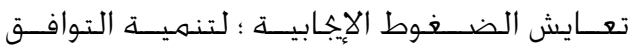

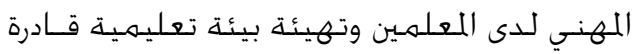

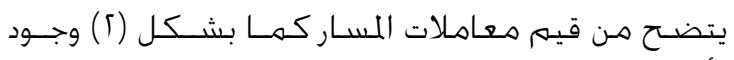

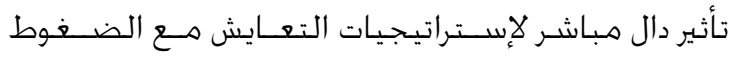

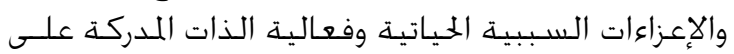

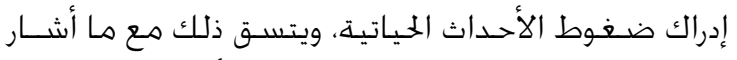

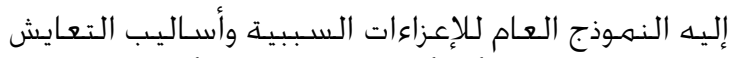

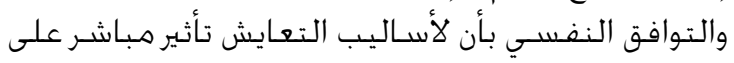

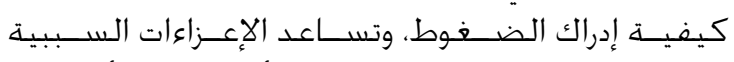

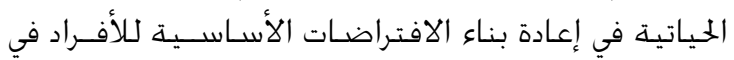

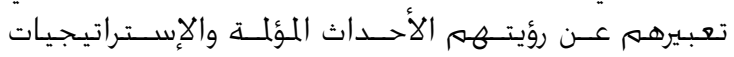

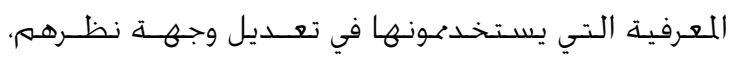

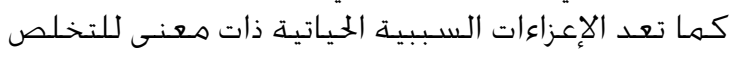

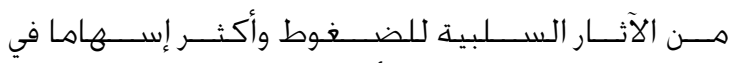

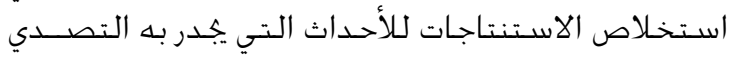

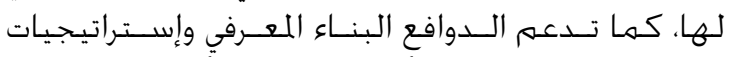

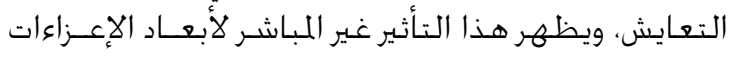

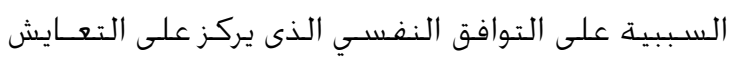

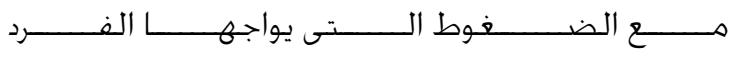

.(Roesch \& Weiner , 2001 , 205)

كذلك يتفق النموذج المقترح مع مـا أشـارت إليــــ أدبيـات

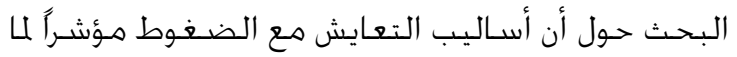

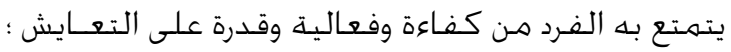

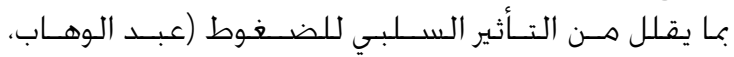

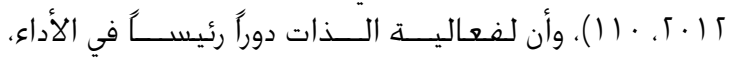

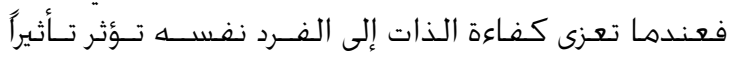

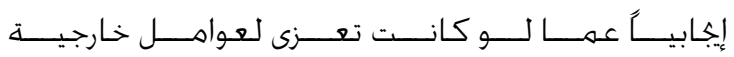

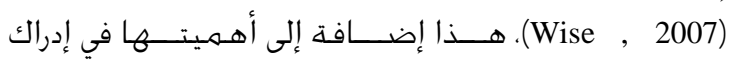

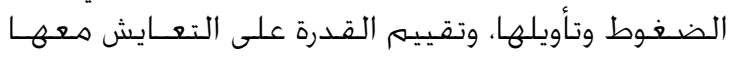

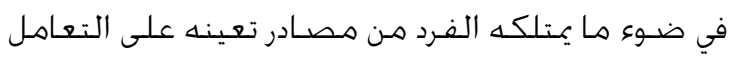

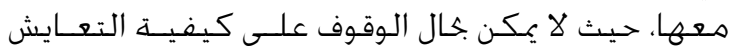

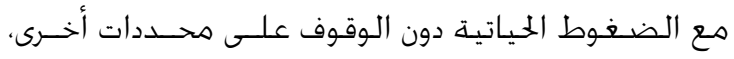

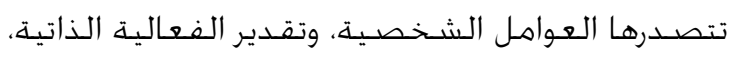

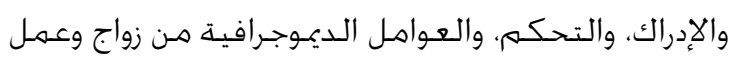

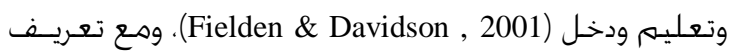

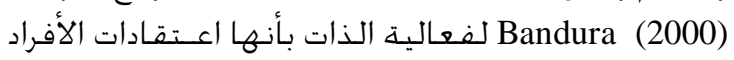

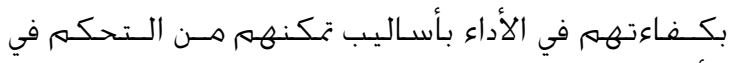

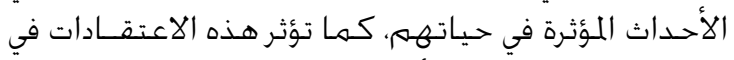

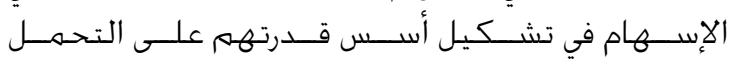

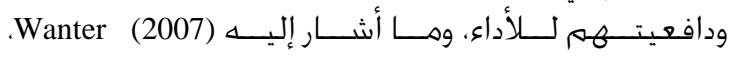

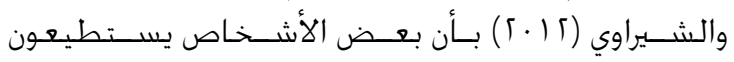

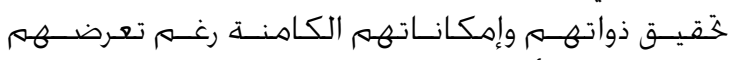

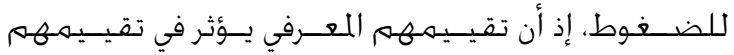

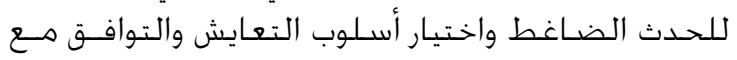
الضغن.

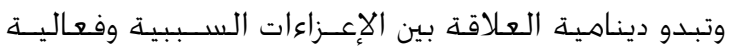

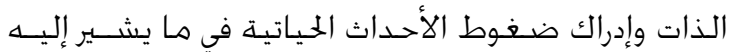




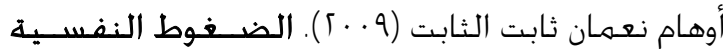

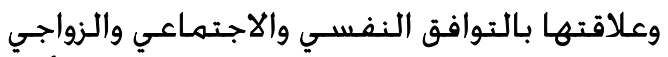

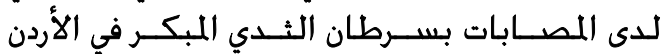

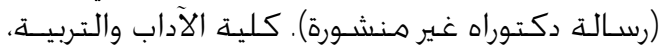
الأكاديمية العربية المفتوحة بالدنمارك.

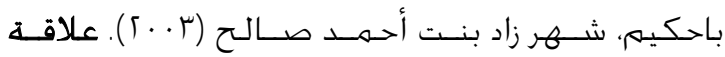

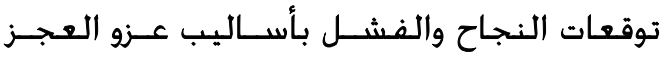

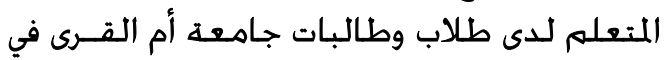

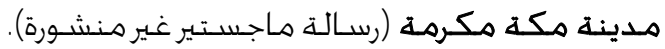
كلية التربية، جامعة أم القرى، مكة المكرمة.

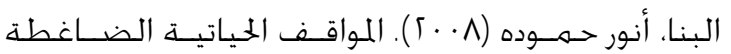

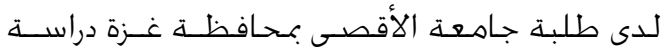

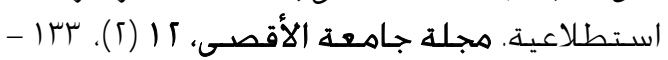

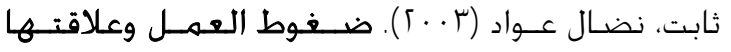
بالاجّاه خو مهنة التدريس لدى المعلمين بمحافظات

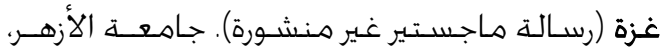
غزة.

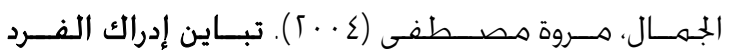

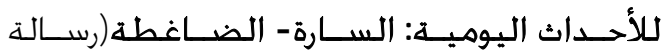

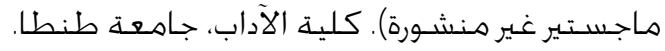

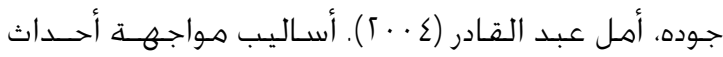

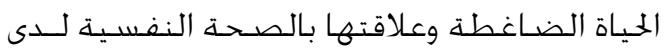

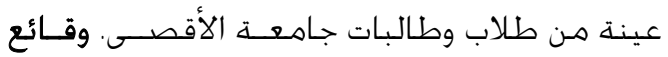

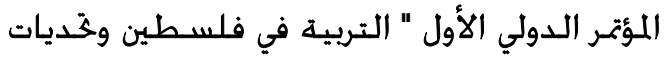

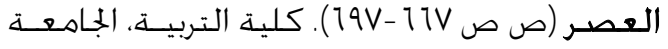
الإسـامية بغزة، آ - ع؟ نوفمسبر.

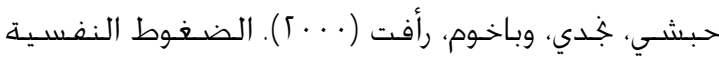

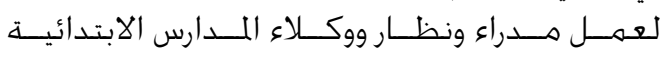

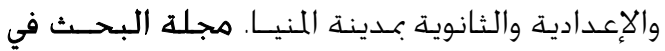
التربية وعلم النفس، كلية التربية، جامعة المنيا، 14 . $50-101 .(\mu)$

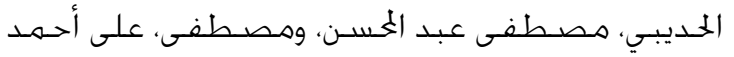

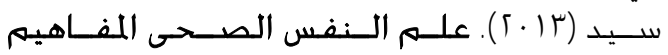
الأسـاسية. الرياض: مكتبة الزهراء.

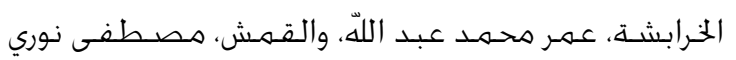

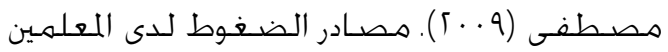

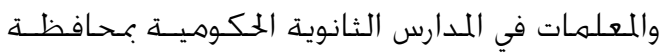

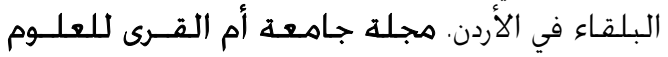

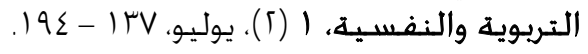

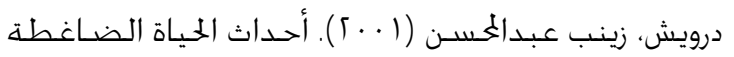

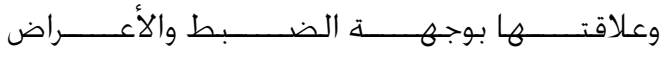

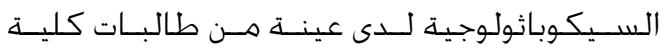

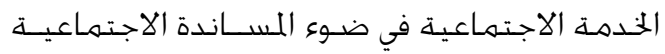

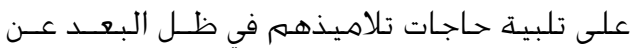
ضغوط الأحداث الحياتية السـلبية.

إعادة النظر - في ظل أن المعلم الكفء هو الركيزة

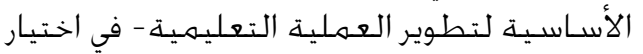

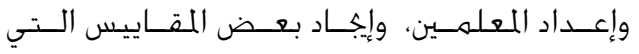

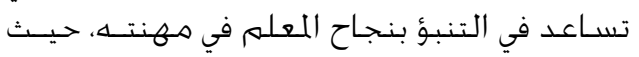

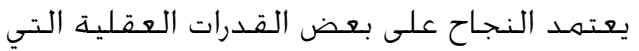

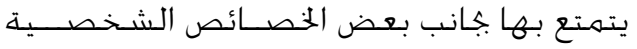

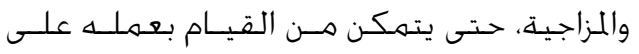
خـيروجـه.

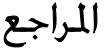

\section{References}

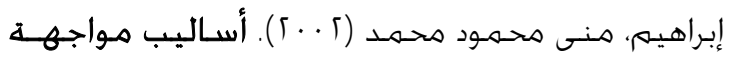
الضغوط لدى طلاب المرحلتين الإعدادية والثانوية:

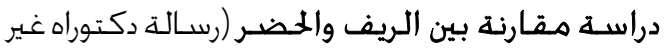

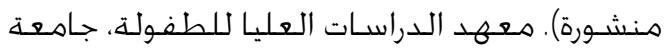
القـاهـرة.

أبو القاسـم، عماد (1997 ). دراسـة مركز التحكم وعلاقته

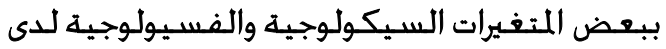
لاعبي كرة اليد (رسـالة دكتوراه غير منشـورة). كلية الية التربية الرياضية، جامعة القاهرة. لاهبـ

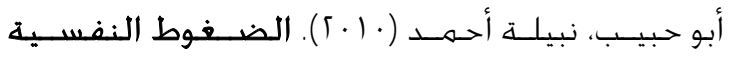

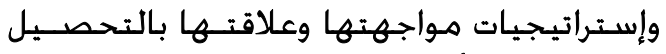

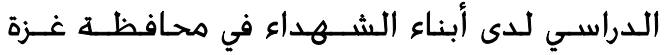

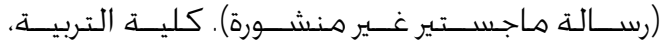

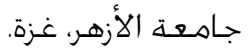

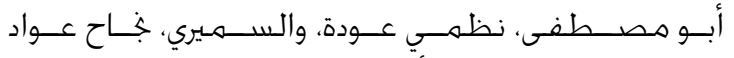

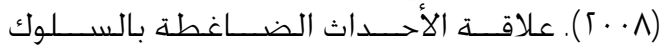

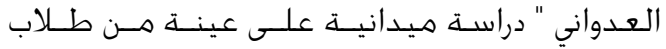

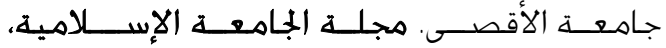

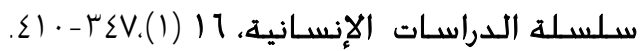

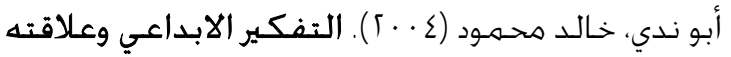

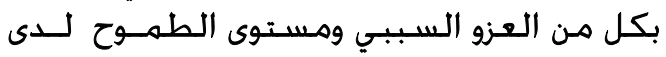
تلاميذ الصـفـين الخـامس والســادس الابتــائيين

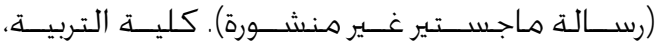

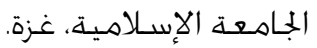

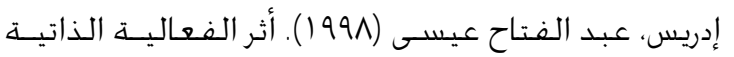

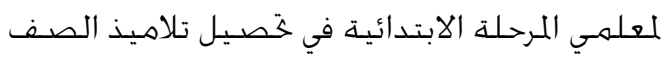

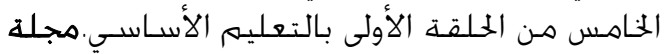

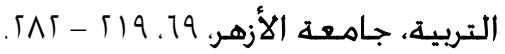

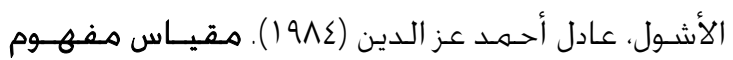

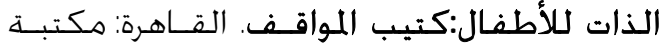
الأجلو المصرية. 


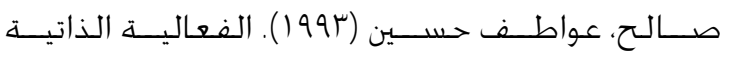

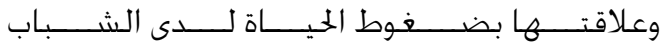

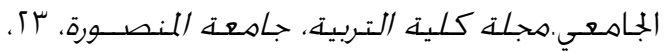
$. \Sigma \wedge V-\Sigma \Delta q$

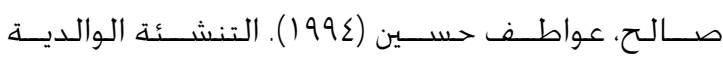
وعلاقتها بفعالية الذات لدى المراهقين مـن الجنسيسن.

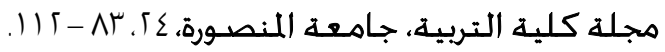
العارضـة، معاذ (991 (). إســراتيجيات تكيف المعلمـين

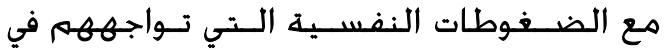

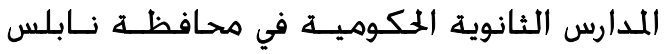

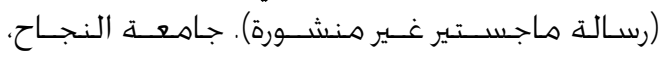
نابلس، فلسـطين.

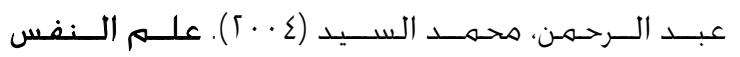

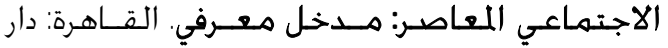

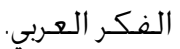

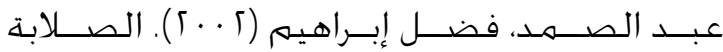

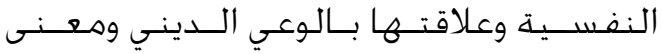

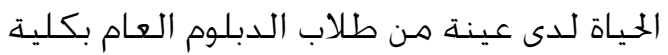

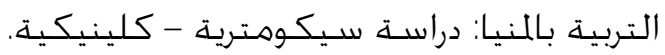
مجلة البحث في التربية وعلم النفس، كليـة

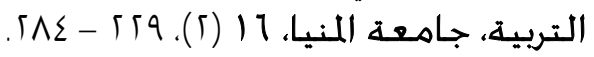
عبد المعطي، حسـن مصـطفى (992) ). ضغوط أحسـداث

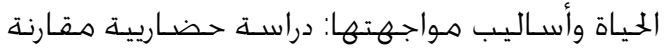

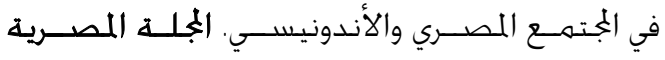

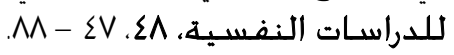

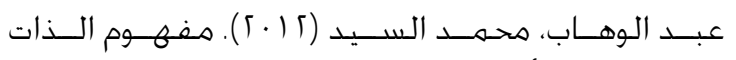

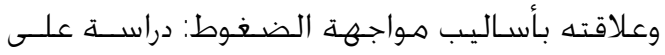

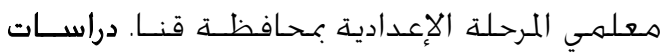

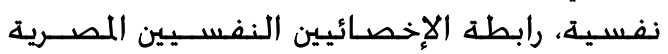

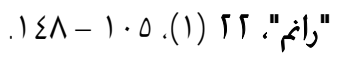

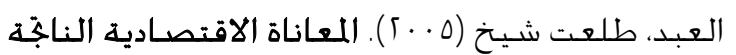

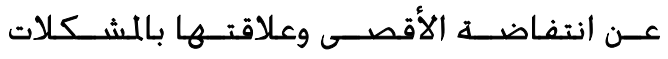

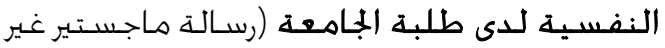

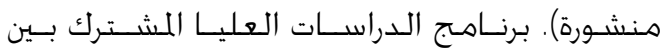

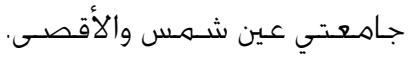

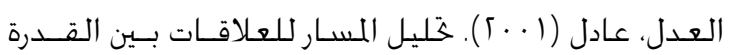

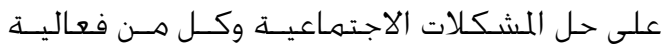

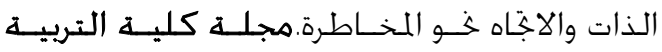

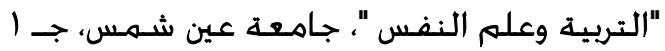

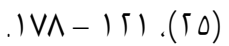

عطية، عز الـدين جـيل (1997) (1). تفسير الناس للسـلوك والمواقف مـن منظور علم النفس المعاصـر. القـاهرة: عالم الكتب.

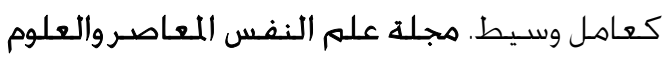

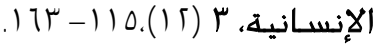

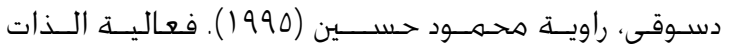

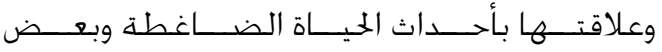

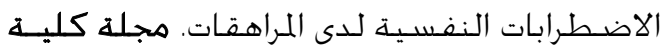

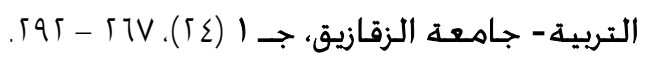

رزق، كوثر إبراهيم (1991) ). مشكـلات البطالة بين خريجـي

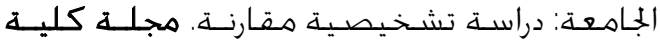

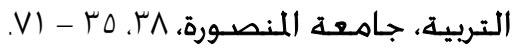

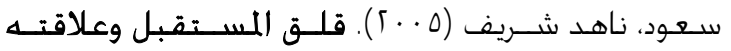

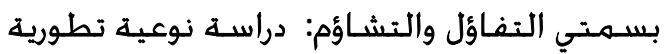

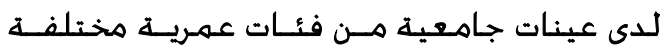

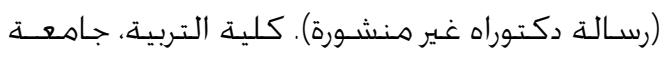
دهشتق.

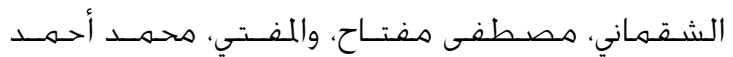

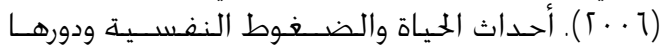

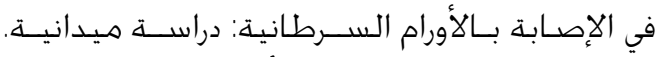

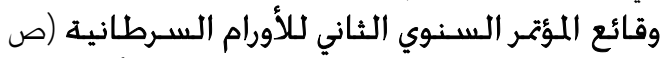

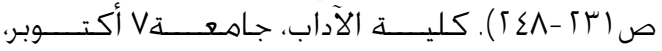
هصـراته ليبيا.

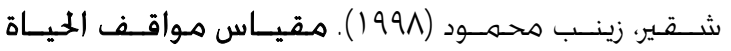
الضـاغطة في البيئة العربية المصـرية -السعـودية:

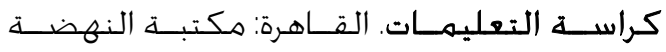
المصـريتة.

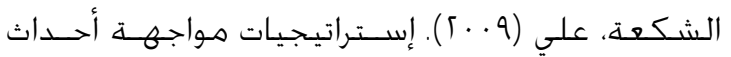

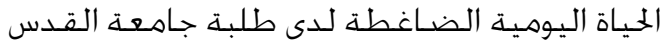

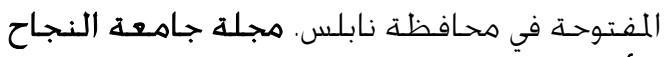

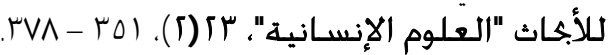

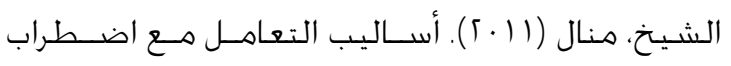

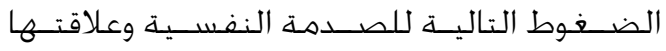

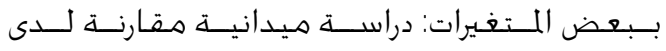

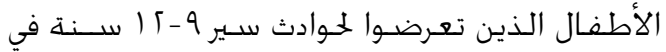

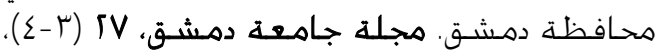
$. \Lambda \mathrm{V}-\Lambda \Sigma V$

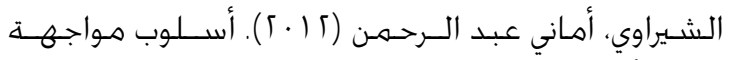

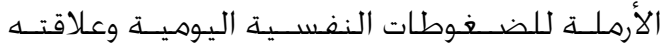

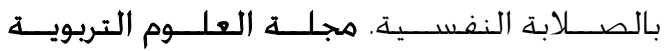

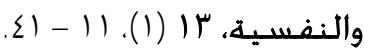

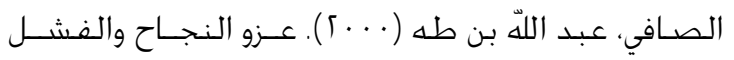

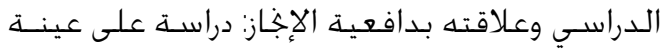

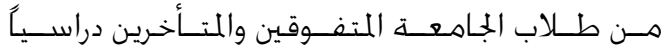
بمدينة أبها. مجلة جامعة أم القـرى للعلوم التربوية

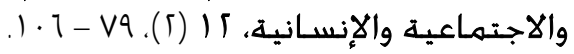


الإسـلامية، سـلسـلة الدراسـات الإنسـانية، 9 (1). $.7 V \Lambda-1 \leqslant V$

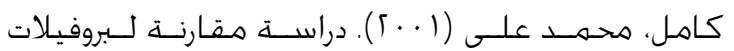

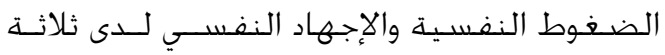

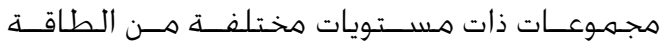

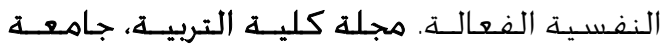

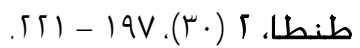

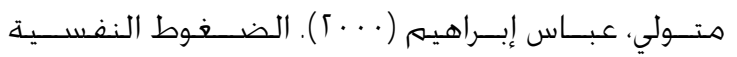

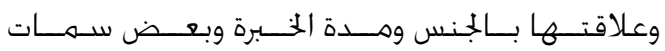

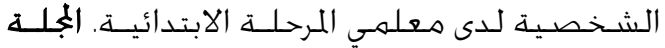

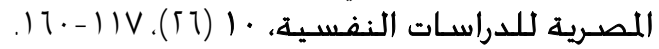

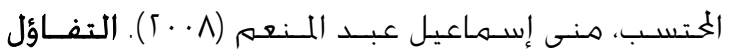

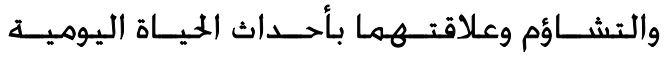

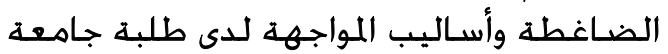

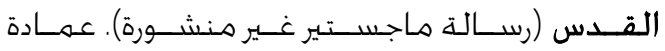
الدراسـات العليا، جامعة القدس. ماسي.

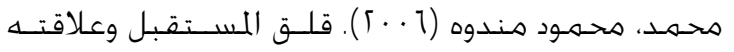

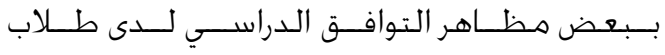
الجامعة، الجلة المصـرية للدراسـات النفسـية، 11 . IV) - $119 .(0 \%)$

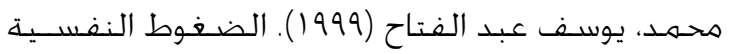

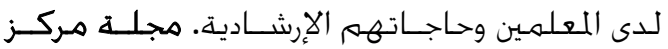

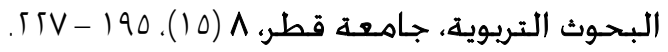

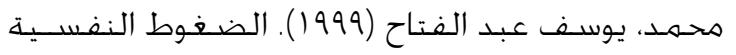

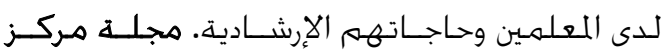

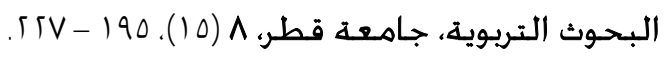

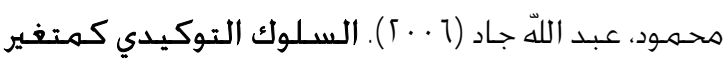

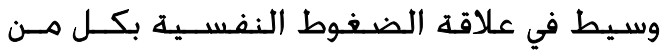

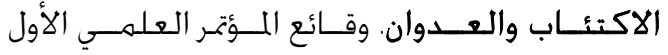

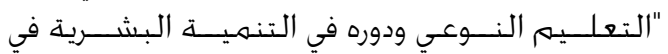

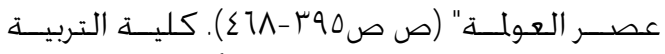

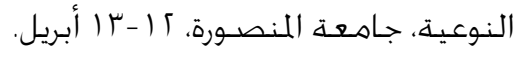

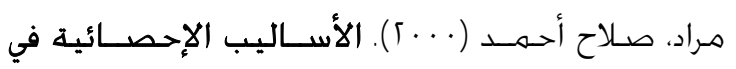
العلوم النفسية والتربوية والاجتماعية. القـاهرة:

$$
\text { مكتبة الأجنلو المصـرية. }
$$

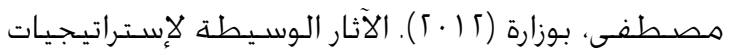

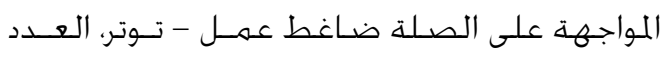

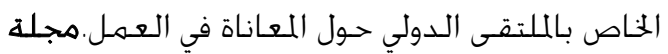

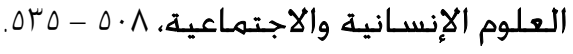

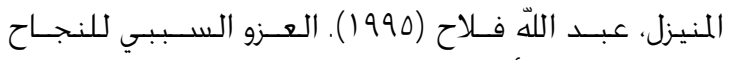

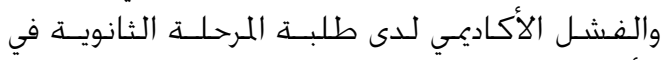

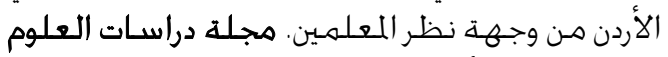

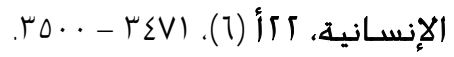

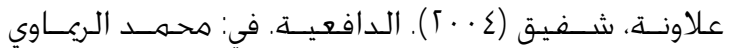

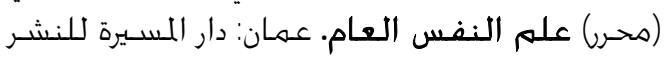
والتوزيع والطباعة. عالنغ الن.

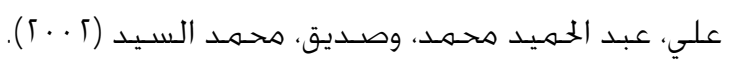

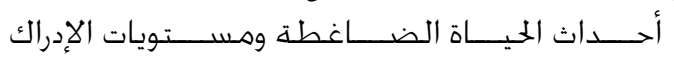

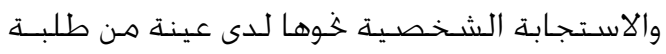

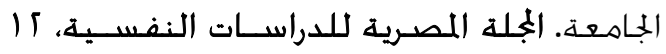
$.10 T-9 V .(T V)$

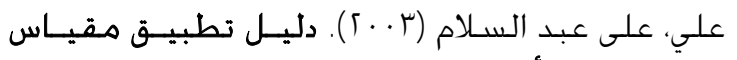

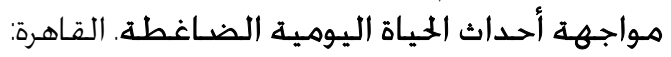
مكتبة الأجلو المصدرية.

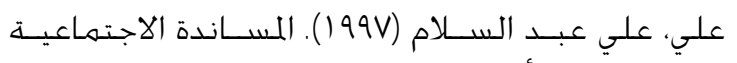

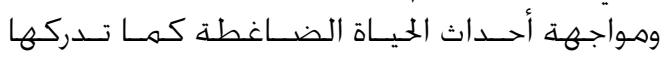

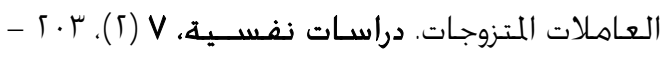
THT

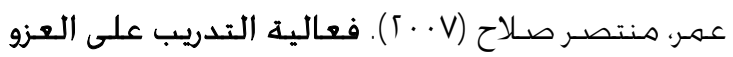

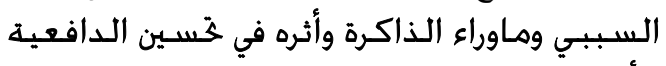

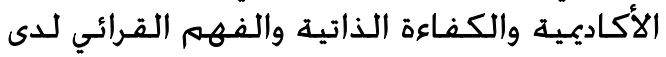

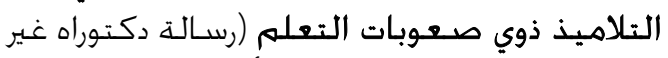
منشـورة). كلية التربية، جامعة أسبوط. أسيات

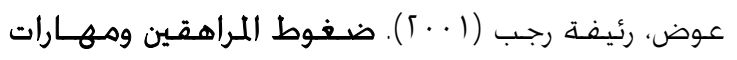

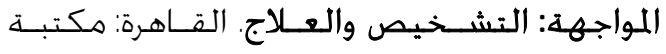

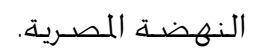

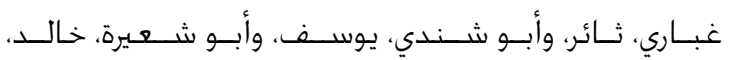

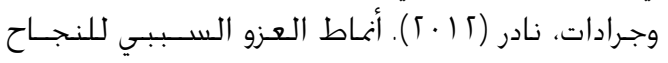

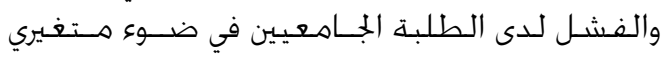

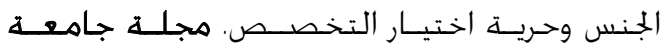

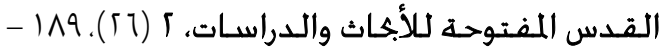
.1) 1

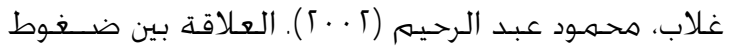

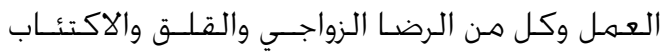

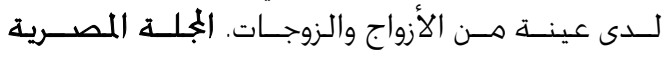

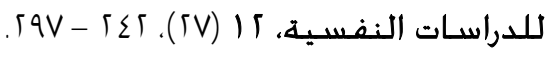

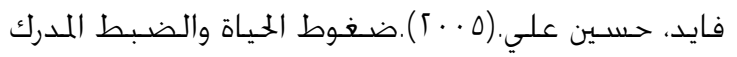

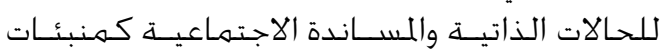

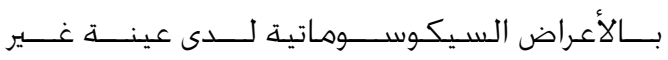
إكلينيكية، دراسـات نفسية، 10 (1)، 0 - 0 (1)

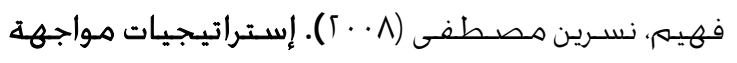
المشكلات وعلاقتها بالتوافق لدى التلاميذ المعاقين التهاتين

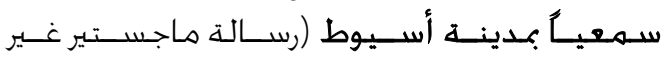

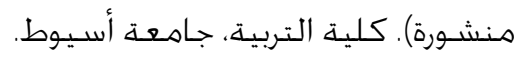

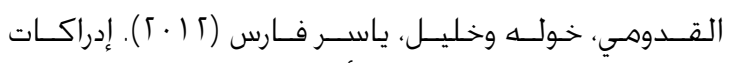

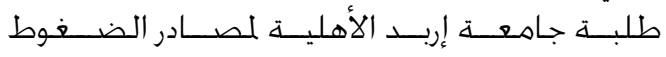

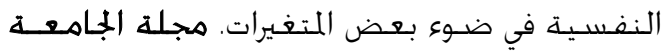


American Psychiatric Association (APA). (1980). Diagnostic and statistical manual of mental disorder (3rded.). Washington, DC: American Psychiatric Association.

Bandura, A., \& Wood, R. (1989). Effect of perceived controllability and performance standards on selfregulation of complex decision making. Journal of Personality and Social Psychology, 56(5), 805-814.

Bandura, A. (1994). Self-efficacy. In A. Ramashaudran, (Ed),Encyclopedia of Human Behavior (pp. 71-84). New York: Acdemic Press.

Bandura, A. (2000). Self-efficacy, In: Kazdin, A (Ed). Encyclopedia of psychology. New York: Oxford University Press.

Chan, L. (1996). Combined strategy and attributional training for seventh grade and poor reader. Journal of Research in Reading, 19(2), 111-127.

Cofer, C., \& A pply, M. (2008). M otivation: Theory and research. N ew York: Joy Wiley $\&$ Sons.

Compass, B.,Connor-Smith, J., Saltzman, H., Thomsen, A., \& Wadsworth, M. (2001). Coping with stress durning childhood and adolescence, problems, progress and potential in theory and research. Psychological Bulletin, 12,87-100.

David, K. (2000).For the love of life, Tikkun, 15 (1), Database: A cademic Search Premier.

Fielden, S., \& Davidson, M. (2001). Strees and gender in unemployed female and male managers. Applied Psychology: An International Review, 50(2), $260-275$.

Folkman, S., \& Moskowitz, J. (2004). Coping Pitfalls and Promise. Annual Review Psychology, 55, 745774.

Gafvels, C., \& Wandell, P. (2006). Coping strategies in men and women with type $2 \mathrm{~s}$ diabetes in swedish primary care. Diabetes Research and Clinical Practice, 71, 280-289.

Halahan, C \& Moos, H. (1995). Life stress and health: personality, coping and fanily support in stress resistance. Journal of Personality and Social Psychology, 35(3), 572-578.

Hartley, S., \& Maclean, W. (2005). Perceptions of stress and coping strategies among adults with mild mental retardation.Insight into psychological distress. American Journal of $M$ ental Retardation, 110(4), 285-297.

Heiman, T. (2004). Examination of the salutogentic model,support resources, coping style, and stressors among israeli university student. The Journal of Psychology, 138(6), 505-520.

Kardum, I., \& Karpic, N. (2003). Personality traits, stressful life events and coping styles in early adolescence. Personality and Individual Differences, 30(3), 503-515.

Krueger, N., \& Dickson, P. (1993). Perceived selfefficacy and perceptions of opportunity and threat. Psychological Reports, 72, 1235-1240.

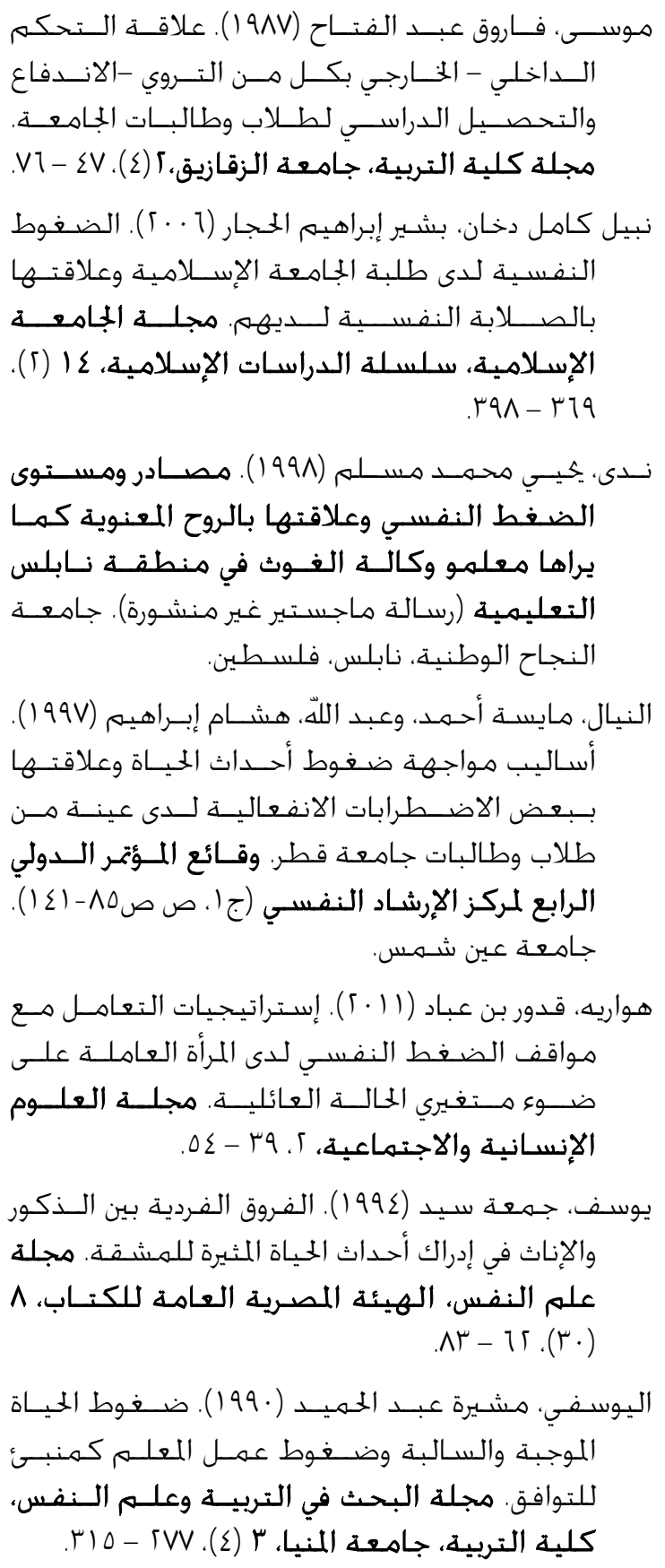


Kruz, M. (1992).The Influence of family Structure on the Relationship between Stressful Life and IIIness.Disertation Abstract International, 47, 2141-2144.

Lazarus, R. (2000). Toward better research on stress and coping. Journal of American Psychology, 55(6), 665-673.

Lazarus, R. (2006).Stress and emotion: A new Synthesis. New York: Springer.

Lease, S. (1999). Occupational rolestressors, coping, support, and hardiness as predictors of strian in academic facualty: A $n$ emphasis on new and female faculty. Research In Higher Education, 40(3), 285-307.

Lisa, K. (2005). Assessment of stress in physician assistant students. Journal of Instructional Psychology,32(2), 167-181.

Litt, M., Kadden, R., Cooney, N., \& Kabela, E. (2003).Coping skills and treatment outcomes in cognitive-behavioral and interactional group therapy for al coholism. Journal of Consulting and Clinical Psychology, 71, 118-128.

Marcotte, T. (2002). Gender differences in depression symptoms during adolescence: role of gender-typed characteristics, self-esteem, body image, stressful live events, and pubertal status. Journal of Emotional \& Behavioral D isorder, 10(1), 29-42.

Mc Carthy, C., Fouledi, R., Juncker, B.,\& Matheny, K. (2006). Psychological resources as stress buffers their relationship to university students anxiety and depression. Journal of College Counselling, 9, 99-112.

Michelle, M. (1999).Hardiness and college adjustment identifying students in need of servies. Journal of College Student D evelopment, 40(4), 305-309.

Muris, P. (2001). A brief questionnair for measuring self-efficacy in youths.J ournal of Psychopathology and Behavioral Assessment, 23(3), 103-132.

Naill, B., \& Adam, Z. (1995). A framework for studying personality in the stress process. Journal of Personality and social Psychology, 69(5), 890-902.

Natalie, S., \& N eil, B. (2002). Thedynamics of theart and challenge appraisals prior to stressful achievement events.Journal of Personality and social Psychology, 83(3), 678-692.

Olaekan, M. (2004). Stress Management Strategies of Secondary School Principals in Nigeria. Educational Research, 46(2), 105-207.

Pedhazurr, E., \& Schmelkin, L. (1991). M easurement design and analysis: An integrated approach. Hills Dale, N. J. Lawrence Erlbaum A ssociates.
Puskar, K., \& Lamb, J. (1991). Life events, problems, stresses and coping methods of adolescents. Issues in M ental H ealth N ursing, 12, 267-281.

Richard, A., \& Nancy, E. (1997). Regulatory control and adults stress-related responses to dialy life events.Journal of Personality and social Psychology, 73(5), 1107-1117.

Richard, A., Cathleen, G., \& James, E. (1999). Life's stress events that A merican River college students experience. Paper presented at the Annual Conference of the Research and Planning Group for California Community Colleges, April.

Rita, A. (2001). Stress in life and at work.London: Sage Publications.

Robotham, S. (2008). Stress among higher education Students: Towards aresearch agenda.Higher Education, 56(6), 735-746.

Roesch, S., \& Weiner, B. (2001). A meta-analytic review of coping with illness, do causual attribution Matter? Journal of Psychosomatic Research, 50, 205-219.

Ruth, H., \& Judy, A. (1995). A test of the Cognitive diathesis - Stress Model of depression in Children: Academic Stressors, Atributional Style, Perceived Competence and Control.Journal of Personality and social Psychology, 69(2), 370-380.

Schwarzer, R. (1993). M easurement of Percei ved Selfefficac Psychometric Scales for cross-cultural research, Berlin Germany: Freie University Berlin.

Schwarzer, R. (1999). self-regulatory processes in the adoption and maintenance of health behaviours.The role of optimism, goals, and threats. Journal of H ealth P sychology, 4, 115-127.

Sharp, S., \& Thompson, D. (1992). Sources of Stress: A contrast Between Pupil Perspective and Pastoral Teachers. Perceptions School-Psychology International, 23(4), 671 - 688.

Somerfeld, M., \& Mccrea, R. (2000). Stress and coping research,methodlogical challenges, thedretical advancesand clinical application, A pplications. A merican Psychologiest, 55, 620-625.

Steve, M. (1992).Human perspectives on teacher resignation: Darwen. New Sauth Wales: Asshalia.

Steven, P., Shanker, G., \& Goutam, C. (2001). Selfefficacy as amoderator of information - seeking effectiveness. Journal of Applied Psychology, 80(5), 1043-1051.

Wanter, D. (2007). The relations among hardiness, coping, autsim symptoms, perrrenting stress, and parent psychopathology among parents (Unpublihed Doctoral Dissertation). St. John University, New York. 
Wasteson, E., Glimelias, B., Sjoden, P., \& Nordin, K. (2006). Comparison of a questionnaire commonly used for measuring coping with a daily-basis prospective coping. Journal of Psychosomatic Research, 61, 813-820.

Wise, J. (2007). Testing a theory that explains how self-efficacy beliefs are formed: Predicting selfefficacy appraisals across recreation activities. Journal of social and clinical Psychology, 26(7), 841-848.

Zidner, M., \& Saklofske, D. (1996).Adaptive and Maladaptive Coping.Eidner, $\mathrm{M} \&$ \& Endler, N (Eds), Handbook of coping theory, research and appllcations (pp. 505-531), New York: Johnwiley.

Zimmerman, B. (1989). Models of self regulated learning and academic achievement. Journal of A merican Educational, 12(3), 1-25. 